\title{
Modelo de Impacto del Consumo Masivo de Productos y Servicios Digitalizados
}

\author{
Leonardo Montesano ${ }^{1,2}$ \\ 1. Maestría en Administración de Negocios. Universidad Tecnológica Nacional (FRBA). \\ Buenos Aires, Argentina \\ 2. Grupo Investigación en Sistemas de Información. Universidad Nacional de Lanús. \\ Remedios de Escalada, Argentina \\ lmontesano@arnapsis.com.ar
}

\begin{abstract}
Resumen-La actual revolución que propone Internet ofrece una serie de productos y servicios digitalizados que circulan en un medio completamente abierto, sin reglas ni reglamentaciones, entre la masa de usuarios. Algunos de los cuales evidencian una serie de nuevos conflictos inherentes al comportamiento, la personalidad y otras afecciones físicas, manifestando un tipo de ciber-adicción. En este trabajo, el autor propone un modelo conceptual para evaluar el impacto económico, ambiental y social del consumo masivo de estas nuevas tecnologías, centrándose en los aspectos relacionados con negocios de comercio electrónico escalable.
\end{abstract}

Palabras Clave-Productos y Servicios Digitalizados, Modelo de Impacto, Consumo Masivo, Negocios Escalables, Comercio Electrónico, Cyber-adicciones.

\section{INTRODUCCIÓN}

En este apartado se presentan aspectos contemporáneos para el desarrollo de la investigación (sección $A$ ), a fin de dar basamento al objetivo del trabajo (sección $B$ ) y finalizar con una visión sobre la estructura del mismo (sección $C$ ).

\section{A. Contexto de la investigación}

En el año 1994 y a causa de la sanción del "Acta de Libre Comercio y Zona Franca", por el gobierno de Antigua y Barbuda [1], comienza la distribución abierta de contenidos digitalizados por Internet, haciendo a la industria del juego una pionera en esta temática. Algunas organizaciones comenzaron a operar con base administrativa y tecnológica en estos paraísos cuyo objetivo fiscal era licenciar a las mismas a fin de generar alguna actividad factible de recaudación impositiva.

El avance en los campos de construcción de software, las comunicaciones y el acceso masivo a Internet, posibilitaron el desarrollo de empresas con la tecnología operacional necesaria, para distribuir un amplio abanico de posibilidades digitales hacia los consumidores de la nueva generación [2].

Los países desarrollados comenzaron a observar de cerca la actividad sobre los juegos de apuesta en línea, generando los primeros debates sobre la materia. En el año 1999 el senador John Kyl (por Arizona, USA), uno de los principales oponentes al juego de apuestas por Internet, introdujo el "Acta de Prohibición del Juego en Línea" diseñada para erradicar a cualquier compañía que ofrezca productos de juego en línea en los Estados Unidos de América. La ley finalmente no fue sancionada [3].

Hacia el año 2003, comenzó la estandarización e incremento de la seguridad informática, así como el asentamiento de bases hacia la regulación de la actividad lúdica por Internet [4] dando paso a grandes disputas transnacionales.

Internacionalmente asentó jurisprudencia el fallo, en 2004, de la Organización Mundial de Comercio a favor del estado de Antigua y Barbuda, en su caso contra los Estados Unidos de América, afirmando que las leyes de este último, son ilegales en territorio del primero [5].

La característica de extraterritorialidad de estos medios y la falta de normativa específica para los juegos por Internet, televisión digital interactiva o telefonía móvil debía ser reconsiderada. La identificación del ámbito espacial sobre los bienes y servicios digitalizados era irrelevante para estas nuevas tecnologías [6]. Los equipos computacionales que los sirven podían ser ubicados físicamente donde la jurisdicción permita por ley su operación y las comunicaciones e Internet faciliten el uso transnacional. Aún así, también es necesaria una masa de usuarios.

Una cámara de apelaciones del Estado de New York fue más allá de la mediación internacional de la Organización Mundial del Comercio alegando que un usuario de Internet no puede desconocer la normativa vigente del lugar que habita, dictaminando: "El sitio de Internet se aloja en la computadora del usuario, no siendo relevante el lugar donde se instale físicamente el servidor ya que éste no puede ser un escudo contra la norma que reprima actos ilegales" [7].

Las pujas legales trasnacionales sobre estas metodologías de distribución de contenidos continúan. La actuación del estado moderno toma relevancia, pues deber velar por el bien común de la población potencialmente vulnerable [8].

Bajo el refugio de los paraísos fiscales se distribuye amplia variedad productos y servicios que configuran una Internet en perpetua innovación, donde los contenidos digitalizados son la materia prima y la vez; la creación [9]. En este marco, ciertos estudios $[10 ; 11]$ indican que algunos usuarios de la red enfrentan potencialmente una serie de nuevos conflictos inherentes al comportamiento. Compulsividad y trastornos de la personalidad son devenidos del consumo exagerado de contenidos de Internet, experimentando un tipo de ciberadicción, referida a la desmedida búsqueda de información de todo tipo, el exceso de contacto en entornos (o redes) sociales, la compulsión por el uso de los juegos (de apuestas o no), compras compulsivas y finalmente ciber-sexo [10]. Individuos como los niños, adolescentes y adultos vulnerables se encuentran en mayor grado de exposición que otros [12] y algún segmento de la población podría ser más afectado. 
Se agrega otra serie de inconvenientes físicos ya que largas jornadas frente a una computadora tiene consecuencias nocivas para la vista y el sistema músculo-esquelético [13] auspiciando la disminución de actividad física e inversión del tiempo libre en actividades de escaso o ningún consumo calórico [14].

En los sistemas políticos con economías de libre mercado, no existe un estado que permita la proliferación de compañías sin algún tipo de regulación. Aunque la mayoría de los bienes y servicios ofrecidos en Internet son legales, ética y legalidad son conceptos distintos [15]. El factor moral de consumo responsable debe ser aportado por los individuos de la sociedad. La moral sólo existe en primera persona. Aún con todas las fallas, un sistema político abierto no es moral ni tampoco inmoral, es simplemente amoral [16]. La responsabilidad del sistema recae en la regulación de los estados. El sistema no es nadie. Se cuenta con opinión pública y su grado de influencia para que el consumo individual, que podría ser masivo, no comprometa el desarrollo de la humanidad.

\section{B. Objetivo del trabajo}

El propósito de este escrito es formular un modelo conceptual de impacto de consumo masivo de productos $\mathrm{y}$ servicios digitalizados en comercio electrónico escalable.

Se busca realizar un aporte al campo de investigación científica, en el área de administración de negocios, a fin de acuñar conceptos que permitan proyectar la incidencia de las nuevas posibilidades que trae consigo la aplicación de la tecnología actual.

Se persigue poder influenciar positivamente en el centro de la responsabilidad empresarial, necesaria y fundamental, para llevar adelante la implementación negocios escalables con bienes y servicios digitalizados, así como colaborar con el estado moderno para alcanzar la legislación y regulación adecuada a las nuevas tecnologías.

Se pretende acercar a toda la comunidad nociones sobre las posibilidades y potencialidades que brinda la tecnología a partir del uso medido, maduro y conciente a fin de introducir al lector sobre la necesidad de informar y difundir aspectos de consumo responsable para la utilización de estos nuevos servicios de valor agregado.

Se busca formular contribuciones sobre: [a] El marco teórico y la evolución histórica internacional de los negocios escalables sobre la plataforma de Internet. [b] El diseño conceptual de un modelo estratégico de implementación y comercialización de un negocio escalable en línea en base a productos y servicios digitalizados. [c] La formulación de una propuesta de implementación del modelo estratégico de implementación con un sistema informático de acceso público montado sobre Internet. [d] El desarrollo de una simulación de uso y consumo público del negocio escalable para establecer la probable sensación masiva de los productos y servicios en línea.

\section{Estructura del trabajo}

El escrito se estructura en siete secciones: Introducción, estado de la cuestión, delimitación del problema, solución propuesta, experimentación, conclusiones y referencias.

El escrito comienza con la introducción (apartado I), donde se exponen aspectos de contexto sobre el cual se desarrolla la investigación y el objetivo del trabajo, para finalizar con la estructuración del escrito.
Se agrega el estado de la cuestión (apartado II) que presenta el marco de la economía digital actual, para dar abordaje a la literatura sobre adicciones digitales y para finalizar con los asuntos relacionados a modelos y simulaciones.

Continúa como se delimita el problema a estudiar (apartado III) el cual comenta el contexto acerca del consumo de bienes y servicios digitalizados por Internet y profundiza el desarrollo del problema sobre tres pilares: Se comienza con la cuestión sobre el eje económico, le sigue el ambiental y el desarrollo sobre el social, para finalizar con el sumario de la investigación.

El escrito del trabajo agrega la solución propuesta (apartado IV) donde se presenta un conjunto de generalidades que dan base al desarrollo del modelo conceptual de impacto de consumo, para finalizar con la formulación de la encuesta digital que cuantifica a la muestra de perfiles de usuarios de Internet.

El siguiente apartado adiciona la experimentación (apartado V) que expone una introducción sobre el desarrollo de los experimentos, para dar paso al diseño de las pruebas y centrar el análisis en las gráficas e interpretaciones de los resultados experimentales, a fin de obtener posibles conclusiones.

A continuación se exponen de las conclusiones (apartado VI) destacándose las aportaciones, los resultados obtenidos y las futuras líneas de investigación.

Se finaliza el escrito con las referencias de todas las publicaciones consultadas para el desarrollo de esta publicación.

\section{ESTADO DE LA CUESTIÓN}

En este apartado se presenta un marco referido a la economía digital (sección $A$ ) para seguir el abordaje de la cuestión sobre la adicción digital (sección $B$ ) y finalizar con asuntos relacionados a modelos y simulaciones (sección $C$ ).

\section{A. El marco de la economía digital}

La economía digital podría explicar el progreso de las próximas décadas [17]. Debe considerarse un nuevo sistema socio-político y económico que se caracteriza por un espacio inteligente plagado de instrumentos de acceso a la información, el procesamiento y la capacidad para su comunicación [18].

En los ciber-mercados [19] la identificación de los modelos de negocio y las fuentes de creación de valor [20] se agregan al importante papel que desempeña el desarrollo tecnológico de las TIC (tecnologías de información y comunicación), la tercera revolución industrial, el avance de las comunicaciones, los ordenadores, Internet y el conocimiento aplicado [9].

Para la Comisión Económica para America Latina y el Caribe (CEPAL) la infraestructura de telecomunicaciones, las industrias TIC y la red de actividades económicas y sociales facilitadas por Internet, podrían actuar como fuerza motriz para el cambio estructural en la búsqueda de la igualdad entre personas, dando lugar a formas complementarias de generación de valor [21].

La transformación de la economía tradicional podría apuntalar el desarrollo de una nueva sociedad basada en el conocimiento y la transferencia de idoneidad [22] que facilite a las empresas desenvolverse en entornos complejos, dinámicos e inciertos de difícil competencia. En esta naturaleza la economía digital tiene cada vez mayor presencia en el mundo de los negocios y los empresarios deben diseñar estrategias basadas en las tecnologías de la información y la comunicación 
(TIC) y utilizar Internet a fin de mejorar el desempeño de las organizaciones [23]. Lo cual implica una oportunidad infinita y una inmensa responsabilidad, debiendo velar por la sanidad de un medio completamente abierto, sin reglas ni reglamentaciones [9] y en constante reelaboración [24].

Las empresas participantes de la economía digital deben ganar y conservar su "licencia social para operar" a fin de mantener la aprobación de las personas o grupos de interés afectados por su actividad [25] que impacta de lleno en la vida de la sociedad de consumo. Mejorar la comunicación de acciones referidas al compromiso con la comunidad, optimizar la operación interna y construir relaciones sólidas dentro de la cadena de valor, debe ser prioritario para considerar a todas las partes involucradas [26].

Desde el punto de vista macroeconómico y microeconómico se puede considerar que en la economía digital se relaciona el avance tecnológico y la innovación en los modelos empresariales [27].

Otros autores consideran que el aporte de las TIC a la gestación de la aldea global, ha posibilitado cambios estructurales en los negocios, pero no es suficiente para afirmar que se está en presencia de una nueva economía [20]. Siguiendo esta línea, se establece que los paradigmas, los conceptos y las teorías que se utilizan en el estudio de la nueva economía, aparentemente son los mismos que los de la vieja economía.

Por lo expuesto en lo precedente, los negocios que tratan con productos y servicios digitalizados comercializables por Internet constituyen un campo de investigación de creciente interés en el área de administración de negocios de base tecnológica $[28 ; 29 ; 30 ; 31 ; 32 ; 33 ; 34 ; 35,36,37 ; 38]$ ya que podrían apuntalar una nueva forma económica que se desarrolla con fuerza.

Analizar el contexto de la economía digital implica comprender la interacción de al menos cuatro componentes: infraestructura (sub-sección 1) y aplicaciones (sub-sección 2) por un lado; nuevos intermediarios (sub-sección 3) y comercio electrónico (sub-sección 4) por otro [17].

\section{1) Infraestructura}

Pueden considerarse tres fases para el surgimiento de Internet: la primera, entre los años 1960 y 1970, con el nacimiento y desarrollo de las redes con fines militares; la segunda, durante la década de 1980, con la extensión de su uso civil en el ámbito académico; y la tercera, desde el comienzo de 1990 hasta la actualidad, en la que se produce la gran expansión comercial y doméstica. [39].

Se reconoce a noventa y tres países que establecieron sus respectivos enlaces dedicados a Internet antes de mayo de 1995. De ese total, diecinueve pertenecen al continente americano: Argentina, Bermuda, Brasil, Canadá, Chile, Colombia, Costa Rica, Ecuador, Estados Unidos, Islandia, Jamaica, México, Nicaragua, Panamá, Perú, Puerto Rico, República Dominicana, Uruguay y Venezuela [40].

Al analizar algunos datos sobre la situación actual de los usuarios de Internet se puede estimar que más de la mitad de los pobladores de las Américas utilizan la red [41] como se presenta en la Tabla I "Estimación de usuarios de Internet al año 2012".
TABLA I - ESTIMACIÓN DE USUARIOS DE INTERNET AL AÑO 2012

\begin{tabular}{|c|c|c|c|c|c|}
\hline $\begin{array}{c}\text { Población } \\
\text { Estimada }\end{array}$ & $\begin{array}{c}\text { Habitantes } \\
\text { (cantidad) }\end{array}$ & $\begin{array}{c}\text { Habitantes } \\
\text { (porcentaje) }\end{array}$ & $\begin{array}{c}\text { Usuarios } \\
\text { de Internet } \\
\text { (cantidad) }\end{array}$ & $\begin{array}{c}\text { Usuarios } \\
\text { de Internet } \\
\text { (porcentaje) }\end{array}$ & $\begin{array}{c}\text { Penetración } \\
\text { (porcentaje) }\end{array}$ \\
\hline $\begin{array}{c}\text { En las } \\
\text { Américas }\end{array}$ & 941.968 .792 & $13,42 \%$ & 528.701 .158 & $21,97 \%$ & $56,12 \%$ \\
\hline $\begin{array}{c}\text { En el resto } \\
\text { del mundo }\end{array}$ & 6.075 .878 .130 & $86,58 \%$ & 1.876 .817 .218 & $78,03 \%$ & $30,88 \%$ \\
\hline Total & 7.017 .846 .922 & $100,00 \%$ & 2.405 .518 .376 & $100,00 \%$ & $34,27 \%$ \\
\hline
\end{tabular}

El mismo estudio presenta la penetración de Internet en los habitantes de América del Sur cercana a la mitad de su población, superando al promedio mundial [40]. Para el caso particular de la República Argentina, se estima por encima de la mitad de su población (66\%) [41] pudiendo indicar el alcance de los bienes y servicios digitalizados sobre la masa de usuarios.

Las dimensiones de accesibilidad a Internet se apoyan en infraestructura tecnológica que presenta abundancia para los usuarios. Al estimar el parque informático de la tecnología móvil, en la República Argentina se registran [42]:

- $\quad$ Más de 59 (cincuenta y nueve) millones de teléfonos celulares en servicio.

- Penetración superior al $139 \%$ de la población.

- Desde 2004 hay más teléfonos celulares que teléfonos fijos.

- Más del 70\% de los celulares del mercado tiene menos de 2 años de antiguedad.

- Los nuevos teléfonos celulares disponen de amplia potencia computacional.

En los últimos años sobre un sólo dispositivo inteligente de telefonía celular se centraliza y convergen las tareas que antes eran exclusivas de las otras pantallas, como la computadora personal. La tendencia hacia la ubicuidad es un rasgo distintivo de la nueva sociedad y presenta a los dispositivos móviles como la herramienta predilecta [43].

Las ventas anuales de computadoras personales alcanzaron en la República Argentina al 2012 los 2,7 millones de unidades, con una proporción creciente de equipos portátiles (66\% de los equipos vendidos). El parque en servicio de computadoras se estima en 17,5 millones de unidades [44].

Para dar cobertura y acceso a Internet a un parque computacional creciente, se cuenta en la República Argentina con más de trescientos proveedores privados y cooperativas ubicadas en todo país [45] asumiendo que el empleo de las TIC ha tenido un desarrollo anárquico signado por la falta de políticas públicas, tendencia que se ha revertido en los últimos años presentando un importante y sostenido desarrollo del sector de software y servicios informáticos [22].

En la República Argentina la industria del software y servicios informáticos (SSI) crece de forma continua desde el año 2003, superando volúmenes de ventas e ingresos desde el exterior [46], generando nuevos puestos de trabajo a una tasa superior a otras industrias y aportando al crecimiento económico del pais [47].

2) Aplicaciones

La Informática es una disciplina científica porque está compuesta por un conjunto de conocimientos de validez universal y porque utiliza el método científico para el logro de sus objetivos. Su cuerpo de conocimientos, sustentado por teorías, evoluciona y progresa [48]. Es el camino sistemático que se ha logrado para desarrollar nuevas tecnologías. 
La disponibilidad de acceso a Internet apuntala la gestación de una nueva sociedad basada en el conocimiento [49] que debe ser entendida como producto de los cambios tecnológicos y el agregado de información en todos los ámbitos, auspiciando el desarrollo económico y humano e impactando en cambios organizacionales [50].

En los innovadores modos de pensamiento humano y en las aplicaciones más importantes de las TIC se incuba la nueva economía. Una posible clasificación de las TIC se presenta como: servicios a medida, tecnología de redes, voz y lenguaje, tecnologías ubicuas, medios híbridos, servicios de comunicaciones, ambientes virtuales, entretenimiento y soluciones técnicas [22].

Pero aún los desarrollos actuales que permiten la implementación de productos y servicios digitalizados, a veces, son superados por la capacidad de aceptación de los consumidores [51]. En base al trabajo de estos autores, se considera la aceptación de los usos potenciales de los teléfonos móviles en una escala 1-5 (donde 1 no es importante y 5 es muy importante). Los 251 entrevistados calificaron a la mensajería de texto como el servicio más importante $(3,92)$, luego aplicaciones vinculadas al esparcimiento $(2,84)$, siguen las aplicaciones para pago electrónico $(2,75)$ como más importante que la publicidad personalizada $(2,03)$ y las ofertas de compras personalizadas $(1,85)$. Estos datos se han utilizado para innovaciones tales como la distribución de publicidad [52]. Se ha sostenido que factores tales como la confianza y la percepción de riesgo, están influyendo en la disposición a aceptar estas nuevas tecnologías [53]. Se estima que el alcance generacional puede ayudar a vencer estas barreras acerca de la aceptación y utilización [54].

Aquellas organizaciones que planean innovaciones como productos digitalizados para teléfonos móviles [55], reconocen que una porción de la comunidad reporta problemas [56]. Cuando se consideran posibles desarrollos para los dispositivos móviles, ciertos estudios previos han encontrado que aproximadamente el $20 \%$ de la comunidad usa el teléfono móvil en actividades recreativas [56]. Sin embargo, el 2,6\% de los individuos aseguran que sufren problemas técnicos con sus teléfonos móviles, otro 5,6\% declara que usan su tiempo con el teléfono móvil cuando deberían estar haciendo otras cosas y el $7,7 \%$ de las personas informa sobre los problemas para pagar sus facturas [56]. Siguiendo al autor, estas cifras representan una minoría dentro de la comunidad y es difícil argumentar que una innovación sobre esta plataforma sea detenida sólo con estas bases.

La capacidad para inventar e innovar, crear nuevos saberes e ideas que se materializan luego en productos, procedimientos y organizaciones, ha alimentado históricamente al desarrollo. La esencia del desarrollo económico es la innovación, los monopolios son una fuente de innovación en las economías capitalistas [57]. El conocimiento ha ocupado el lugar central del crecimiento económico con la elevación progresiva del bienestar social [58].

En la actualidad se ha desarrollado una variedad de segmentos focalizados en Internet: e-publicidad, ecapacitación, e-emprendimientos, e-legislación, e-pagos, edocumentos, e-seguridad, e-recursos humanos, e-logística, etrabajo, e-beneficios, e-turismo, e-gobierno, e-confianza, eresponsabilidad social empresaria, e-eventos, e-salud, eperiodismo, e-comercio exterior y e-red social son algunas categorías en la que cuadran varios ofrecimientos y demandas del mercado digital [44].

Para poder avanzar y crecer en el desarrollo de aplicaciones es necesario el apuntalamiento de políticas y apoyos de un estado moderno [47]. En la República Argentina, con la creación del Foro Nacional de Competitividad de la Industria del Software y Servicios Informáticos, en el año 2003, se logró la sanción de la Ley Nacional 25856 [59] que declaró al software como industria. A sólo un año de aquella carta orgánica, la Ley Nacional 25922 [60] da impulso y promociona a toda la industria de SSI con un plan estratégico que proyecta la actividad hasta el 2014 [47] asignando aportes no reembolsables y auspiciando la creación de polos tecnológicos. Este marco legal posiblemente haya favorecido el fortalecimiento de las partes involucrados en la industria del software.

\section{3) Intermediarios}

La cadena del valor de Porter [61] sigue siendo un marco válido para analizar los procesos de creación de valor de las empresas tradicionales o con el apoyo de las TIC. Un modelo de negocio en Internet tendría por objeto identificar la forma a través de la cual la empresa puede crear valor en esa red [34].

Se cuenta con cuatro características únicas de Internet frente a cualquier otra red de transmisión de información: la ubicuidad, la interactividad, la velocidad y la inteligencia, siendo aspectos claves a la hora de definir un negocio por esa vía [62]. Cuando se trate de escalar en el comercio electrónico, se deben conectar virtualmente todos los eslabones posibles, alineando y homologando: códigos, tiempo, procesos y operaciones [63].

Un modelo de negocio con base tecnológica debe definir la forma en la que las empresas planifican hacer dinero a largo plazo usando Internet [64]. Otros autores creen que un modelo de negocio debe describir el contenido, estructura y gobierno de las transacciones diseñadas, así como la creación de valor a través de la explotación de las oportunidades de negocio [20].

Algunas empresas fueron detectando un marco legal propicio en estados auspiciantes de políticas industriales para las TIC $[59 ; 60]$ y aprovecharon la ventaja de la tecnología para experimentar nuevos modelos de negocios planificando hacer dinero a largo plazo en Internet [64]. En su máxima evolución todos los elementos de la cadena de valor deben ser integrados, reduciendo y en búsqueda de eliminar, la necesidad de operaciones físicas e intermediarias.

Los costos relacionados con la producción, transacción y administración de las operaciones disminuyen, lo que a su vez abre la posibilidad de establecer precios más bajos [65]. El factor de integración de los elementos de la cadena de valor es un aspecto fundamental para los negocios en los cibermercados, dando por sentada la necesidad de virtualizar el mayor grado posible [63].

Es necesario hacer experiencia, conocer el mercado, elegir la meta adecuada y crear valor [61] a fin de ajustar todos los elementos que permitan tomar una dirección en el mundo Internet para establecer y mantener un posicionamiento estratégico [63].

Otros estudios sostienen que en la economía digital la identificación de los modelos de negocio y las fuentes de creación de valor [20] se agregan a una estrategia corporativa enfocada en la explotación del desarrollo tecnológico y la actual revolución virtual [66]. 
Los sectores de la industria que sufran de miopía en la comercialización [67] deberán despertar cuanto antes y abordar el mundo digital. La tendencia muestra que las versiones electrónicas suplantarán a los productos y servicios de carácter físico [28].

\section{4) Comercio electrónico}

La información es una mercadería fundamentalmente distinta a otros bienes. Es costosa de producir y muy barata para reproducir, los mercados de información tienen graves fallas a causa de esta característica. La producción de un programa informático puede requerir de tiempos extremadamente grandes respecto a la copia o reproducción del mismo. Esta representa la gran diferencia respecto a los productos físicos [68].

Se considera digitalizado a aquello que puede ser transformado en "bits" de información pudiendo ser trasferido por intermedio de alguna tecnología, producto, bien o servicio [28]. Eventos sociales, banca comercial, libros, periódicos, música, videos, cine, enciclopedias y juegos son algunos ejemplos de bienes y servicios que pueden ser digitalizados [65].

Los bienes y servicios digitalizados no disponen de valor económico por el medio físico que los soporta, no son tangibles [63]. La cuantificación del costo puede depender de los derechos de autor y otros conexos [69] pudiendo establecer su valor económico la cantidad y calidad de información que almacena y acerca al consumidor [28].

Para el desarrollo de la digitalización, el conocimiento es un factor vital. Se está ingresando a una era donde el capital físico no tiene suprema relevancia. Es el momento del talento individual y grupal, apuntalado por capacitación, redefiniendo mercados, productos, servicios [70] y eslabones en la cadena de valor hasta el consumidor, estableciendo novedosas formas de comercio [34].

Los agentes principales del comercio electrónico son las empresas, los consumidores y la administración pública. Entre ellos se producen tres tipos básicos de comercio [71]:

- $\quad$ B2B (Business to Bussines) o entre empresas.

- $\quad$ B2C (Business to Consumers) o entre empresa y consumidor. Algunos reconocen una modalidad de esta denominada: $\mathrm{C} 2 \mathrm{C}$ (entre consumidores).

- $\quad$ B2A (Business to Administrations) o entre empresa y la administración publica.

El comercio electrónico no sólo incluye la compra y venta de bienes, información o servicios brindados por la red; sino cualquier forma de transacción o intercambio de información comercial basados en la transmisión de datos sobre redes de comunicaciones informáticas [63].

En los ciber-mercados [19] se desarrolla el comercio de modo electrónico [71] con bienes y servicios digitalizados [28] creando valor hacia el consumidor y rentabilidad para la empresa [72] pudiendo presentar una modalidad de intercambio de crecimiento acelerado y sostenido [23].

Se ampliará el desarrollo sobre comercio electrónico a través de la presentación del concepto de escalabilidad (subsección $a$ ), para hondar en el factor de integración (sub-sección $b$ ) a fin de presentar una hipótesis de rentabilidad en negocios escalables (sub-sección c) y finalizar con un posible contexto contemporáneo sobre el comercio electrónico en la República Argentina (sub-sección $d$ ).

a) Concepto de escalabilidad
Los negocios escalables se caracterizan por incrementar las ventas de modo exponencial y mantener costos lineales eliminando en gran medida los problemas de crecimiento y expansión [73]. Esta posibilidad puede ser lograda por arquitecturas comerciales montadas en Internet sobre productos y servicios digitalizados [28].

Para lograr negocios escalables, las empresas deben crecer hasta virtualizarse en su totalidad [65]. Los modelos de negocio que progresan en Internet atraviesan el camino: institucionalidad, comercio electrónico, negocio electrónico y empresa electrónica, como se presenta en la Figura 1 "Maduración hacia la empresa electrónica" [74].

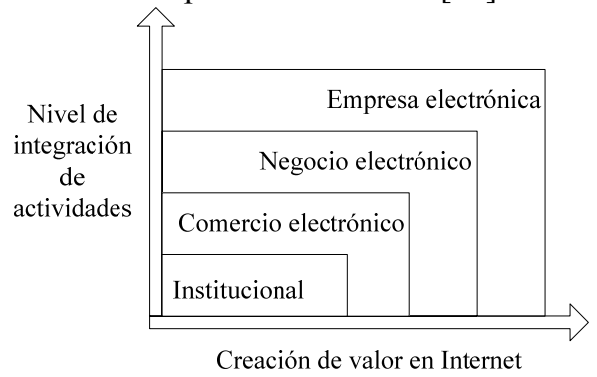

Fig. 1. Maduración hacia la empresa electrónica

El primer paso en Internet es la presencia mediante un sitio institucional corporativo [32]. El incremento de los estándares de seguridad informática, los métodos de criptografía, la firma digital y los medios de pago con dinero electrónico agregan otra complejidad de gestión [69]. El comercio electrónico supone un paso importante para la creación de valor y la empresa debe integrar desde proveedores hasta clientes en su sistema relacionamiento [74].

La participación activa de un estado moderno facilitaría la definición de políticas para la administración tributaria, incluyendo entes fiscalizadores y bancos centrales, a fin de accionar sobre los negocios participantes de la red, escalando en la maduración de la actividad comercial [69]. La integración hacia el negocio electrónico no es un esfuerzo adicional. Es un impulso de fondo que optimiza las estructuras, permite crear alianzas flexibles y genera modelos administrativos de fácil configuración. La base para evolución es una estrategia de integración multicanal [63].

La empresa virtual o electrónica es un modelo de negocio ciento por ciento montado sobre Internet, una evolución del negocio electrónico, un nuevo grado de maduración. Este nuevo tipo de empresa necesita de estructura como cualquier otra: personal cualificado, soporte tecnológico, instalaciones, acceso financiero, fuente de ingresos, propaganda y debe considerarse desde una nueva perspectiva de integración completa [74].

\section{b) Factor de Integración}

Si se logra modificar la configuración de partes y los mecanismos coordinadores [75] en las estructuras internas de la empresa, pudiendo flexibilizarse y aplicar un modelo organicista [76] apoyado en la ciencia informática, posiblemente se alcance una gestión mecanizada a fin de obtener rendimientos superlativos.

Las aplicaciones deben ser sólidas y escalables, orientadas a satisfacer el cliente, mientras a la vez permitan mejorar el caos de las mezclas confusas de sistemas administrativos y electrónicos no relacionados dentro de una misma empresa [65]. 
Un modelo orientado a la empresa electrónica trabaja alineando y homologando toda la cadena de negocio. Esto representa incrementar costos en cada etapa de maduración en busca de la orientación a sabiendas de que una vez lograda, el mismo efecto se produce sobre los ingresos. Al estandarizar electrónicamente la oferta se alcanzan nuevos mercados para los bienes y servicios digitalizados, elevando los volúmenes de venta con el correspondiente efecto multiplicador sobre los ingresos. Algunos autores denominan al fenómeno como "Factorial de Comercio" [63].

Sobre Internet el efecto de disponer orientado y virtualizado el canal, desde que el usuario solicita y hasta que se produce la entrega y el cobro, conduce a una multiplicación de efectos particulares, muy similar al cálculo de un número factorial. Esto se presenta en la Figura 3 "Factorial de comercio en un caso completamente integrado y virtualizado". Si la cadena no está totalmente integrada, el efecto multiplicador se pierde, por tanto el producto final es relativamente es menor [63] como se presenta en la Figura 2 "Factorial de comercio en un caso poco integrado y virtualizado".

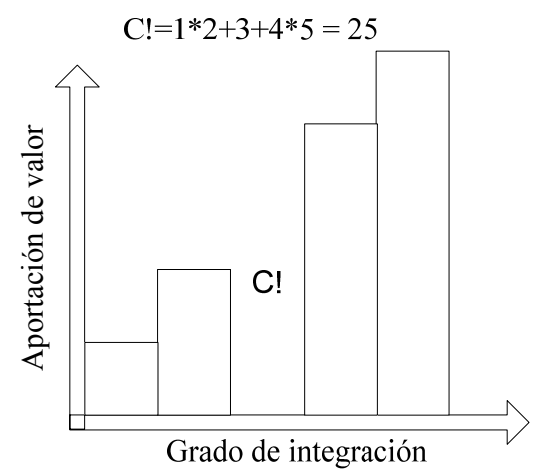

Fig. 2. Factorial de comercio en un caso poco integrado y virtualizado

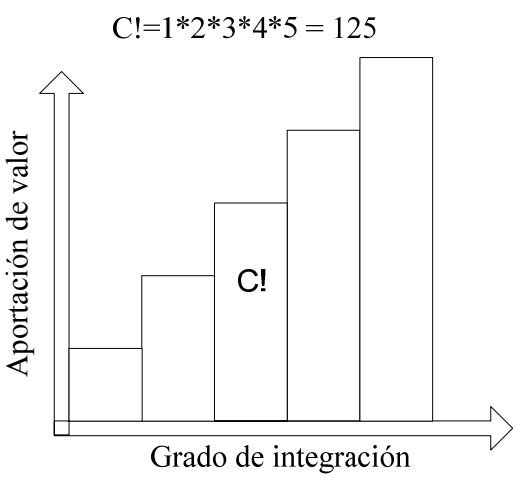

Fig. 3. Factorial de comercio en un caso completamente integrado y virtualizado

En un negocio montado sobre Internet podría cuantificarse su potencial analizando la cadena de valor [61] y su grado de virtualización, para utilizar el método de cálculo de factorial de comercio [63] y obtener una medición de la oportunidad en la creación de valor [73].

En los casos donde la actividad de la empresa se encuentra completamente integrada y virtualizada, el factorial de comercio es elevado, lo que podría expresarse en alta rentabilidad, escalando en oportunidades de negocio, creciendo y expandiendo las operaciones de distribución [63].

c) Hipótesis de rentabilidad en negocios escalables
Para ampliar el concepto de escalabilidad en el comercio electrónico se simplifica la operación de una empresa que brinda productos y servicios digitalizados por Internet a una cantidad de usuarios (representada por q), utilizando capital, trabajo y materiales que compra en los mercados de factores.

El costo total (CT) de la empresa se compone de un término fijo (CF) y otro variable (CV) [77] tal que: $\mathrm{CT}=\mathrm{CF}+\mathrm{CV}$.

Mantener en operación la tecnología necesaria para brindar productos y servicios digitalizados $7 \times 24$ (toda la semana, todo el día) para ningún usuario, pocos y hasta $n$ cantidad, podría soportarse con un mismo costo fijo (CF) de estructura (cuantificado por $\mathrm{x}$ ), como se presenta en la Tabla 2.2. "Formulación de costo total en un comercio electrónico escalable".

El costo variable (CV, expresado como p1..pn) indica la cuantificación que implica mantener en consumo a uno, dos, o $\mathrm{n}$ cantidad de usuarios. El marco legal y transnacional acciona para que el costo variable tienda a cero. Se presentan vacíos en materia de derechos de autor, propiedad intelectual, distribución digital, copia legal o piratería sobre contenidos digitalizados por Internet [6]. En condiciones de plena legalidad, se debe considerar que el aumento en el costo total (CT) se produce a medida que ingresan más usuarios (q) debido al incremento del costo variable (CV). La formulación matemática para la deducción de costeo se presenta en la Tabla II "Formulación de costo total en un comercio electrónico escalable" y se expone una relación en la Figura 4 "Curvas de costo total, variable y fijo en comercio electrónico escalable".

TABLA II - FORMULACIÓN DE COSTO TOTAL EN COMERCIO ELECTRÓNICO ESCALABLE

\begin{tabular}{|c|c|c|c|}
\hline Usuarios & $\begin{array}{c}\text { Costo } \\
\text { Fijo }\end{array}$ & Costo Variable & Costo Total \\
\hline $\mathrm{q}$ & $\mathrm{CF}$ & $\mathrm{CV}$ & $\mathrm{CT}=\mathrm{CF}+\mathrm{CV}$ \\
\hline 0 & $\mathrm{x}$ & 0 & $\mathrm{x}$ \\
\hline 1 & $\mathrm{x}$ & $\mathrm{p} 1$ & $\mathrm{x}+\mathrm{p} 1$ \\
\hline 2 & $\mathrm{x}$ & $\mathrm{p} 1+\mathrm{p} 2$ & $\mathrm{x}+\mathrm{p} 1+\mathrm{p} 2$ \\
\hline 3 & $\mathrm{x}$ & $\mathrm{p} 1+\mathrm{p} 2+\mathrm{p} 3$ & $\mathrm{x}+\mathrm{p} 1+\mathrm{p} 2+\mathrm{p} 3$ \\
\hline$\ldots$ & $\ldots$ & $\ldots$ & $\ldots$ \\
\hline $\mathrm{n}$ & $\mathrm{x}$ & $\mathrm{p} 1+\mathrm{p} 2+. .+\mathrm{pn}$ & $\mathrm{x}+\mathrm{p} 1+\mathrm{p} 2+. .+\mathrm{pn}$ \\
\hline
\end{tabular}

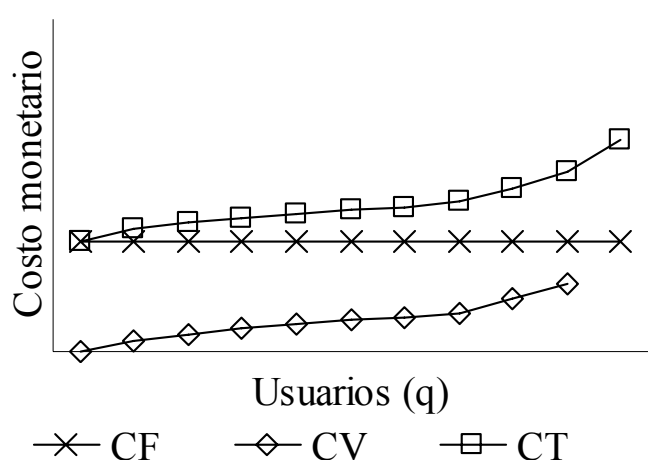

Fig. 4. Curvas de costo total, variable y fijo en comercio electrónico escalable.

El costo marginal (CM) de producción es el costo monetario adicional en que se incurre al disponer de una unidad adicional de q. El costo medio unitario (CMe) es el costo total dividido por el número de usuarios q [77].

El costo medio unitario $(\mathrm{CMe})$ suele reducirse cuando se digitaliza un producto. Los costos relacionados con la 
concentración, distribución, transacción y procesamiento administrativo disminuyen, lo que a su vez abre la posibilidad de establecer precios de venta más bajos [65].

Las formulaciones matemáticas para los costos por unidad se presentan en la Tabla III "Formulación de costo marginal unitario y medio unitario en comercio electrónico escalable" y se expone una relación en la Figura 5 "Curvas de costo marginal unitario y medio unitario en comercio electrónico escalable".

TABLA III - FORMULACIÓN DE COSTO MARGINAL UNITARIO Y MEDIO UNITARIO EN COMERCIO ELECTRÓNICO ESCALABLE

\begin{tabular}{|c|c|c|}
\hline Usuarios & $\begin{array}{c}\text { Costo Marginal } \\
\text { por Unidad }\end{array}$ & $\begin{array}{c}\text { Costo Medio por } \\
\text { Unidad }\end{array}$ \\
\hline $\mathrm{q}$ & $\mathrm{CM}$ & CMe $=\mathrm{CT} / \mathrm{q}$ \\
\hline 0 & 0 & infinito \\
\hline 1 & $\mathrm{p} 1$ & $\mathrm{x}+\mathrm{p} 1$ \\
\hline 2 & $\mathrm{p} 2$ & $(\mathrm{x}+\mathrm{p} 1+\mathrm{p} 2) / 2$ \\
\hline 3 & $\mathrm{p} 3$ & $\ldots$ \\
\hline$\ldots$ & $\ldots$ & $(\mathrm{x}+\mathrm{p} 1+\mathrm{p} 2+. .+\mathrm{pn}) / \mathrm{n}$ \\
\hline $\mathrm{n}$ & $\mathrm{pn}$ &
\end{tabular}

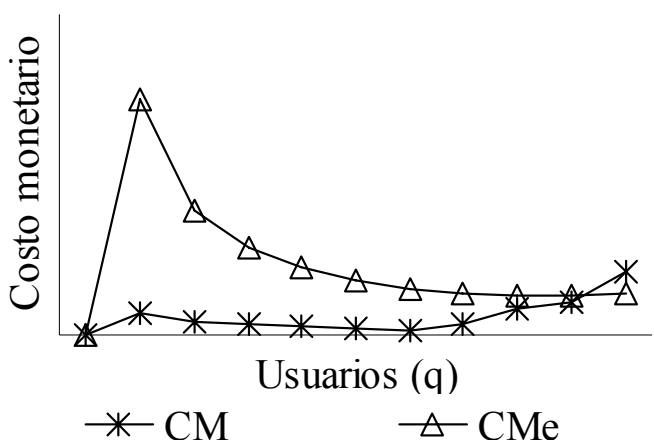

Fig. 5. Curvas de costo marginal unitario y medio unitario en comercio electrónico escalable.

Si la empresa sobre la que se basa la presente hipótesis dispone de:

[a] Alto grado de orientación y virtualización sobre el canal de Internet, desde que el usuario solicita y hasta que se produce la entrega y el cobro, el factorial de comercio se presenta elevado [63].

[b] Cuenta con la ventaja de comerciar bienes y servicios digitalizados, lo cual implica la reproducción multimedial rápida y accesible [68] a costo total relativamente bajo y con disminución de costo medio unitario [65].

Al considerar [a] el factorial de comercio y [b] la digitalización de bienes y servicios, se podría sostener en comercio electrónico escalable se tiende hacia la linealidad del costo total.

Al mes de septiembre del año 2012, se estimó en más de veinte millones de usuarios residentes en la República Argentina para la red social "Facebook" [41]. Con base a este dato, se podría sostener que los ciber-mercados alcanzan a gran cantidad de clientes potenciales [19]. Esta podría representar una ventaja competitiva para las empresas, que apalancadas con políticas de precios bajos en la oferta de bienes y servicios digitalizados [65], obtendrían ingresos altos por su consumo masivo.
El ingreso total (IT) corresponde a la acumulación del ingreso monetario aportado [77] por cada usuario q en consumo. El ingreso total será creciente con el aumento de la cantidad q de usuarios en consumo.

El beneficio total (BT) dado por la formulación: BT $=\mathrm{IT}-$ $\mathrm{CT}$, expresa la diferencia entre ingreso total y costo total [77]. Este último tiene dos términos fundamentales: el costo fijo y el costo de variable.

La maximización de beneficios puede obtenerse al aumentar la cantidad de usuarios q, exponenciando el ingreso total y manteniendo lineal el costo total como se presenta en la Tabla IV "Relación de ingreso y rentabilidad en un comercio electrónico escalable". Se expone una relación en la Figura 6 "Curvas de ingreso total y costo total en comercio electrónico escalable".

TABLA IV - RELACIÓN DE INGRESO Y RENTABILIDAD EN COMERCIO ELECTRÓNICO ESCALABLE

\begin{tabular}{|c|c|c|}
\hline Usuarios & Ingreso Total & Beneficio Total \\
\hline $\mathrm{q}$ & $\mathrm{IT}$ & $\mathrm{BT}=\mathrm{IT}-\mathrm{CT}$ \\
\hline 0 & 0 & $-\mathrm{x}$ \\
\hline 1 & $\mathrm{i} 1$ & $\mathrm{i} 1-(\mathrm{x}+\mathrm{p} 1)$ \\
\hline 2 & $\mathrm{i} 1+\mathrm{i} 2$ & $(\mathrm{i} 1+\mathrm{i} 2)-(\mathrm{x}+\mathrm{p} 1+\mathrm{p} 2)$ \\
\hline 3 & $\mathrm{i} 1+\mathrm{i} 2+\mathrm{i} 3$ & $\ldots$ \\
\hline$\ldots$ & $\ldots$ & $(\mathrm{i} 1+\mathrm{i} 2+\ldots+\mathrm{in})-(\mathrm{x}+\mathrm{p} 1+\mathrm{p} 2+. .+\mathrm{pn})$ \\
\hline $\mathrm{n}$ & $\mathrm{i} 1+\mathrm{i} 2+\ldots+\mathrm{in}$ &
\end{tabular}

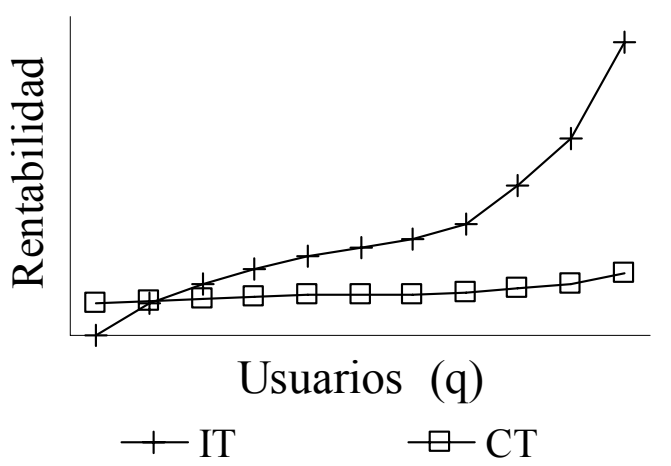

Fig. 6. Curvas de ingreso total y costo total en comercio electrónico escalable.

Si la empresa sobre la que se basa la presente hipótesis dispone de: [c] Llegada a gran cantidad de usuarios de Internet que potencialmente son consumidores de bienes y servicios digitalizados [19] podría disponer de una demanda de volumen masivo.

Al considerar [c] el crecimiento del ingreso total de modo exponencial, manteniendo al costo total lineal y por debajo del ingreso, debido a la integración de [a] la cadena de valor y [b] el comercio de bienes y servicios digitalizados, se podría fundamentar una hipótesis sobre la posible maximización del beneficio en un negocio escalable con el incremento de la cantidad de usuarios q.

d) Contexto de comercio electrónico en la República Argetnina

La Cámara Argentina de Comercio Electrónico puede considerarse una entidad que concentra esfuerzos para el desarrollo de los ejes principales del comercio electrónico. De su último informe se destacan algunas cuantificaciones que se 
presentan en la Tabla V "Progresión del comercio electrónico en la República Argentina" [44].

TABLA V - PROGRESIÓN DEL COMERCIO ELECTRÓNICO EN REPÚBLICA ARGENTINA

\begin{tabular}{|c|r|r|r|r|r|r|r|r|r|r|r|r|}
\hline Argentina & 2001 & 2002 & 2003 & 2004 & 2005 & 2006 & 2007 & 2008 & 2009 & 2010 & 2011 & 2012 \\
\hline $\begin{array}{c}\text { Ventas = B2C+C2C } \\
\text { (Millones de \$) }\end{array}$ & 80 & 240 & 560 & 1020 & 1430 & 2300 & 3100 & 4050 & 5240 & 7755 & 11593 & 16700 \\
\hline $\begin{array}{c}\text { \% Variacion Anual de } \\
\text { Venta }\end{array}$ & 239,1 & 200,0 & 133,3 & 82,1 & 40,2 & 60,8 & 34,8 & 30,6 & 29,4 & 48,0 & 48,5 & 44,0 \\
\hline $\begin{array}{c}\text { Usuarios de Internet } \\
\text { (Millones) }\end{array}$ & 3,7 & 4,1 & 5,7 & 7,6 & 10,0 & 13,0 & 16,0 & 20,0 & 23,0 & 26,5 & 28,8 & 31,1 \\
\hline $\begin{array}{c}\text { Gasto Anual por Usuario } \\
\text { de Internet }\end{array}$ & 21,6 & 58,5 & 98,2 & 134,2 & 143,0 & 176,9 & 193,8 & 202,5 & 227,8 & 292,6 & 380,1 & 537,0 \\
\hline $\begin{array}{c}\% \text { Usuarios de e- } \\
\text { commerce }\end{array}$ & 11,8 & 9,8 & 10,5 & 11,8 & 12,0 & 15,0 & 17,0 & 20,0 & 22,0 & 32,0 & 29,5 & 32,4 \\
\hline $\begin{array}{c}\text { Usuarios de e-commerce } \\
\text { (En Millones) }\end{array}$ & 0,4 & 0,4 & 0,6 & 0,9 & 1,2 & 2,0 & 2,7 & 4,0 & 5,1 & 8,5 & 9,0 & 10,0 \\
\hline $\begin{array}{c}\text { Gasto Promedio Anual } \\
\text { por Comprador (en \$) }\end{array}$ & 183,0 & 597,0 & 935,0 & 1137,0 & 1191,0 & 1179,0 & 1139,0 & 1012,0 & 1035,0 & 914,5 & 1288,0 & 1670,0 \\
\hline
\end{tabular}

El 32\% de las empresas pequeñas y medianas (PyMes) y el $35 \%$ de grandes empresas vende o compra en línea, frente a unas pocas decenas de hace menos de diez años, aumentando la variedad de rubros, productos y servicios ofrecidos [44].

El mismo estudio explica que los pagos con tarjeta de crédito y débito siguen incrementando su participación debido a:

- La promoción y continuidad de planes de cuotas sin interés y con atractivos descuentos.

- Incremento de la sensación de seguridad y confianza por parte de los usuarios.

- Aumento del $14 \%$ a $16 \%$ de la bancarización del sistema de base y oferta monetaria.

- La aparición de empresas de descuento y clubes de compra en línea.

La evolución del perfil de los compradores de comercio electrónico ha cambiado cada año, pasando de ser un pequeño grupo de alto nivel socioeconómico y de alta calificación educativa y laboral, a un amplio segmento donde aquellos de nivel socioeconómicos medio y alto son un $25,9 \%$ del total de compradores, el resto se compone por usuarios crecientes de los niveles económicos medio y medio bajo [65].

La alta concentración inicial de compradores en la Ciudad de Buenos Aires, ha dado lugar a una distribución a nivel nacional más pareja, en la cual un $30,6 \%$ de los compradores son del interior del país y el 69,4\% corresponden a la Ciudad Autónoma de Buenos Aires y Área Metropolitana de Buenos Aires. Esta proporción refleja una aproximación de los volúmenes por región. Por grupos etáreos los usuarios de comercio electrónico se distribuyen de forma pareja. Un 33,7\% de los compradores es menor de 25 años, un $32,1 \%$ tiene entre 26 y 35 años inclusive, un 13,5\% entre 36 y 45 años mientras que los mayores de 45 años son $20,7 \%$ del total [44].

Con poco mas de diez años de comercio electrónico, la compra, el pago, las consultas, la operatoria, la logística de entrega y todo el circuito generado en la cadena de valor facilita, no solo la operación, sino la recepción y abono del cliente como al proveedor su parte, auspiciando la igualdad entre los elementos intervinientes [21].

Considerando el escenario político y económico actual, en la República Argentina se proyecta un crecimiento anual para la actividad comercial por Internet de un $48 \%$ en pesos, respecto al monto facturado en 2012, pudiendo superar los 25 mil millones (entre B2B y B2C) [44].

\section{B. Adicciones digitales}

Se presenta controversia actual sobre el concepto de adicción digital (sub-sección 1), para continuar con las consecuencias sobre la actitud (sub-sección 2), posibles afecciones al cuerpo humano (sub-sección 3), y finalizar el desarrollo con el efecto de masa (sub-sección 4).

\section{1) Controversia sobre el concepto de adicción digital}

Las adicciones no pueden limitarse exclusivamente a las conductas generadas por sustancias químicas. Existen hábitos aparentemente inofensivos que pueden convertirse en adictivos e interferir gravemente en la vida cotidiana de las personas afectadas [78].

Cuando se manipulan artefactos electrónicos e informáticos, hay una diferencia entre uso, abuso y adicción. El uso es que sea utilizado un breve tiempo todos los días. El abuso se da cuando se utiliza más de la mitad de un día. La adicción se produce cuando esta última conducta se reitera los siete días de la semana [79].

Una persona que sufre tecnoestrés se encuentra preocupada por el efecto psicosocial negativo de la tecnología en su vida [80]. Puede progresar hacia la tecno-fobia y rechazar por completo a las nuevas tecnologías. Ó alcanzar algún grado de tecno-dependencia que la impulse a estar continuamente en uso. Se encuentra molesto cuando permanece horas o días sin teléfono móvil o sin conexión a Internet, se encuentra irritable y con síntomas depresivos pudiendo llegar al extremo de la tecno-adicción [81].

La población de mayor afectación podrían ser los niños y adolescentes, a los que el abuso de las nuevas tecnologías puede acabar perjudicando en su desarrollo intelectual, físico y emocional [12]. Ya son considerados nativos digitales y por tanto usuarios mucho más avezados e intuitivos que gran parte de los adultos [54].

Las ciber-adicciones o tecno-adicciones incluyen todos aquellos fenómenos o problemas de abuso de las nuevas tecnologías de información y comunicación (NTIC) [82; 11]. Otras consideraciones sobre el concepto lo vinculan con el trastorno de adicción a Internet. Se trata del uso excesivo de Internet, a través de diversos dispositivos que interfieren con la vida diaria de un individuo [83].

La Asociación de Psiquiatría Americana (APA), en torno a los diagnósticos y estadísticas de los trastornos mentales DSMIV ("Diagnostics and Statistics of Mental Disorders DSM-IV" en inglés) no considera ninguna adicción no química, y por tal, las adicciones se definen según la sustancia que las causa. La entidad afirma que los comportamientos compulsivos han existido siempre, pero pertenecen a una categoría diagnóstica muy distinta [84].

La inclusión del problema en el DSM-V, la última versión que data del año 2000, se encontraba a debate. Al parecer fue nuevamente rechazada, fundamentándose la relación con Internet. Sólo la adicción al juego patológico por Internet, como variante de la adicción al juego, se reconoce, desestimando de nuevo que exista algo llamado ciber-adicción 0 adicción a Internet [85].

Se considera que puede existir un "uso excesivo", pero nunca una "adicción" ya que las causas no vendrán motivadas por la propia Internet, sino otras externas que llevan al usuario a buscar una vía de escape y utiliza Internet como una posibilidad [85]. Una consecuencia sobre el abuso de Internet se da en el establecimiento físico de relaciones sociales, algo 
más sencillo de conseguir por Internet gracias al anonimato y desinhibición, aunque puedan resultar más efímeras [86].

Por lo expuesto en lo precedente se debate si constituye un abuso o una adicción, pero se reconocen cinco categoría de exceso: adicción computacional (específicamente a juegos en línea, excluidos los juegos de azar), sobrecarga de información (navegación compulsiva por diferentes sitios, incluso con múltiples ventanas a la vez), compulsiones en red (gasto de dinero en sitios de apuestas y compras en línea), adicción ciber-sexual (acceso a la pornografía y a relaciones sexuales explícitas) y adicción a las ciber-relaciones (mediante el uso de redes sociales) [11].

Otros autores categorizan en: desmedida búsqueda de información de todo tipo, le sigue el exceso de contacto en entornos (o redes) sociales, la adicción a los juegos (de apuestas o no), compras compulsivas y finalmente ciber-sexo [10].

\section{2) Consecuencias sobre la actitud}

Internet ha revolucionado la comunicación, planteado nuevos paradigmas y abriendo una nueva dimensión en la conducta humana, presentando nuevos beneficios pero afrontando un alto costo [87]. Siguiendo al autor, no contar con su acceso puede alterar la vida rutinaria generando ansiedad y frustración. Utilizarla todo el tiempo puede llevar a elevados estados de adicción.

Los estudios recientes presentan los problemas incrementales de los usuarios para lograr controlar el uso de Internet. En 1999 se reportó 6\% de prevalencia sobre 17.251 sujetos evaluados [88]. Una revisión de trabajos realizados entre 2000 y 2009 en Estados Unidos y en Europa halló una prevalencia entre $1,5 \%$ y $8,2 \%$ [89]

En las regiones más tecnologizadas los valores crecen fuertemente. Llama la atención lo que ocurre en los países asiáticos donde la prevalencia se eleva entre $20,3 \%$ y $37,9 \%$ en poblaciones coreanas estudiadas [90], lo que coincide con lo hallado en 28 escuelas secundarias de Hong-Kong, donde se halló una prevalencia del $26 \%$, principalmente en la población de niños y de adolescentes [91].

La adicción a Internet causa problemas similares a otras adicciones como: pérdida del control, ansiedad, síndrome de abstinencia, aislamiento social, conflicto conyugal, fracaso escolar, deterioro económico y hasta pérdida del empleo [92; 93].

Se ha encontrado que los adictos a la Internet presentan una alta prevalencia de comorbilidades psiquiátricas: depresión, trastorno bipolar, ansiedad y trastornos de hiperactividad por déficit de atención; además de factores predictivos: baja autoestima, fobias, hostilidad familiar, consumo de alcohol y ansiedad social [11]. Dada esta diversidad y a la heterogeneidad de la población, el estudio manifiesta que este tipo de adicción es, a menudo, de difícil diagnóstico porque sus síntomas pueden estar enmascarados por el uso legítimo de Internet.

Sobre trastornos de salud mental los síntomas evidencian cambios en el humor, aislamiento social y familiar, cambios en el ritmo de sueño y vigilia, pérdida de apetito, horarios desordenados y falta de higiene personal [94]

Estas razones estimulan a los médicos a hacer preguntas sobre el uso de la computadora durante la confección de la historia clínica. Se ha encontrado que los sujetos con estados pre-mórbidos tienen mayor riesgo de adicción, lo cual exige una prioritaria estrategia e prevención, debido a que, a diferencia de las drogas y el alcohol, es aún irrestricto el acceso a la Internet [95].

Estudios recientes han confirmado que el impacto psicológico de Internet llega mucho más allá de lo que realmente se conoce, donde se determina que los adictos a Internet y los drogadictos presentan síntomas similares en el proceso de desintoxicación [96]. Siguiendo a los autores se expone que a los adolescentes con dependencia digital les cuesta levantarse para ir al baño o dormir, volviéndose cada vez más irascibles, ariscos, malhumorados y ansiosos.

\section{3) Afecciones al cuerpo humano}

Las afecciones derivadas de la vida conectada a Internet aparecen cada vez con más frecuencia presentando alto impacto en el rango de los doce (12) a los cuarenta (40) años [94].

Hay evidencia clara de que largas jornadas frente a una computadora tiene consecuencias nocivas para la vista y el sistema músculo-esquelético [13]. Los problemas asociados al uso de computadoras, tabletas y teléfonos celulares también se ven y tratan en los servicios de hospitales públicos, donde aumentaron las consultas en las áreas de oftalmología, traumatología y salud mental [94].

Uno de los mayores inconvenientes físicos por estar varias horas seguidas frente a una pantalla es el cansancio visual y la falta de lubricación en los ojos. La frecuencia del parpadeo disminuye entre un $30 \%$ y $40 \%$. La tecno-adicción trae consecuencias físicas como ojos secos $y$ rojos que se manifiestan al terminar la jornada [94].

Se encuentra alta prevalencia al estudiar factores como sobrepeso y obesidad debido al desmedido uso de nuevas tecnologías. Los casos se incrementan en niños y adolescentes donde a una conducta alimentaria no adecuada se agrega la disminución de actividad física e inversión del tiempo libre en actividades de escaso o ningún consumo calórico [14].

La postura inadecuada para sentarse frente al monitor de la computadora o la forma de usar los teléfonos mientras se camina o se está en la cama provoca la flexión excesiva y prolongada del cuello y espalda baja provocando problemas musculares, dolor de cuello, conflictos vertebrales y tortícolis [94].

Los teléfonos móviles pueden ser nocivos para la salud afectando al sistema nervioso central. Se debería disminuir la densidad de potencia de los campos electromagnéticos del sistema de telefonía móvil para mejorar el índice de absorción específica, a fin de cuidar la salud del usuario y dar prosperidad las nuevas metodologías de comunicación [97]. Se reconoce la necesidad de hondar las investigaciones sobre el potencial carcinógeno de los campos de radiofrecuencias producidos por los teléfonos móviles [98].

En el hombre, la cercanía del móvil en la zona pélvica mientras se da una comunicación telefónica, modifica la calidad del esperma [99]. Un efecto similar se produce con la utilización de las computadoras portátiles sobre las piernas, sumado al síndrome de la piel tostada por el calor del equipo [100].

El exceso de volumen en los auriculares podría causar la disminución de la capacidad auditiva y conducir hasta el principio de sordera, aunque se reconoce que la amplificación sonora ayuda a las personas en los casos de disfunción auditiva [101].

Las enfermedades en el miembro superior se dan un $34 \%$ más en quienes abusan de la tecnología. Se presentan micro- 
traumatismos generados por una acción sostenida durante muchas horas como teclear, usar el ratón o digitar la pantalla del teléfono en forma repetida y constante. Los síntomas comunes en las manos son el adormecimiento y la pérdida de fuerza en los dedos, llegando hasta inflamación o irritación de tendones (tendinitis) cuando superan el umbral de tolerancia del cuerpo humano [94].

\section{4) El efecto de masa}

Internet es la sociedad, expresa los procesos sociales, los intereses sociales, los valores sociales, las instituciones sociales. Permite el desarrollo de una serie de nuevas formas de relación social que no tienen su origen Internet, son fruto de una serie de cambios históricos que no podrían desarrollarse sin Internet [102].

El ciber-espacio da entrada a ideas de millones de personas que suben y bajan contenidos democratizando el conocimiento humano, disfrutando un efecto de igualdad entre usuarios en la red [9]. Sobre ella se gesta una nueva sociedad que dispone de una estructura construida en torno a redes de información haciendo al corazón de un nuevo paradigma socio técnico [102].

En este espacio de conglomeración de usuarios se genera una multitud, donde podrían borrarse o disminuir las adquisiciones individuales, tendiendo a la desaparición de la personalidad de cada uno que la integra. En el mundo físico se comprueba que en alta medida difiere el individuo integrado en una multitud, del individuo aislado [103]. El autor indica que una tal masa primaria es una reunión de individuos, que han reemplazado su ideal del "yo" por un mismo objeto, a consecuencia de lo cual se ha establecido entre ellos una general y recíproca identificación del "yo".

Algunas personas expresan la necesidad de consumir bienes y servicios digitalizados por Internet porque otros, que ellos conocen, también lo hacen manifestando un efecto de masificación [104].

Se reconocen algunas alteraciones de identidad que se relacionan con el uso problemático de Internet y móvil [83] pero debe resaltarse la importancia que tiene para los jóvenes con discapacidad las redes sociales de Internet en sus relaciones sociales [105].

Internet procesa la virtualidad y la transforma en nuestra realidad, constituyendo la sociedad red, que es la sociedad en que vivimos [102]. El efecto de amplia difusión de sus contenidos produce efectos positivos o negativos en cada individuo, pues es el consumidor quien en su plena libertad decide hacerlo o no. El factor moral de su decisión debe ser aportado individualmente. La moral sólo existe en primera persona [16].

Al considerar la nueva sociedad en red [102], la amplia difusión de bienes y servicios digitalizados [68] y la posible masificación que podrían experimentar los usuarios [83], debería esperarse algún impacto inmediato. El proceso hacia su adicción presenta síntomas como: negación, deshonestidad, desordenes de pensamiento, grandiosidad y desconexión de los sentimientos [106].

Se estima que cerca de un $6 \%$ de los usuarios que se conectan en redes abiertas son adictos a Internet. Se han desarrollado programas de tratamiento, que incluyen hasta la internación, para recuperar adictos en forma muy parecida a como ya lo hacen otros programas como "Alcohólicos Anónimos" o los "Jugadores Compulsivos" [107]. Siguiendo al estudio, se conoce que los programas constan de, al menos, los siguientes elementos: control de los estímulos vinculados a la adicción, acotamiento a la exposición a Internet, solución de problemas específicos (como control de la ansiedad, control de la depresión y control de los conflictos interpersonales), creación de un nuevo estilo de vida y prevención de recaídas.

Hay más de doscientas (200) organizaciones en China que ofrecen tratamiento por desórdenes relacionados con la red. La mayoría de sus afectados son niños o adolescentes a los que se le imparte una estricta metodología militar y acompañados por sus padres, se les prohíbe el contacto con el mundo exterior [108].

La disminución de los problemas referidos a la adicción digital debe ser responsabilidad de los consumidores, por la característica de apertura y libertad de contenidos de Internet [9], la empresa privada, a fin de dar y mostrar la honestidad necesaria para ganar la confianza de los demás [109] y el estado para velar por el bien común de toda la actividad de los involucrados [12].

\section{Modelos y simulaciones}

Se desarrollan definiciones y conceptualizaciones sobre modelos y simulaciones (sub-sección 1), el apoyo que brinda la sustentabilidad para el desarrollo de modelos (sub-sección 2) y se finaliza el estado de la cuestión con un estudio sobre la literatura actual en modelos de impacto de consumo (subsección 3).

\section{1) Definiciones y conceptualizaciones}

Pueden considerarse diferentes enfoques para trasmitir el concepto de sistema, en síntesis; es una colección de partes o elementos que interactúan entre si para alcanzar un objetivo definido [110]. Los sistemas reciben (entrada) datos, energía o materia del ambiente y proveen (salida) información, energía o materia [111].

Al considerar la variación de tiempo e introducirla en el concepto de sistema podrían describirse diferentes momentos, como si fuese tomada una foto que capture un preciso instante del sistema. En cada instante se encontraran un conjunto mínimo de variables cuantificadas dentro del sistema que podrían describir su estado [112].

En función de la evolución de las variables de estado, un sistema podría clasificarse en $[113 ; 112]$ :

- Determinístico: es un sistema que no contiene ningún elemento aleatorio, todas las variables son determinadas.

- $\quad$ Estocástico: en este caso algún elemento del sistema tiene una conducta aleatoria.

- Continuo: las variables de estado evolucionan de modo continúo a lo largo del tiempo.

- Discreto: las variables de estado cambian únicamente en un cierto instante o secuencia de instantes y permanecen constantes el resto del tiempo.

- Orientados a eventos discretos: es un sistema discreto donde la secuencia de instantes en los cuales el estado del sistema puede presentar un cambio obedece a un patrón aleatorio.

- Combinados: subsistemas cuyas dinámicas responden a características determinísticas, estocásticas, continuas o discretas.

$\mathrm{Si}$ las variables de estado del modelo toman valores diferentes, entonces el sistema está en movimiento, produciendo cambios que al ser analizados podrían describir la órbita interna y externa del sistema. El objetivo del modelo de 
simulación consiste en comprender, analizar y mejorar las condiciones de operación del sistema en estudio [114].

La simulación es un soporte indispensable para el proceso de construcción de un modelo en sus diferentes grados de aproximación (o niveles de agregación) ya que aporta imágenes (con sus variables cuantificadas) que indican el acierto de la matemática sobre la realidad que se intenta modelar [115]. Es una herramienta que aporta a la validación final de modelo conceptual, el análisis de sensibilidad y la experimentación con propósitos de conocimiento [114]. La técnica puede ser usada para aprender sobre nuevas situaciones, en las cuales se dispone de poca o ninguna información. Como principal desventaja requiere de apoyo en equipo computacional y desarrollo en base a recursos humanos costos [116].

Un modelo conceptual es una representación externa y simplificada de objetos, fenómenos o situaciones reales que facilita la comprensión o la enseñanza de sistemas o estados de cosas del mundo con formulaciones matemáticas y lógicas. Son representaciones precisas, completas y consistentes con el conocimiento científicamente compartido [117]. Siguiendo a los autores, se debe considerar que la transmisión del modelo conceptual es parte de la técnica de modelado. Este será transformado por representaciones internas, personales idiosincrática, incompletas, inestables y funcionales por el modelo mental del receptor. Un modelo conceptual no puede ser desprendido del modelo mental que lo interpreta.

Auque se trabaje en pos de la objetividad para el desarrollo de un modelo conceptual, el modelador (equipo que modela) aporta un grado de subjetividad, que suele configurar la columna vertebral, aportando el modo en que se desea explicar la realidad [118].

\section{2) El apoyo de la sustentabilidad}

Si se dispone de un modelo que solo se orienta a reproducir las salidas de un sistema, sin modelar su comportamiento interno, como una caja negra, será un modelo experimental. Si se agrega el intento por reproducir las relaciones funcionales del sistema será un modelo de base teórica [119].

El diseño del modelo aumenta el grado de conceptualización a medida que se maximiza la comprensión sobre el sistema real a modelar [114]. Integrar el corto con el largo plazo para satisfacer la necesidades del presente, sin comprometer la capacidad de las generaciones futuras para satisfacer las suyas [120] podría presentar un marco amplio y propicio para desarrollar un modelo. Incluir conceptos de sustentabilidad dentro de un modelo conceptual implica colaborar con un crecimiento humano justo, conectado, prudente y seguro [121].

El desarrollo sustentable surge como posibilidad de mitigar impactos adversos que provoca el ser humano en los sistemas que dan soporte a su vida. En términos ambientales podrían mencionarse: el cambio climático, la degradación del suelo y desertificación, pérdida de la diversidad biológica y contaminación del agua del planeta [120]. Siguiendo al autor, en otros planos como el económico y sociológico, se da: aumento de la brecha entre ricos y pobres, mayoría de población mundial con necesidades básicas insatisfechas, sistemas económicos injustos, grupos indígenas y étnicos en riesgo y violación de derechos humanos.

En un intento por mitigar las inequidades que vienen ocurriendo, surge la posibilidad de balancear aspectos económicos, ambientales y sociales para conseguir un desarrollo sustentable para todos los habitantes del planeta, de forma que progresen los recursos naturales, mejore el comportamiento de la sociedad global y a la vez se genere riqueza [122].

La explosión demográfica de los últimos sesenta años podría indicar que el futuro debe apuntalarse para todas las especies, incluida la humana. El 12\% de la población mundial posee recursos, acceso y riqueza, mientras emerge una clase media del $24 \%$, lo que implica que el $64 \%$ de la población del planeta es pobre y representa a la base de la pirámide poblacional [123]. Tomar de conciencia acerca de esta realidad podría ser el factor clave para brindar otro tipo de posibilidades hacia la población de la base de pirámide.

La concepción del mundo debe innovarse radicalmente y las empresas deben tomar la delantera. Los individuos o grupos involucrados que pueden afectar o son afectados por los objetivos de una empresa deben entenderse como partes involucradas y las organizaciones que pretendan prosperidad deberán crear valor para só y los involucrados en términos: económicos, ambientales y sociales [124].

No sólo se trata de cumplir objetivos o metas, sino de lograr un involucramiento completo que permita alcanzar mejoras en los tres pilares de sustentabilidad para llegar al desarrollo, la maduración y facilitar la convivencia de los intereses involucrados. Con mayor frecuencia los inversores han ido reparando en criterios éticos a la hora de apoyar posibles inversiones [26]. La sustentabilidad podría ser un camino que se apoye en el compromiso de los empleados, el involucramiento de la cadena de valor (proveedores), las relaciones con la comunidad y organismos no gubernamentales para lograr un mundo mejor [125].

Más de la mitad de los pobladores del planeta aspiran ingresar a un mundo que no les es accesible todavía. Las compañías deben combinar crecimiento con responsabilidad social y ambiental ya que han colaborado a generar la realidad ambiental actual. Los nuevos modelos de negocios que generen los empresarios del futuro deben contemplar el desarrollo sustentable como opción [126].

La comunidad científica podría aportar valor al proceso de cambio necesario agregando fundamentos de desarrollo sustentable en sus trabajos. Esto podría facilitar la difusión y discusión de los conceptos relacionados, aportando bases sólidas para la creación de nuevas y mejoradas visiones a fin de pensar un futuro mejor.

\section{3) Modelos de impacto de consumo}

Existen metodologías, modelos y procedimientos para la evaluación de impactos en diferentes factores, algunos generales y en pos de la universalidad [127] y otros específicos para situaciones $\mathrm{o}$ aspectos de carácter cualitativo o cuantitativo, con operación de bases de datos e instrumentos de cálculo sofisticados, estáticos o dinámicos [128].

Al realizar una búsqueda bibliográfica sobre modelos de impacto se encuentran los relacionados con medicina [129; 130], ecología marina [131], aspectos de períodos geológicos del planeta tierra [132], análisis de la política de productos agrícolas y su comercio [133], cambio de variabilidad en sistemas de software orientado a objetos [134], probabilidades estimadas sobre acontecimientos futuros [135], modelo de impacto de ruido ambiental [136], impacto económico de eventos culturales [137] entre otros.

Al agregar el concepto de sustentabilidad a los modelos de impacto, se encuentran los relacionados a la transferencia de 
conocimiento [138], medio ambiente y comportamiento humano [139], calidad de vida urbana para el desarrollo [140], mejora forestal para el alcance de paisajes sostenibles [141], modelo sustentable de gestión de chatarra de cobre [142] e impacto sobre la sostenibilidad de los programas de desarrollo profesional [143] como destacados.

Sobre modelos de consumo de bienes y servicios digitalizados en Internet se destaca el consumo de videos sobre en sitios específicos [144], la televisión por Internet móvil [145], modelos de comunicación, nuevos medios y nuevo público [146] e impacto de Internet sobre la estructura de los mercados [147].

No se ha encontrado estudios previos sobre modelos de impacto de consumo masivo de productos y servicios digitalizados en comercio electrónico escalable. Existe variada literatura sobre el concepto en sus partes desagregadas que serán expuestas a lo largo del presente trabajo.

\section{DESCRIPCIÓN DEL PROBLEMA}

En este apartado se presenta un marco contextual acerca del consumo de bienes y servicios digitalizados sobre Internet (sección $A$ ). Se continúa con la delimitación del problema basada en tres pilares: el primero se refiere al eje económico (sección $B$ ), para continuar sobre el ambiental (sección $C$ ) y seguir el desarrollo sobre con el eje social (sección $D$ ). Se finaliza el apartado con el sumario de la investigación (sección E).

\section{A. Consideraciones sobre el consumo en el marco digital}

Actualmente entre el $30 \%$ y $35 \%$ de los habitantes del planeta disponen de acceso a la Internet [41]. Esta es un espacio perfecto para las ideas que da entrada a millones de personas que suben y bajan contenidos intentando democratizar el conocimiento humano [9]. Se presentan dos mundos, no excluyentes sino complementarios: uno real de recursos que se pueden ver y tocar, y otro, virtual en el que los bienes y servicios adoptan la forma digital [148].

En medios de soporte electrónico pueden alojarse; libros, imágenes, videos, música, programas informáticos y otros entretenimientos, que son solicitados, entregados y comerciados por vía de ciber-mercados [19], apuntalando al comercio electrónico. El consumidor aumenta su capacidad de acceso, obtiene mayor información y compara características, reduciendo e incluso eliminando a los intermediarios [72].

Este beneficio se debe en parte a la transacción de bienes y servicios digitalizados, donde la infinitud de stock, devenida en ceros y unos, los predispone como nuevas posibilidades de comercio, ampliándolo e innovándolo. La "Ley de los activos digitales" establece, que a diferencia del mundo físico, no se agotan con su consumo [20].

Con base a lo expuesto en lo precedente se sumarizan las preguntas: ¿Podría desarrollarse y validarse un modelo conceptual que estime el impacto económico, ambiental y social por el consumo masivo de bienes y servicios digitalizados?

Debe considerarse la característica de extraterritorialidad de la red y la falta de normativa específica para la administración de sus contenidos, sea por televisión digital interactiva $\mathrm{o}$ telefonía móvil. La identificación del ámbito espacial es irrelevante para estas tecnologías [6].

Algunos países de condiciones físcales paradisíacas comenzaron a alojar productos $\mathrm{y}$ servicios digitalizados controversiales para la población [1]. Mientras, otros de mayor desarrollo, iniciaron los primeros debates de prohibición sobre su consumo [3]. Aunque las pujas legales trasnacionales sobre estas metodologías de distribución continúan, los bienes y servicios digitalizados podrían estar afectando de algún modo a los usuarios expuestos.

Ciertos estudios $[10 ; 11]$ indican que algunos individuos consumidores de la red enfrentan potencialmente una serie de nuevos conflictos inherentes al comportamiento. Compulsividad y trastornos de la personalidad son devenidos del consumo exagerado de contenidos de Internet, experimentando un tipo de ciber-adicción [10]. Las personas como los niños, adolescentes y adultos vulnerables se encuentran en mayor grado de exposición que otros [12] y algún segmento de la población podría, por su edad, ser más afectada [54].

En este contexto, surge el interés de conocer qué posibles consideraciones se relacionan a la ciber-adición [10], teniendo en cuenta a los consumidores más expuestos [54] sobre los tres ejes pilares de la sustentabilidad, enlazando el corto con el largo plazo e integrando los aspectos económicos, ecológicos y sociales [120].

\section{B. Consideraciones económicas}

La distribución de bienes y servicios digitalizados en cibermercados se trata de una modalidad comercial novedosa [19], que acciona sobre empresas y consumidores, influenciados por la actividad publicitaría [9], la disposición de tecnología, los servicios de comunicaciones y datos [38] en el marco de la gestión gubernamental [69]. En este contexto, un individuo podría modificar su conducta respecto a los recursos financieros utilizados para el consumo digitalizado, alterando a la economía individual, familiar o grupal.

Tras estas consideraciones surgen las preguntas: ¿Existe alguna relación entre el impacto económico individual de un usuario que ejerce comercio electrónico de bienes y servicios digitalizados respecto a una estimación de su estado de resultados? ¿Y respecto a una estimación del estado patrimonial? ¿Y sobre la condición de ocupación laboral (o no laboral)? ¿Se presenta algún cambio de tendencia en la preferencia por las compras de bienes y servicios digitalizados respecto a los físicos?

La mejora y actualización sobre el conjunto de normas en derecho de autor y otros conexos podría contribuir en favor del mejoramiento de la tecnología digital [149], apuntalando una fuente para gestar nuevas reglamentaciones a través de las cuales usufructuar obras intelectuales sobre nuevos formatos [150]. Se debe considerar que los agentes principales del comercio electrónico son las empresas, los consumidores y la administración pública [71].

Parece demostrarse que la actuación de los estados no logra controlar efectivamente a las empresas oferentes de bienes y servicios digitalizados, dando libertad a cada individuo usuario, pudiendo estos desarrollar cierta impulsividad para el consumo de contenidos hasta trasgredir normas e incurrir en actos delictivos para poder perpetuar la adquisición de contenidos digitalizados.

En este contexto surgen las preguntas: La característica del consumo y comercio digital; ¿podría facilitar el aumento del ahogo financiero individual debido a posibles excesos? ¿Podría incrementarse la comisión de actos ilegales para obtener más recursos y aumentar el nivel de consumo? y ¿Podría encontrarse alguna relación entre el costo monetario individual 
en el que se incurre por el consumo de bienes y servicios digitalizados y el posible impacto económico que podría producir?

Planteadas las consideraciones económicas se continúa el análisis desde el abordaje ambiental, donde la relación causa y efecto podría producir otro equilibrio.

\section{Consideraciones ambientales}

Al utilizar computación en Internet las empresas se vuelven más ecológicas porque disminuyen su consumo de energía mientras incrementan su capacidad [151]. Este concepto podría extenderse hacia la masa de usuarios, que debido al consumo de bienes y servicios digitalizados, podrían estar disminuyendo el del mundo físico, como también el trasladado hasta los mismos, minimizando el impacto ambiental. Como contrapeso debería considerarse que algunos podrían padecer consecuencias por el uso descontrolado.

Se reconocen al menos cinco categorías de ciber-adicción. La primera refiera a la desmedida búsqueda de información de todo tipo, le sigue el exceso de contacto en entornos (o redes) sociales, la adicción a los juegos (de apuestas o no), compras compulsivas y finalmente ciber-sexo [10]. Siguiendo a los autores, se conoce que la ciber-adicción es perjudicial para la salud, pero aquellos que no manifiesten patologías adversas, disfrutan de un efecto de igualdad entre usuarios en la red [9], dando lugar a servicios abiertos y configurando un modelo revolucionario de intercambio y producción de información [24]. Podría presentarse el comienzo de la ilegalidad en la reproducción de contenidos bajo el delito de robo y piratería, provocando una revolución [9], liberando contenidos por tecnologías verdes, minimizando el impacto en el medio ambiente [151].

Bajo estas consideraciones se formulan las siguientes preguntas: ¿Podría encontrarse una relación ambiental entre un usuario que ejerce el comercio electrónico de bienes y servicios digitalizados respecto a las características de la vivienda que habita? ¿Y respecto a los servicios básicos de su hogar? ¿Y respecto al aporte al desgaste ambiental por el consumo de bienes y servicios tangibles?

Al principio sólo algunos usuarios disponían del privilegio subir información a Internet. Esa primera versión se conoce como la red (web) 1.0. Con el incremento en la cantidad de usuarios de participación activa, se está en presencia de una forma llamada red (web) 2.0 donde predomina el acceso y la proliferación de productos y servicios digitales [24] que se comparten gracias al uso hogareño (o copia hogareña), los buscadores, los programas de descarga, reproducción y los alojamientos en zonas donde su ley los permite [1].

La profusión de herramientas, la capacidad de producción, el incremento de acceso, el tratamiento de la información, la multiplicación de posibilidades de participación y creación a través de servicios y sistemas atractivos y sencillos ha dinamitado las lógicas de creación, producción, distribución y consumo de contenidos digitalizados [152]. Lo que podría fundamentar el aumento de la cantidad promedio de computadoras por individuo [42] y los canales de acceso y uso de Internet [44], acrecentando el tiempo de uso, y por tal, el consumo eléctrico y la emisión de gases calientes.

En este contexto surgen las preguntas: ¿Los usuarios presentan algún efecto de preocupación recurrente por el consumo de bienes y servicios digitalizados que esa red brinda? ¿Podría manifestarse alguna tendencia al incremento del consumo? ¿Se presentan dificultades al momento de abandonar el consumo de bienes y servicios digitalizados por Internet? ¿Puede controlarse el momento de retiro o fin sobre el consumo? ¿Puede comprobarse alguna tendencia sobre la intensión de retiro? ¿Cómo se manifiesta la tendencia a la repetición sobre el consumo de bienes $\mathrm{y}$ servicios digitalizados? ¿Podría encontrarse alguna relación entre el tiempo que un usuario utiliza para el consumo de bienes y servicios digitalizados y el posible impacto ambiental que podría producirse?

Planteadas las consideraciones ambientales se continúa el análisis desde el abordaje social que podría presentar un panorama sobre el impacto relacional sobre otros individuos.

\section{Consideraciones sociales}

El avance en los campos de construcción de software, las comunicaciones y el acceso masivo a Internet, posibilitaron el desarrollo de empresas, con la tecnología operacional necesaria, para distribuir un amplio abanico de posibilidades digitales hacia los consumidores [2]. Es una actividad podría producir un efecto de distracción y diversión, pero superado cierto umbral, se afecta negativamente el auto-estima, el estado de ánimo y las habilidades de relacionamiento social [153], alternando el tiempo de sueño y como consecuencia el de vigilia.

La actual revolución digitalizadora de Internet [9] podría actuar como medio de trasporte de productos y servicios de consumo inagotable [20] hasta poblaciones vulnerables, permeables a tecnologías [54] donde la exposición desmedida podría estar gestando, en silencio, un conjunto de personas ciber-adictas [10].

Con base a lo expuesto en lo precedente se sumarizan las preguntas: ¿Podría encontrarse una relación entre un usuario que ejerce el comercio electrónico de bienes y servicios digitalizados respecto a su situación poblacional? ¿Y respecto a su aspecto de salubridad? ¿Y respecto las características del hogar que habita? ¿Y respecto a su educacional formal?

La afectación individual que podría producir el consumo de bienes y servicios digitalizados se encuentra influenciada por una red como Internet, que parece un espacio sin reglas ni reglamentaciones, auspiciando un nivelamiento de los privilegios de todos los usuarios [9]. Siguiendo al autor, a medida que el sistema crece parece demostrarse lo contrario. Se presenta una paradoja en donde la falta de regulación hace que aquellos que tienen más fuerzas se hagan escuchar, impongan su marca y su autoridad. Entonces algunos tienen más fuerza que otros. Las grandes empresas de buscadores, correos electrónicos, venta de libros, redes sociales y enciclopedias acaparan, filtran y editan contenidos, manifestando como funciona el poder y la actividad comercial. La regulación estatal sobre la actividad de esas empresas podría tomar un carácter fundamental.

Aspectos como la contratación electrónica, seguridad informática y criptografía, firma digital y medios de pago con dinero electrónico, cuadrados por políticas fiscales y comerciales, contextualizarían un nivel óptimo y maduro para el comercio electrónico [69], pudiendo mejorar la posición y protección de los usuarios, a favor del bien común.

Bajo estas consideraciones se formulan las siguientes preguntas: ¿Se presentan dificultades al momento de controlar el consumo de bienes y servicios digitalizados por Internet? ¿Puede un usuario perder el control sobre el consumo? ¿Podría 
utilizarse al consumo de bienes y servicios digitalizados para lograr evadir los conflictos cotidianos? ¿Sería un mecanismo que permitiera un escape de la vida? ¿Existe un grado en el cual el consumo de bienes y servicios digitalizados logre afectar a un individuo de modo que oculte profundamente esa actividad? ¿Qué impacto podría producir a un usuario ese ocultamiento? ¿Se presentan dificultades para mantener relaciones sociales afectivas debido al consumo de bienes y servicios digitalizados? ¿Puede un usuario afectar a sus relaciones por el exceso en el consumo? ¿Podría encontrarse alguna relación entre la cantidad de veces que un usuario utiliza el comercio electrónico para consumir bienes y servicios digitalizados y el posible impacto social que podría producirle?

Debe considerarse que con poco más que diez años de comercio electrónico, algunos de los productos digitalizados como libros, música, películas y aplicaciones móviles; constituyen ejemplos de negocios de alto crecimiento en el planeta [154].

Podría sostenerse que la tecnología permite a las nuevas generaciones consumir bienes y servicios que podrían afectar a su salud. El problema que se presenta es encontrar perfiles comunes, sobre aquellos usuarios de Internet, que consuman productos y servicios digitalizados, de modo que si experimentan algún patrón de conducta compulsiva al hacerlo, puedan minimizarse las consecuencias humanas e individuales en base a la investigación de las causas. Se pretende comprender cómo se comporta la sociedad ante el consumo de contenidos que podrían generar adicción, qué conducta se observa, qué posible respuesta cabe a las preguntas típicas de una sociedad atenta a la cuestión.

\section{E. Sumario de la investigación}

Por lo expuesto precedentemente surgen algunas preguntas para la investigación:

[I] ¿Podría encontrarse una relación entre el impacto económico de un usuario que ejerce el comercio electrónico de bienes y servicios digitalizados respecto a:[a] Una estimación de su estado de resultados? [b] Una estimación de su estado patrimonial? Y [c] Su condición de ocupación laboral (o no laboral)?

[II] ¿Podría encontrarse una línea de tendencia entre los gustos de consumo en comercio electrónico respecto a los bienes tangibles? ¿Se demuestra un cambio hacia la preferencia por las compras de bienes y servicios digitalizados?

[III] ¿Las características económicas y financieras del comercio electrónico podrían: [a] facilitar el aumento del ahogo financiero individual debido a excesos? [b] incrementar la comisión de actos ilegales para obtener más recursos y aumentar el nivel de consumo?

[IV] ¿Podría encontrarse alguna relación entre el costo monetario individual en el que se incurre por el consumo de bienes y servicios digitalizados y el posible impacto económico que podría producir?

[V] ¿Podría encontrarse una relación ambiental entre un usuario que ejerce el comercio electrónico de bienes y servicios digitalizados respecto a: [a]Las características de la vivienda que habita? [b] Los servicios básicos de la vivienda que habita? [c] El aporte al desgaste ambiental por el consumo de bienes y servicios tangibles?
[VI] ¿Se presenta el efecto de preocupación recurrente de un usuario de Internet por el consumo de bienes y servicios digitalizados que esa red brinda? ¿Podría presentarse alguna formulación o tendencia sobre el incremento?

[VII] ¿Se presentan dificultades al momento de abandonar el consumo de bienes y servicios digitalizados por Internet? ¿Puede controlarse el momento de retiro? ¿Puede comprobarse alguna tendencia sobre la intensión de retiro?

[VIII] ¿Cómo se presenta la tendencia a la repetición por el consumo de bienes y servicios digitalizados? ¿Podría presentar patrones de comportamiento hacia la ciberadicción?

[IX] ¿Podría encontrarse alguna relación entre el tiempo que un usuario utiliza para el consumo de bienes y servicios digitalizados y el posible impacto ambiental que podría producirse?

[X] ¿Podría encontrarse una relación social entre un usuario que ejerce el comercio electrónico de bienes y servicios digitalizados respecto a: [a] su situación poblacional? [b] aspectos de salubridad? [c] las características del hogar que habita y el ambiente educacional?

[XI] ¿Se presentan dificultades al momento de controlar el consumo de bienes y servicios digitalizados por Internet? ¿Puede un usuario perder el control sobre ese consumo?

[XII] ¿Podría utilizarse al consumo de bienes y servicios digitalizados para lograr evadir los conflictos cotidianos? ¿Sería un mecanismo que permitiera un escape de la vida?

[XIII] ¿Existe un grado en el cual el consumo de bienes y servicios digitalizados logre afectar a un individuo de modo que oculte profundamente esa actividad? ¿Qué impacto podría producir a un usuario ese ocultamiento?

[XIV] ¿Se presentan dificultades para mantener relaciones sociales afectivas debido al consumo de bienes y servicios digitalizados? ¿Puede un usuario afectar a sus relaciones por el exceso en ese consumo?

[XV] ¿Podría encontrarse alguna relación entre la cantidad de veces que un usuario utiliza el comercio electrónico para consumir bienes y servicios digitalizados y el posible impacto social que podría producirle?

[XVI] ¿Podría desarrollarse y validarse un modelo conceptual que estime?: [a] El impacto económico por el consumo masivo de bienes y servicios digitalizados [b] El impacto ambiental por el consumo masivo de bienes y servicios digitalizados [a] El impacto social por el consumo masivo de bienes y servicios digitalizados.

\section{SOLUCIÓN PROPUESTA}

En este apartado se presenta un conjunto de generalidades de la solución (sección $A$ ) que sirve de basamento para la propuesta de modelo conceptual de impacto de consumo (sección $B$ ). Se finaliza con la formulación de la encuesta digital que cuantifica a la muestra de perfiles de usuarios de Internet (sección $C$ ).

\section{A. Generalidades de la solución propuesta}

Se expone lo referido al marco ético con que se enfoca la investigación (sub-sección 1) y se continúa con la generación de información a través del procesamiento de datos por medios informáticos (sub-sección 2). 


\section{1) La cuestión ética en la investigación}

A pesar de la nobleza y beneficio potencial para las poblaciones que entraña el desarrollo de las investigaciones, no se debe despreciar que podrían conducir a los participantes del estudio a ciertos riesgos, para obtener un beneficio, a veces muy pequeño [155]. El cuidado sobre los individuos a la exposición directa de nuevas tecnologías debe ser tratado por personal adiestrado e infraestructura adecuada. La preocupación por el bienestar de los seres humanos debe tener primacía sobre los intereses de la ciencia y sociedad [156].

El estudio de una masa social debe considerar los aspectos que podrían afectarla de modo grupal e individual. Toda investigación o experimentación realizada sobre seres humanos debe hacerse de acuerdo a tres principios éticos básicos: el respeto a las personas (principio de autonomía), búsqueda del bien (principio de beneficencia y de no-maleficencia) y la justicia [157].

Al tratarse de asuntos relacionados con el consumo de productos y servicios digitalizados por Internet, colateralmente se capacita a la muestra de usuarios sobre el uso de herramientas y metodologías para efectuarlo [152] incrementando el posible efecto, que a la vez, se pretende medir, distorsionando o afectando a la masa de usuarios de la muestra. Debe considerarse que impacto en una definición propone: "efecto producido en la opinión pública por un acontecimiento, una disposición de la autoridad, una noticia, una catástrofe, etc.'[158] pudiendo deducirse que se producirá un efecto, cuya causa es la exposición individual por el consumo de bienes y servicios digitalizados de Internet.

Comprender el efecto masivo de nuevas tecnologías por Internet en los seres humanos, debería ser el resultado de un camino metodológico que asegure no serán afectados los participantes involucrados en el proceso. Es responsabilidad de los investigadores, como de las autoridades que las aprueban, garantizar que el riesgo sea minimizado y los beneficios potenciales maximizados [157].

Avanzar la presente investigación dentro de un entorno simulado, de laboratorio, podría producir una serie de resultados experimentales que permitan interpretar, al menos, si es posible continuar hacia una muestra real, humana y de mayor grado de representatividad.

\section{2) El procesamiento de datos como fuente de información}

La red de Internet posiblemente dispondrá del contorno que tiene la cultura. Habrá jerarquías, élites, orden y responsables. Tal vez sea algo más que el simple reflejo de nuestro mundo. Esta revolución virtual es un extraordinario desafío, una inmensa responsabilidad y una oportunidad infinita [9]. Se reinventa indefinidamente, dando más poder a la gente que la utiliza. Es un espacio de perpetua creación e innovación [24] donde los contenidos digitalizados en productos y servicios son la materia prima y la vez la creación, gracias a la participación de millones de personas usuarios [152].

Toda la información se encuentra distribuida y almacenada, dando espacio a nuevos mercados de información o cibermercados [19] que son lo suficientemente grandes y representativos y a la vez, más precisos que otras técnicas para la extracción de información difusa, como las encuestas y sondeos de opinión [159].

Los contenidos ya no son entes cerrados, objetos finitos y finalizados, sino contenedores abiertos, en constante reelaboración. Los flujos de producción, modificación, intercambio y remixación de información responden a lógicas propias de entes colectivos [2]. Los servicios abiertos están configurando un modelo revolucionario de intercambio $\mathrm{y}$ producción de información en la red [24].

En los últimos años es común aprovechar la potencia informática para predecir resultados de comportamiento social [159]. Algunas teorías matemáticas pueden aplicarse para resolver dilemas de carácter social dentro del marco de la teoría de juegos [160]. La información correctamente procesada podría aportar una forma de sabiduría colectiva para predecir resultados del mundo real [159] asistiendo a usuarios y colaborando con el estado y las empresas en sus emprendimientos.

Los datos pueden obtenerse de fuentes abiertas, como podría ser el caso de una red social como "Twitter", para ser procesados en masa [161]. Al ser recopilados por terceros se trata de una fuente secundaria [162]. Si se utiliza la potencia computacional para desarrollar un conjunto de datos propios, para estudiar algo específico, se constituye una fuente primaria [162].

Al desarrollar datos propias sobre una posible realidad podría considerarse que se tiene una muestra simulada [119], obtenida a través de un proceso que incluye diseñar un modelo sobre un sistema real para llevar a cabo experiencias con él, a fin de aprender sobre su comportamiento [163].

El método de simulación de Montecarlo es una técnica que combina conceptos estadísticos de muestreo aleatorio con la capacidad que tienen las computadoras para generar números pseudo-aleatorios y automatizar cálculos [164; 165]. Al agregar información acerca del comportamiento de una muestra representativa, podría disponerse de mejoras incrementales en la calidad de los datos y ser considerados confiables para obtener posibles conclusiones.

La evaluación de los resultados de una simulación podría dar entendimiento sobre el conjunto de consecuencias provocadas por un hecho o actuación afectada [163]. La solución propuesta, al problema descrito en este trabajo, consiste en simular el consumo de bienes y servicios digitalizados por Internet, generando una muestra representativa de perfiles de usuario, apuntalado sus datos individuales con información de fuentes fidedignas sobre la sociedad contemporánea de la República Argentina y otros típicos de usuarios de La Internet.

\section{B. Propuesta de modelo conceptual de impacto de consumo}

Para formular los aspectos relevantes del sistema de estudio se desarrollará un modelo conceptual, que apoyado en matemática y estadística, analice el modo de satisfacer las necesidades del presente, sin comprometer a las generaciones futuras para satisfacer las suyas, integrando los aspectos económicos, ecológicos y sociales, que son dinámicos e interactúan entre si, influenciándose el uno con los otros dos, enlazando el corto con el largo plazo [120].

El apoyar el paradigma conceptual en criterios de sustentabilidad podría colaborar con un crecimiento humano justo, conectado, prudente y seguro [121] donde la innovación y el cambio tecnológico posiblemente permitan alcanzar el desarrollo sustentable, colaborando con usuarios, empresas oferentes y estados fiscalizadores.

Se propone medir el impacto del consumo masivo de productos y servicios digitalizados por Internet en términos económicos, ambientales y sociales pudiendo presentar un panorama acerca de la actividad de cada consumidor, para 
obtener líneas de conducta, prevenir consumos desmedidos, y alertar al entorno sobre posibles consecuencias, a través de la investigación de las causas.

Para concretar el efecto entre hechos y consecuencias se contará con la apoyatura brindada por ciencia matemática, que permite formular los conceptos para desarrollar y cuantificar algún nivel de relación entre el consumo de bienes y servicios digitalizados, y el posible impacto que podría producir.

Se presenta la formulación del campo vectorial del modelo de impacto de consumo (sub-sección 1), para continuar con el análisis de la imagen del campo vectorial (sub-sección 2), a fin de determinar el dominio del campo vectorial (sub-sección 3), vislumbrar un aspecto gráfico del campo vectorial del modelo de impacto de consumo (sub-sección 4) y concluir con formulaciones finales sobre el campo vectorial del modelo de impacto de consumo (sub-sección 5).

1) Formulación del campo vectorial del modelo de impacto de consumo

Una función se llama "campo vectorial" cuando asocia a cada vector $X=(x 1, x 2, \ldots, x n)$, que pertenece a $\mid R n$ del subconjunto de dominio, otro vector $F(X)=(f 1(X)$, $\mathrm{f} 2(\mathrm{X}), \ldots \mathrm{fz}(\mathrm{X}))$ que pertenece a $\mathrm{IRz}$ del subconjunto de la imagen [166].

En la transformación se cambia un conjunto de valores de números reales a otro conjunto de números reales, conceptualizando cierta lógica aritmética a través de una formulación.

Un posible modelo de impacto de consumo (siglado como MIC en lo sucesivo) como se presenta en la Ecuación 1 "Modelo conceptual de impacto de consumo" podría facilitar el ordenamiento conceptual al dividir los tres conceptos en los que se apuntala la sustentabilidad $[121 ; 120]$.

$\operatorname{MIC}\left(\left(e_{1}, e_{2}, \ldots e_{1}\right),\left(a_{1}, a_{2}, \ldots a_{m}\right),\left(s_{1}, s_{2}, \ldots s_{n}\right)=\right.$

$\left(\operatorname{IE}\left(\mathrm{e}_{1}, \mathrm{e}_{2}, \ldots \mathrm{e}_{1}\right), \operatorname{IA}\left(\mathrm{a}_{1}, \mathrm{a}_{2}, \ldots \mathrm{a}_{\mathrm{m}}\right), \operatorname{IS}\left(\mathrm{s}_{1}, \mathrm{~s}_{2}, \ldots \mathrm{s}_{\mathrm{n}}\right)\right)$

El campo vectorial del modelo conceptual de impacto de consumo (MIC) podría materializar algunos aspectos acerca del consumido de bienes y servicios digitalizados en el dominio, de forma que se determine el impacto por esa actividad sobre cada eje del conjunto imagen, lo que indica que:[a] El conjunto de valores del eje económico: $\left(\mathrm{e}_{1}, \mathrm{e}_{2}, \ldots \mathrm{e}_{1}\right)$ será transformado por la formulación del modelo en impacto económico en: IE $\left(\mathrm{e}_{1}, \mathrm{e}_{2}, \ldots \mathrm{e}_{1}\right)$, con IE perteneciente a los números reales. [b] El conjunto de valores del eje ambiental: $\left(\mathrm{a}_{1}, \mathrm{a}_{2}, \ldots \mathrm{a}_{\mathrm{m}}\right)$ será transformado por la formulación del modelo en impacto ambiental en: IA $\left(\mathrm{a}_{1}, \mathrm{a}_{2}, \ldots \mathrm{a}_{\mathrm{m}}\right)$ con IA perteneciente a los números reales. [c] El conjunto de valores del eje social: $\left(\mathrm{s}_{1}, \mathrm{~s}_{2}, \ldots \mathrm{s}_{\mathrm{n}}\right)$ será transformado por la formulación del modelo en impacto social en: IS $\left(\mathrm{s}_{1}, \mathrm{~s}_{2}, \ldots \mathrm{s}_{\mathrm{n}}\right)$ con IS perteneciente a los números reales.

Al considerar [a], [b] y [c], dado un subconjunto de valores del dominio que cuantifique a las variables independientes o dependientes, el modelo de impacto de consumo (MIC) que las transforma, generará un punto en un hiper-plano tridimensional sobre los ejes: económico, ambiental y social.

El método de regresión lineal múltiple $[167 ; 168 ; 169]$ podría corregir posibles errores durante la cuantificación y transformación de las variables del dominio en el conjunto tridimensional de la imagen. Para contemplar las posibilidades de error de cada variable se aumenta la Ecuación 1 "Modelo conceptual de impacto de consumo" hasta el campo vectorial de la Ecuación 2 "Campo vectorial del modelo conceptual de impacto de consumo".

MIC: $\left|R^{93}->\right| R^{3} /$

$\operatorname{MIC}\left(\left(\mathrm{e}_{1}, \mathrm{e}_{2}, \ldots \mathrm{e}_{1}\right),\left(\mathrm{a}_{1}, \mathrm{a}_{2}, \ldots \mathrm{a}_{\mathrm{m}}\right),\left(\mathrm{s}_{1}, \mathrm{~s}_{2}, \ldots \mathrm{s}_{\mathrm{n}}\right)\right)=$

$\left(\operatorname{IE}\left(\mathrm{k}_{1} * \mathrm{e}_{1}+\mathrm{k}_{2} * \mathrm{e}_{2}+\ldots+\mathrm{k}_{1} * \mathrm{e}_{1}\right), \mathrm{IA}\left(\mathrm{k}_{1+1} * \mathrm{a}_{1}+\mathrm{k}_{1+2} * \mathrm{a}_{2}+\ldots+\right.\right.$

$\left.\left.\mathrm{k}_{\mathrm{m}} * \mathrm{a}_{\mathrm{m}}\right), \mathrm{IS}\left(\mathrm{k}_{\mathrm{m}+1} * \mathrm{~s}_{1}+\mathrm{k}_{\mathrm{m}+2} * \mathrm{~s}_{2}+\ldots+\mathrm{k}_{\mathrm{n}} * \mathrm{~s}_{\mathrm{n}}\right)\right)$

Al aplicar el método estadístico de regresión lineal múltiple [167; 168; 169] se logra obtener el valor de los cofactores: $\mathrm{k} 1, \mathrm{k} 2 \ldots \mathrm{kn}$. Con las variables del dominio cuantificadas y transformadas en imágenes y los cofactores de corrección se podría determinar el valor final de impacto sobre cada eje, lo que brindaría la posibilidad de comprender las relaciones que se producen en su imagen.

2) Análisis de la imagen del campo vectorial

Interpretar la imagen del campo vectorial MIC presentada en la Ecuación 4.2 "Campo vectorial del modelo conceptual de impacto de consumo", implica asumir la correspondencia entre un vector perteneciente a IR3 con los tres ejes en los que se apuntala a en concepto de sustentabilidad. Cada valor de ese vector se expresa por un número real y cuantifica al impacto sobre el eje.

El conjunto imagen de la forma vectorial: (IE, IA, IS) perteneciente a IR3, valoriza al impacto económico (IE), al impacto ambiental (IA) y al impacto social (IS) individual, de un perfil de usuario de Internet, en valores numéricos. Si se contase con un conjunto de puntos en el espacio, derivado de la aplicación del campo vectorial MIC, sobre una muestra de perfiles de usuario de Internet, se podrían revelar datos sobre el impacto del consumo masivo de productos y servicios digitalizados, presentando una masa de conductas individualizadas a fin de desarrollar información sobre la tendencia a la ciber-adicción.

Utilizando metodologías de análisis de función se podría obtener: información sobre el tipo de hiper-plano, el conjunto del dominio, simetrías, asíntotas, cortes por planos, cortes por eje, máximos y mínimos relativos, puntos de inflexión o cambios de tendencia, valores promedio o líneas de tendencia o el conjunto de la imagen entre otros [166; 170]. Con técnicas de la ciencia informática pueden procesarse masivos volúmenes de datos para explotar información y obtener patrones de conductas de grupos y nuevas inferencias de comportamiento [171].

La interpretación de los resultados experimentales podría aportar un nuevo conocimiento sobre el conjunto de conductas masivas e inferir el impacto en los aspectos económico, ambiental y social por el consumo, determinando nuevas y posibles líneas de investigación para explotar el mismo conjunto de datos.

Las posibilidades de información e interpretación sobre la imagen que aporta la formulación del modelo de impacto de consumo (MIC) se encuentran relacionadas con el conjunto de conceptos que se entraman en su dominio.

\section{3) Determinación del dominio del campo vectorial}

En el conjunto de dominio se enlazan variables de encuestas centrales con otras de carácter orbital. Aquellos datos fundamentales y personalísimos de un individuo dan forma al centro o núcleo del mismo. En la Tabla VI "Encuestas centrales del modelo de impacto de consumo y su relación con la sustentabilidad" se asocia a cada encuesta central con el eje de sustentabilidad correspondiente. 
TABLA VI - ENCUESTAS CENTRALES DEL MODELO DE IMPACTO DE CONSUMO Y SU RELACIÓN CON LA SUSTENTABILIDAD

\begin{tabular}{|l|l|}
\hline \multicolumn{1}{|c|}{ Encuesta central } & \multicolumn{1}{c|}{ Eje de sustentabilidad } \\
\hline Ocupacional-Económica (EOE) & Económico \\
\hline Habitacional-Energética (EHE) & Ambiental \\
\hline Socio-Demográfica (ESD) & Social \\
\hline
\end{tabular}

A la información central de cada individuo, se agrega en el dominio, la propia característica como usuario de Internet, a fin de determinar una modalidad de consumo de contenidos digitalizados. La unión de lo nuclear y lo orbital podría describir un perfil de usuario de Internet, y a la vez, presentar una metodología que podría extenderse con más detalles sobre lo central u orbital.

Fueron seleccionadas un conjunto de encuestas orbitales entre la extensión, variedad y amplitud de encuestas sobre el consumo de contenidos de Internet.

La metodología de sondeo central mas orbital se apuntaló abstrayendo la información orbital en términos de los diez criterios de la Asociación de Psiquiatría Americana (APA), en torno al manual de diagnóstico y estadística de los trastornos mentales DSM-IV ("Diagnostics and Statistics of Mental Disorders DSM-IV" en ingles), que posibilitan la clasificación del grado de ludopatía [84] extendiendo el concepto hacia los bienes y servicios digitalizados por Internet y abarcando varios tipos de ciber-consumo.

Las preguntas de las escalas orbitales seleccionadas sobre: adicción a Internet [93; 82], juego patológico [172], adicción a redes sociales [173] y escala de compulsión hacia las compras [174], fueron clasificadas y ordenadas dentro de los diez criterios propuestos en el manual de DSM-IV [84]. Cada uno de estos criterios se relaciona con uno y solo un eje de sustentabilidad pudiendo presentase en la Tabla VII "Criterios de diagnóstico DSM-IV y su relación con la sustentabilidad", la relación entre cada criterio de análisis y el eje de sustentabilidad que más podría encuadrarlo.

TABLA VII - CRITERIOS DE DIAGNÓSTICO DSM-IV Y SU RELACIÓN CON LA SUSTENTABILIDAD

\begin{tabular}{|l|ll|}
\hline Ítem & \multicolumn{1}{|c|}{ Criterio DSM-IV } & \multicolumn{1}{c|}{ Eje de sustentabilidad } \\
\hline 1 & Preocupación recurrente (PR) & Ambiental \\
\hline 2 & Progresión del incremento (PI) & Ambiental \\
\hline 3 & Pérdida de control (PC) & Social \\
\hline 4 & Intención de retiro (IR) & Ambiental \\
\hline 5 & Escape de la vida (EV) & Social \\
\hline 6 & Tendencia a la repetición (TR) & Ambiental \\
\hline 7 & Tendencia al ocultamiento (TO) & Social \\
\hline 8 & Comisión de actos ilegales (CAI) & Económico \\
\hline 9 & Afectación de relaciones afectivas (ARA) & Social \\
\hline 10 & Ahogo financiero (AF) & Económico \\
\hline
\end{tabular}

Tomando como base lo precedente, la metodología de la presente solución propuesta consiste en investigar acerca de dos cuestiones de un perfil de usuario de Internet:

[d] Cuál es la situación individual del usuario de Internet respecto a: su condición ocupacional y actividad económica. Su encuadre habitacional y consumo energético para finalizar con la determinación social y demográfica del individuo.

[e] Cuál es la situación individual de un usuario de Internet respecto a su adicción a Internet [93; 82], hacia el juego patológico [172], la adicción a redes sociales [173] y la compulsión hacia las compras [174].
Al unir información de [d] la cuestión central del individuo y [e] qué tipo de conducta presenta como usuario de Internet, se desarrolla una metodología de estudio que puede ser corregida y aumentada con vistas al futuro. Encuestas actuales o futuras, referidas al consumo de contenidos digitalizados por Internet, podrían complementar a las utilizadas para el modelo MIC. Entender a la persona desde lo individual, su circunstancia y su relación con la revolución visualizadora de Internet [9] tal vez permita proyectar más información sobre ciber-adicción.

Las cuestiones centrales presentadas en la Tabla VI "Encuestas centrales del modelo de impacto de consumo y su relación con la sustentabilidad" al unirse con los criterios orbitales de la Tabla VII "Criterios de diagnóstico DSM-IV y su relación con la sustentabilidad" conforman la Tabla VIII "Encuestas y criterios del modelo de impacto de consumo".

TABLA VIII - ENCUESTAS Y CRITERIOS DEL MODELO DE IMPACTO DE CONSUMO

\begin{tabular}{|ll|l|}
\hline \multicolumn{1}{|c|}{ Eje Económico } & \multicolumn{1}{c|}{ Eje Ambiental } & \multicolumn{1}{c|}{ Eje Social } \\
\hline $\begin{array}{l}\text { Encuesta: Ocupacional- } \\
\text { Económica (EOE) }\end{array}$ & $\begin{array}{l}\text { Encuesta: Habitacional- } \\
\text { Energética (EHE) }\end{array}$ & $\begin{array}{l}\text { Encuesta: Socio- } \\
\text { Demográfica (ESD) } \\
\text { Comisión de actos ilegales } \\
\text { (CAI) }\end{array}$ \\
$\begin{array}{lll}\text { Preocupación recurrente } \\
\text { (PR) }\end{array}$ & Pérdida de control (PC) \\
Ahogo financiero (AF) & $\begin{array}{l}\text { Progresión del incremento } \\
\text { (PI) }\end{array}$ & Escape de la vida (EV) \\
\hline & Intención de retiro (IR) & $\begin{array}{l}\text { Tendencia al ocultamiento } \\
\text { (TO) }\end{array}$ \\
\hline & Tendencia a la repetición & $\begin{array}{l}\text { Afectación de relaciones } \\
\text { afectivas (ARA) }\end{array}$ \\
\hline
\end{tabular}

Las encuestas y criterios presentados en cada eje de estudio de sustentabilidad se traducen a una serie de variables independientes y dependientes que hacen al dominio del campo vectorial de la Ecuación 4.2 "Campo vectorial del modelo conceptual de impacto de consumo". Interiorizarse con la conceptualización de cada una y el grado relativo de influencia e impacto sobre el eje en el que acciona, podría presentar detalles del conjunto de dominio del campo vectorial de impacto de consumo.

Se expone una introducción al desarrollo de las variables del dominio del modelo conceptual de impacto de consumo (sub-sección a), para especificar las variables del eje económico (sub-sección $b$ ), las del eje ambiental (sub-sección c) y finalizar con las del eje social (sub-sección $d$ ).

\section{a) Introducción al desarrollo de las variables del modelo}

Se presentará el conjunto de variables independientes y dependientes por cada eje de estudio del modelo conceptual de impacto de consumo que sigue la abstracción matemática de la Ecuación 2 "Campo vectorial del modelo conceptual de impacto de consumo".

Cada sub-sección expresa a un eje de influencia (económico, ambiental o social). Dentro de cada una, se agrupan las variables por tipo (independiente o dependiente). Se presenta una sigla representativa, seguida del concepto completo de la variable.

Para el modelo de impacto de consumo se elaboraron tres encuestas centrales (ocupacional-económica, habitacionalenergética y socio-demográfica) y se adaptaron otras cuatro orbitales sobre ciber-adicciones (adicción a Internet [93; 82], juego patológico [172], adicción a redes sociales [173] y escala 
de compulsión hacia las compras [174]). Cada variable independiente pertenece a una y solo una encuesta central $\mathrm{u}$ orbital cuyo nombre será indicado durante el desarrollo de la misma.

Para expresar a cada variable independiente se menciona a la encuesta específica de pertenencia y se plantea la pregunta de la encuesta para aumentar la representación del concepto. Le sigue la tabulación de las posibles respuestas y el impacto numérico que indica el valor que cuantifica a la variable en la imagen. El porcentaje de la muestra expresa la cantidad de perfiles de usuario que encuadran en la posible respuesta. El criterio de impacto explica el modo en que la variable cuantifica los valores discretos de impacto por cada posible respuesta.

Por cada variable dependiente se expone la encuesta a la cual pertenecen las independientes que hacen a la formulación que le dan magnitud. Se completa con la descripción del concepto que representa y enlaza con otras independientes o cálculos específicos.

\section{b) Variables del eje económico}

Se consideran las siguientes variables independientes para el eje económico:

$\mathrm{ABS}=$ Acceso a bienes y servicios.

Encuesta: ocupacional-económica (EOE).

Pregunta: ¿Cómo accede generalmente a la información de los productos y servicios que consume?

$\begin{array}{lll}\text { Respuesta posible } & \text { Impacto } & \% \text { de la muestra } \\ \text { Amigos } & 20 & 65 \% \\ \text { Familiares } & 20 & 65 \% \\ \text { En el trabajo } & 40 & 65 \% \\ \text { Publicidad gráfica } & 60 & 25 \% \\ \text { Publicidad televisiva } & 60 & 25 \% \\ \text { Publicidad en Radio } & 60 & 25 \% \\ \text { Publicidad en Internet } & 80 & 8 \% \\ \text { Otros medios } & 20 & 2 \%\end{array}$

Criterio de impacto: Cuanto mayor acceso por canales relacionados con Internet, mayor impacto económico. Se estima que cuanto más interacción por ese canal, más aumentan las posibilidades de gastar recursos económicos en bienes y servicios digitalizados. El impacto económico disminuye cuando el acceso a bienes y servicios refiere a canales de menor tecnologización.

[175].

$\mathrm{CAE}=$ Categoría de actividad económica.

Encuesta: ocupacional-económica (EOE).

Pregunta: Si usted trabaja percibiendo un pago en dinero o en especie por la tarea que realiza; ¿cuál es su condición de actividad económica?

$\begin{array}{lcc}\text { Respuesta posible } & \text { Impacto } & \% \text { de la muestra } \\ \text { Sólo trabaja } & 100 & 62,47 \% \\ \text { Trabaja y estudia } & 100 & 5,68 \% \\ \text { Trabaja y percibe jubilación o pensión } & 503,33 \% \\ \text { No es mi caso } & 0 & 28,52 \%\end{array}$

Criterio de impacto: Cuanto mayor cantidad de vías de ingresos, menor impacto económico. Disminuye el impacto económico cuando el perfil de usuario trabaja y percibe jubilación o pensión.

[176;177; 178]

$\mathrm{CdO}=$ Categoría de desocupación.

Encuesta: ocupacional-económica (EOE).
Pregunta: Si usted no tiene ocupación laboral pero busca activamente trabajo; ¿cuál es su actividad principal?

$\begin{array}{lll}\text { Respuesta posible } & \text { Impacto } & \% \text { de la muestra } \\ \text { Sólo busca trabajo } & 100 & 22,25 \% \\ \text { Busca trabajo y estudia } 100 & 4,83 \%\end{array}$

Busca trabajo y percibe jubilación o pensión $50 \quad 1,42 \%$

$\begin{array}{lll}\text { No es mi caso } & 0 & 71,5 \%\end{array}$

Criterio de impacto: Si el perfil de usuario no percibe recursos económicos, aumenta el impacto económico. Disminuye el impacto económico cuando el perfil de usuario busca trabajo y percibe jubilación o pensión.

[176; 178]

COna = Condición de ocupación de población económicamente no activa.

Encuesta: ocupacional-económica (EOE).

Pregunta: Si usted no tiene ocupación laboral y no la busca activamente; ¿cuál es su actividad principal?

$\begin{array}{lll}\text { Respuesta posible } & \text { Impacto } & \% \text { de la muestra } \\ \text { Estudiante } & 100 & 26,02 \% \\ \text { Jubilado o Pensionado } & 50 & 26,46 \% \\ \text { No es mi caso } & 0 & 47,52 \%\end{array}$

Criterio de impacto: Cuanto mayor cantidad de vías de ingresos, menor impacto económico. Disminuye el impacto económico cuando el perfil de usuario es jubilado o pensionado. Aumenta el impacto económico cuando el perfil de usuario estudia.

[176; 178]

$\mathrm{EA}=$ Estimación del activo.

Encuesta: ocupacional-económica (EOE).

Pregunta: ¿Cómo cuantifica su conjunto de recursos, bienes y derechos propios?

$\begin{array}{lll}\text { Respuesta posible } & \text { Impacto } & \% \text { de la muestra } \\ \text { Alto } & 0 & 7 \% \text { (clase ABC1) } \\ \text { Medio } & 50 & 46 \% \text { (clases C2 y C3) } \\ \text { Bajo } & 100 & 47 \% \text { (clases D2E y C1) }\end{array}$

Criterio de impacto: Indica que el consumo de bienes y servicios digitalizados afecta menos, en términos económicos, a quien mas activos posee. Menor impacto económico para quien posee un conjunto alto de activos. Mayor impacto económico para quien posee un conjunto bajo de activos.

[77; 179]

$\mathrm{EP}=$ Estimación del pasivo.

Encuesta: ocupacional-económica (EOE).

Pregunta: ¿Cómo cuantifica su conjunto de obligaciones y deudas propias?

$\begin{array}{lll}\text { Respuesta posible } & \text { Impacto } & \text { \%de la muestra } \\ \text { Alto } & 0 & 47 \% \text { (clases D2E y C1) } \\ \text { Medio } & 50 & 46 \% \text { (clases C3 y C2) } \\ \text { Bajo } & 100 & 7 \%(\text { clase ABC } 1)\end{array}$

Criterio de impacto: Indica que el consumo de bienes y servicios digitalizados afecta menos, en términos económicos, a quien dispone pocas obligaciones y deudas. La variable de estimación de pasivo (EP) se acota entre [$100 \ldots 0]$ en su cuantificación y explica que el mayor impacto económico se da en quien posee un conjunto alto de pasivos.

$[77 ; 179]$

$\mathrm{ETI}=$ Egreso total individual.

Encuesta: ocupacional-económica (EOE).

Pregunta: ¿Cuál es su egreso financiero promedio por mes? 
Respuesta posible

Hasta U\$S 1000 al mes

Impacto \%de la muestra

básico)

De U\$S 1001 a U\$S 2000 al mes $20 \quad 50 \%$ ( fuerte consumo)

$\begin{aligned} & \text { De U\$S } 2001 \text { a U\$S } 3000 \text { al mes } \\ & \text { consumo) }\end{aligned}$
$\begin{aligned} & \text { De U\$S } 3001 \text { a U\$S } 4000 \text { al mes } \\ & \text { consumo) }\end{aligned}$

De U\$S 4001 a U\$S 5000 al mes $80 \quad 25 \%$ (alto consumo)

Mas de 5000 al mes $\quad 10025 \%$ (alto consumo)

Criterio de impacto: Indica que el consumo de bienes y servicios digitalizados afecta menos, en términos económicos, a quien dispone de menor egreso. La variable egreso total individual (ETI) se acota entre [-100...0] en su cuantificación, y explica que el mayor impacto económico se da en quien presenta mayor egreso total individual

$[180 ; 181 ; 179]$

ITI $=$ Ingreso total individual.

Encuesta: ocupacional-económica (EOE).

Pregunta: ¿Cuál es su ingreso financiero promedio por mes?

Respuesta posible

Hasta U\$S 1000 al mes

Impacto \%de la muestra

$10047 \%$ (clases D2E/D1)

De U\$S 1001 a U\$S 2000 al mes $80 \quad 30 \%$ (clase C3)

De U\$S 2001 a U\$S 3000 al mes $60 \quad$ 16\% (clase C2)

De U\$S 3001 a U\$S 4000 al mes $40 \quad 7 \%$ (clase ABC1)

De U\$S 4001 a U\$S 5000 al mes $20 \quad 7 \%$ (clase ABC1)

Mas de 5000 al mes $\quad 0 \quad 7 \%$ (clase ABC1)

Criterio de impacto: Menor impacto económico, por el consumo de bienes y servicios digitalizados, para quien posee mayor ingreso financiero individual. Mayor impacto económico para quien posee escaso ingreso financiero individual.

[180; 181; 179]

MPPE = Modalidad preferida de pago para el comercio electrónico.

Encuesta: ocupacional-económica (EOE).

Pregunta: ¿Qué medio de pago utiliza preferentemente para el comercio electrónico?

\begin{tabular}{|c|c|c|}
\hline Respuesta posible & acto & \%de la muestra \\
\hline $\begin{array}{l}\text { Depósito en cuenta } \\
\text { los usuarios) }\end{array}$ & 100 & $5,11 \% \quad(11 \% \mathrm{de}$ \\
\hline $\begin{array}{l}\text { Trasferencia bancaria } \\
\text { los usuarios) }\end{array}$ & 80 & $19,06 \%(41 \% \mathrm{de}$ \\
\hline $\begin{array}{l}\text { Tarjeta de crédito o débito } \\
\text { los usuarios) }\end{array}$ & 60 & $34,46 \%(74 \% \mathrm{de}$ \\
\hline $\begin{array}{l}\text { Portales de pago electrónico } \\
\text { los usuarios) }\end{array}$ & 40 & $19,06 \%(41 \% \mathrm{de}$ \\
\hline $\begin{array}{l}\text { Cheque o giro postal } \\
\text { los usuarios) }\end{array}$ & 20 & $(11 \% \mathrm{de}$ \\
\hline $\begin{array}{l}\text { Contra entrega } \\
\text { los usuarios) }\end{array}$ & 10 & $12,09 \%(26 \% \mathrm{de}$ \\
\hline Otro modo & 10 & (11\% de \\
\hline
\end{tabular}

los usuarios)

Criterio de impacto: Menor impacto económico, por el consumo de bienes y servicios digitalizados, para quien posee mayor posibilidad de arrepentimiento en la compra. Mayor impacto económico para quien abona con mayor grado de liquidez, minimizando a posibles arrepentimientos.
$[182 ; 183]$

Se consideran las siguientes variables dependientes para el eje económico:

$\mathrm{AF}=$ Ahogo financiero.

Encuesta: escala de medida de la compra compulsiva (CBMS) [174].

Formulación: $\mathrm{AF}=\mathrm{CBMS}(11)+\mathrm{CBMS}$ (12)

Concepto: Suma de impacto individual de las respuestas para las preguntas 11 y 12 de la escala de medida de la compra compulsiva (CBMS) [174].

$\mathrm{CAI}=$ Comisión de actos ilegales.

Encuesta: cuestionario de múltiples respuestas DSM-IVMR-J para el juego patológico (DSM) [172].

Formulación: $\mathrm{CAI}=\mathrm{DSM}(8)$

Concepto: Impacto individual de la respuesta para la pregunta 8 de cuestionario de múltiples respuestas DSM IV-MR-J para el juego patológico (DSM) [172].

$\mathrm{COa}=$ Condición de ocupación del individuo.

Encuesta: ocupacional-económica (EOE).

Formulación: $\mathrm{COa}=\mathrm{CAE}+\mathrm{CdO}+\mathrm{COna}$

Concepto: Suma de impacto individual de las categoría de actividad económica (CAE), la categoría de desocupación $(\mathrm{CdO})$ y la condición de ocupación de población económicamente no activa (COna).

$\mathrm{EER}=$ Estado del estado individual de resultados.

Encuesta: ocupacional-económica (EOE).

Formulación: EER $=$ ITI - ETI

Concepto: Diferencia entre impacto por el ingreso total individual (ITI) y el impacto por egreso total individual (ETI).

$\mathrm{EPN}=$ Estimación del estado patrimonial individual.

Encuesta: ocupacional-económica (EOE).

Formulación: EPN $=\mathrm{EA}-\mathrm{EP}$

Concepto: Diferencia entre impacto por la estimación de activo (EA) y el impacto por la estimación del pasivo (EP).

$\mathrm{IE}=$ Impacto económico.

Encuesta: ocupacional-económica (EOE), escala de medida de la compra compulsiva (CBMS) [174] y cuestionario de múltiples respuestas DSM-IV-MR-J para el juego patológico (DSM) [172].

Formulación $\mathrm{IE}=\mathrm{EER}+\mathrm{EPN}+\mathrm{PSU}+\mathrm{COa}+\mathrm{PCo}+\mathrm{AF}+$ CAI

Concepto: Sumatoria de todos los impactos individuales de todas las variables dependientes del eje económico.

$\mathrm{PCo}=$ Preferencia de compras.

Encuesta: ocupacional-económica (EOE).

Formulación PCo $=\mathrm{MPPE}+\mathrm{ABS}$

Concepto: Sumatoria del impacto por la modalidad preferida de pago para el comercio electrónico (MPPE) y el acceso a bienes y servicios (ABS).

PSU $=$ Puntos por consumo de contenidos por usuario en el simulador.

Encuesta: Sin encuesta.

Formulación: PSU $=\Sigma$ debitos

Concepto: Acumulación de débitos por consumo de contenidos digitalizados en el sistema software simulador durante la simulación.

c) Variables del eje ambiental

Se consideran las siguientes variables independientes para el eje ambiental:

$\mathrm{C}=$ Existencia de cloacas. 
Encuesta: habitacional-energética (EHE).

Pregunta: ¿La vivienda que habita esta conectada a la red de cloacas?

$\begin{array}{lll}\text { Respuesta posible } & \text { Impacto } & \text { \%de la muestra } \\ \mathrm{No} & 100 & 51,2 \% \\ \mathrm{Si} & 0 & 48,8 \%\end{array}$

Criterio de impacto: Si el perfil de usuario habita una vivienda no conectada a la red cloacal, aumenta el impacto ambiental. En otro caso, no agrega impacto.

[184]

$\mathrm{CC}=$ Características constructivas.

Encuesta: habitacional-energética (EHE).

Pregunta: ¿Cuál es el material predominante de la vivienda que habita?

$\begin{array}{lll}\text { Respuesta posible } & \text { Impacto } & \text { \%de la muestra } \\ \text { Cemento } & 0 & 60,2 \% \text { (CALMAT I) } \\ \text { Ladrillo } & 25 & 21,6 \% \text { (CALMAT II) } \\ \text { Madera } & 50 & 18,2 \% \text { (CALMAT III,IV,V) } \\ \text { Metal } & 75 & 18,2 \% \text { (CALMAT III,IV,V) } \\ \text { Otro } & 100 & 18,2 \% \text { (CALMAT III,IV,V) }\end{array}$

Criterio de impacto: Si el perfil de usuario habita una vivienda de condiciones precarias o no basadas en cemento y ladrillo, aumenta el impacto ambiental. Si la predominancia de los materiales constructivos de la vivienda posibilita el usufructo en el tiempo, impacto ambiental disminuye.

$[177 ; 185]$

$\mathrm{CEE}=$ Consumo de energía eléctrica de red.

Encuesta: habitacional-energética (EHE).

Pregunta: ¿Qué cantidad de artefactos eléctricos se usan en la vivienda que habita?

$\begin{array}{lll}\text { Respuesta posible } & \text { Impacto } & \% \text { de la muestra } \\ \text { Hasta } 5 & 50 & 5 \% \\ \text { De } 6 \text { a } 10 & 75 & 20 \% \\ \text { Mas de } 10 & 100 & 75 \%\end{array}$

Criterio de impacto: Si el perfil de usuario habita una vivienda con multiplicidad de aparatos de consumo de energía, aumenta el impacto ambiental. En otro caso, el agregado de impacto es menor.

[186]

CGas $=$ Consumo de gas natural de red, envasado o a granel.

Encuesta: habitacional-energética (EHE).

Pregunta: ¿Qué cantidad de artefactos a gas se usan en la vivienda que habita?

$\begin{array}{lll}\text { Respuesta posible } & \text { Impacto } & \text { \%de la muestra } \\ \text { Hasta } 5 & 50 & 75 \% \\ \text { De } 6 \text { a } 10 & 75 & 20 \% \\ \text { Mas de } 10 & 100 & 5 \%\end{array}$

Criterio de impacto: Si el perfil de usuario habita una vivienda con multiplicidad de aparatos de consumo de gas, aumenta el impacto ambiental. En otro caso, el agregado de impacto es menor.

$[186 ; 180]$

CPS $=$ Consumo de productos y servicios no digitalizados.

Encuesta: habitacional-energética (EHE).

Pregunta: ¿Con qué frecuencia adquiere productos o servicios no digitalizados que son, a la vez, ofrecidos aquí?

Respuesta posible Impacto \%de la muestra

$\begin{array}{lll}\text { Ninguna } & 0 & 64 \% \text { (Estimado) }\end{array}$

Alguna vez $\quad 30 \quad 14 \%$ (Estimado)

Varias veces $\quad 60 \quad 12 \%$ (Estimado)
Siempre

100

$10 \%$ (Estimado)

Criterio de impacto: Si el perfil de usuario presenta alta frecuencia de consumo de bienes y servicios no digitalizados, aumenta el impacto ambiental. En otro caso, el agregado de impacto es menor o ninguno [183].

$\mathrm{PA}=$ Procedencia del agua.

Encuesta: habitacional-energética (EHE).

Pregunta: ¿Cuál es la procedencia de agua de la vivienda que habita?

Respuesta posible Impacto \%de la muestra

De red pública (agua corriente) $0 \quad 79,5 \%$

De perforación con bomba $\quad 20 \quad 11,6 \%$

De pozo $\quad 40 \quad 3,3 \%$

De transporte por cisterna $\quad 60 \quad 2,2 \%$

Agua de lluvia $\quad 80 \quad 3,4 \%$

Otra $100 \quad 3,4 \%$

Criterio de impacto: Si el perfil de usuario habita una vivienda sin agua de red o poco tratada potablemente, aumenta el impacto ambiental. En otro caso, el agregado de impacto es menor o ninguno.

$[180 ; 184]$

$\mathrm{PAI}=$ Preferencia por el acceso a Internet.

Encuesta: habitacional-energética (EHE).

Pregunta: ¿Por qué es un usuario de Internet?

Respuesta posible Impacto \%de la muestra

Acceso (Rapidez) $20 \quad 24 \%$ (estimado)

Asequibilidad (se puede usar 7x24) $20 \quad 16 \%$ (estimado)

Anonimato $\quad 60 \quad 5 \%$ (estimado)

Conveniencia $\quad 40 \quad 7 \%$ (estimado)

Desinhibición $\quad 80 \quad 15 \%$ (estimado)

Escape (inmersión o disociación) $100 \quad 22 \%$ (estimado)

Interactividad $\quad 20 \quad 2 \%$ (estimado)

Sociabilidad $\quad 20 \quad 9 \%$ (estimado)

Otros motivos $\quad 0 \quad 0 \%$

Criterio de impacto: Si el perfil de usuario prefiere utilizar Internet por motivos relacionados con afecciones a su personalidad, aumenta el impacto ambiental. En otro caso, el agregado de impacto es menor o ninguno.

[86]

$\mathrm{TV}=$ Tipo de vivienda.

Encuesta: habitacional-energética (EHE).

Pregunta: ¿Cómo determina el tipo de vivienda que habita?

Respuesta posible Impacto $\quad \%$ de la muestra

$\begin{array}{lll}\text { Casa } & 0 & 78,9 \%\end{array}$

Departamento $\quad 20 \quad 16,8 \%$

Pieza(s) en inquilinato hotel o pensión 40 0,8\%

Rancho $60 \quad 1,5 \%$

Local (no construido para habitación) 80 0,2\%

Casilla $\quad 100 \quad 1,8 \%$

Vivienda móvil $\quad 100 \quad 1,8 \%$

En la calle $\quad 100 \quad 1,8 \%$

Criterio de impacto: Si el perfil de usuario habita una vivienda que presenta mayor grado de precariedad, aumenta el impacto ambiental. En otro caso, el agregado de impacto es menor o ninguno.

$[177 ; 180 ; 184]$

$\mathrm{UG}=$ Ubicación geográfica.

Encuesta: habitacional-energética (EHE).

Pregunta: ¿Cómo es la zona donde vive?

Respuesta posible Impacto \%de la muestra

Urbana de 2000 y más habitantes $100 \quad 89,5 \%$ 
Rural agrupada (menos de 2000 habitantes) $50 \quad 7,2 \%$

Rural dispersa $\quad 0 \quad 3,3 \%$

Criterio de impacto: Si el perfil de usuario habita una zona de mayor grado de hacinamiento, aumenta el impacto ambiental. En otro caso, el agregado de impacto es menor o ninguno.

[177; 184; 187]

$\mathrm{UMT}=$ Utilización de medio de trasporte.

Encuesta: habitacional-energética (EHE).

Pregunta: ¿Cuál es el medio de trasporte que utiliza frecuentemente?

Respuesta posible Impacto \% de la muestra

Sin medio de trasporte $0 \quad 5 \%$ (estimado)

Trasporte público de tren $25 \quad 13 \%$ (aprox.282.511.000

pasajeros)

Trasporte público de subte $25 \quad$ 11\%(aprox.

236.180.000 pasajeros)

Trasporte público de colectivo $\quad 50 \quad 61 \% \quad(1.610 .000 .000$ pasajeros)

Automóvil particular

$10010 \%$ (estimado)

Otro medio de trasporte

$100 \quad 0 \%$

Criterio de impacto: Si el perfil de usuario utiliza con frecuencia medios de transporte a base energía sucia (como derivados de petróleo), aumenta el impacto ambiental. En otro caso, el agregado de impacto es menor o ninguno.

[188]

Se consideran las siguientes variables dependientes para el eje ambiental:

$\mathrm{ADA}=$ Aporte al desgaste ambiental.

Encuesta: habitacional-energética (EHE).

Formulación: $\mathrm{ADA}=\mathrm{CPS}+\mathrm{UMT}$

Concepto: Suma de impactos individuales por el consumo de bienes y servicios no digitalizados (CPS) y el modo más frecuente de acercarse hasta los mismos (UMT).

$\mathrm{CaV}=$ Características de la vivienda.

Encuesta: habitacional-energética (EHE).

Formulación: $\mathrm{CaV}=\mathrm{UG}+\mathrm{TV}+\mathrm{CC}+\mathrm{PA}+\mathrm{C}$

Concepto: Suma de impactos individuales por la ubicación geográfica (UG), el tipo de vivienda (TV), las características constructivas (CC), la procedencia del agua (PA) y la conexión a la red cloacal $(\mathrm{C})$ de la vivienda que habita el perfil de usuario.

IA = Impacto ambiental.

Encuesta: habitacional-energética (EHE), escala de medida de la compra compulsiva (CBMS) [174], cuestionario de múltiples respuestas DSM-IV-MR-J para el juego patológico (DSM) [172], adicción a Internet (IAT) [93; 82] $\mathrm{y}$ adicción a redes sociales (BFAS) [173].

Formulación: $\mathrm{IA}=\mathrm{CaV}+\mathrm{SBV}+\mathrm{ADA}+\mathrm{TPP}+\mathrm{PR}+\mathrm{PI}+$ IR + TR

Concepto: Sumatoria de todos los impacto individuales de todas las variables dependientes del eje ambiental.

$\mathrm{IR}=$ Intención de retiro.

Encuesta: escala de medida de la compra compulsiva (CBMS) [174], adicción a redes sociales (BFAS) [173] y cuestionario de múltiples respuestas DSM-IV-MR-J para el juego patológico (DSM) [172].

Formulación: IR = CBMS (13) + BFAS (12) + BFAS (13) + DSM (3)

Concepto: Suma de impacto individual de las respuestas para las preguntas 13 de la escala de medida de la compra compulsiva (CBMS), 12 y 13 de la escala de adicción a redes sociales (BFAS) [173] y 3 de criterios de múltiples respuestas DSM-IV-MR-J para el juego patológico (DSM).

PI = Progresión del incremento.

Encuesta: escala de medida de la compra compulsiva (CBMS) [174], adicción a redes sociales (BFAS) [173], cuestionario de múltiples respuestas DSM-IV-MR-J para el juego patológico (DSM) [172] y adicción a Internet (IAT) $[93 ; 82]$.

Formulación: PI = CBMS (1) + CBMS (5) + BFAS (4) + BFAS (5) + BFAS (6) + DSM (2) + IAT (1) + IAT (14) + IAT (17) + IAT (20)

Concepto: Suma de impacto individual de las respuestas para las preguntas 1 y 5 de la escala de medida de la compra compulsiva (CBMS), 4, 5 y 6 de la escala de adicción a redes sociales (BFAS) [173], 2 de criterios de múltiples respuestas DSM-IV-MR-J para el juego patológico (DSM) y 14, 17 y 20 de adicción a Internet (IAT) [93; 82].

$\mathrm{PR}=$ Preocupación recurrente.

Encuesta: escala de medida de la compra compulsiva (CBMS) [174], adicción a redes sociales (BFAS) [173], cuestionario de múltiples respuestas DSM-IV-MR-J para el juego patológico (DSM) [172] y adicción a Internet (IAT) $[93 ; 82]$.

Formulación: PR $=$ CBMS (4) + CBMS (6) + CBMS (10) + BFAS (1) + BFAS (2) + BFAS (3) + DSM (1) + IAT (7) + IAT (11) +IAT (15)

Concepto: Suma de impacto individual de las respuestas para las preguntas 4,6 y 10 de la escala de medida de la compra compulsiva (CBMS), 1, 2 y 3 de la escala de adicción a redes sociales (BFAS) [173], 1 de criterios de múltiples respuestas DSM-IV-MR-J para el juego patológico (DSM) y 7, 11 y 15 de adicción a Internet (IAT) [93; 82].

$\mathrm{SBV}=$ Servicio básicos de la vivienda.

Encuesta: habitacional-energética (EHE).

Formulación: SBV $=\mathrm{CEE}+\mathrm{CGas}+\mathrm{PAI}$

Concepto: Suma de impactos individuales por consumo de energía eléctrica de red (CEE), consumo de gas natural de red, envasado o a granel (CGas) de la vivienda que habita el perfil de usuario y la preferencia por el acceso a Internet (PAI).

$\mathrm{TPP}=$ Tiempo promedio de permanecía en el simulador.

Encuesta: Sin encuesta.

Formulación: TPP $=\Sigma($ Fecha y hora egreso - Fecha y hora de ingreso)

Concepto: Indica la cantidad total de tiempo dentro del sistema software simulador durante la simulación.

$\mathrm{TR}=$ Tendencia a la repetición.

Encuesta: escala de medida de la compra compulsiva (CBMS) [174], cuestionario de múltiples respuestas DSMIV-MR-J para el juego patológico (DSM) [172] y adicción a Internet (IAT) [93; 82].

Formulación: TR = CBMS (2) + DSM (6) + IAT (16).

Concepto: Suma de impacto individual de las respuestas para la pregunta 2 de la escala de medida de la compra compulsiva (CBMS), 6 de criterios de múltiples respuestas DSM-IV-MR-J para el juego patológico (DSM) y 16 de adicción a Internet (IAT) [93; 82].

d) Variables del eje social

Se consideran las siguientes variables independientes para el eje ambiental: 
$\mathrm{AE}=$ Actividad de esparcimiento emocional.

Encuesta: socio-demográfica (ESD).

Pregunta: ¿Realiza actividad de esparcimiento emocional o artística?

$\begin{array}{lll}\text { Respuesta posible } & \text { Impacto } & \% \text { de la muestra } \\ \text { Nunca } & 100 & 1 \% \text { (estimado) } \\ \text { Alguna vez } & 60 & 4 \% \text { (estimado) } \\ \text { Frecuentemente } & 30 & 10 \% \text { (estimado) } \\ \text { Siempre } & 0 & 85 \% \text { (estimado) }\end{array}$

Criterio de impacto: El impacto social aumenta a medida que el perfil de usuario realiza poca o ninguna actividad de esparcimiento emocional o artística.

[189]

$\mathrm{AFi}=$ Actividad física.

Encuesta: socio-demográfica (ESD).

Pregunta: ¿Realiza actividad física deportiva?

Respuesta posible Impacto \% de la muestra

Nunca $\quad 100 \quad 67,5 \%$ (estimado)

Alguna vez $\quad 60 \quad 16,25 \%$ (estimado)

Frecuentemente $\quad 30 \quad 9,75 \%$ (estimado)

Siempre $\quad 0 \quad 6,5 \%$ (estimado)

Criterio de impacto: El impacto social aumenta a medida que el perfil de usuario realiza poca o ninguna actividad física frecuente. Disminuye cuanto mayor actividad física. [190]

$\mathrm{CH}=$ Cantidad de habitantes del hogar.

Encuesta: socio-demográfica (ESD).

Pregunta: ¿Cuál es la cantidad de habitantes que tienen el hogar?

$\begin{array}{lll}\text { Respuesta posible } & \text { Impacto } & \% \text { de la muestra } \\ \text { Hasta } 4 \text { personas } & 25 & 90 \% \text { (estimado) } \\ \text { De } 5 \text { a } 8 \text { personas } & 50 & 7 \% \text { (estimado) } \\ \text { De } 9 \text { a } 12 \text { personas } & 75 & 2 \% \text { (estimado) } \\ \text { Mas de } 12 \text { personas } & 100 & 1 \% \text { (estimado) }\end{array}$

Criterio de impacto: El impacto social aumenta a medida que aumenta la cantidad de personas que habitan el mismo hogar.

[184]

$\mathrm{CS}=$ Cobertura de Salud

Encuesta: socio-demográfica (ESD).

Pregunta: ¿Tiene cobertura de salud?

$\begin{array}{llc}\text { Respuesta posible } & \text { Impacto } \% \text { de la muestra } \\ \text { Obra social (incluye PAMI) } & 60 & 51,75 \% \\ \text { Prepaga } & 40 & 9,60 \% \\ \text { Planes estatales de salud } & 80 & 2,55 \%\end{array}$

No tiene obra social, prepaga o plan estatal 100 36,10\%

Criterio de impacto: El impacto social aumenta a medida que el perfil de usuario se encuentra desprotegido de cobertura.

[184]

$\mathrm{EC}=$ Estado civil

Encuesta: socio-demográfica (ESD).

Pregunta: ¿Cuál es su estado civil?

$\begin{array}{lll}\text { Respuesta posible } & \text { Impacto } & \% \text { de la muestra } \\ \text { Soltero/a } & 20 & 51,9 \% \\ \text { Casado/a } & 100 & 35,8 \% \\ \text { Divorciado/a } & 40 & 5,8 \% \\ \text { Separado/a legal } & 40 & 5,8 \% \\ \text { Viudo/a } & 20 & 6,5 \% \\ \text { Desconocido } & 0 & 0 \%\end{array}$

Criterio de impacto: El impacto social aumenta a medida que el perfil de usuario posee más obligaciones conyugales. En otro caso, el impacto disminuye.

[184]

Edad $=$ Edad del usuario.

Encuesta: socio-demográfica (ESD).

Pregunta: ¿Cuál es el grupo de pertenencia según su edad?

Respuesta posible Impacto \% de la muestra

Niños, niñas y adolescentes (de 0 a 17 años) $100 \quad 25,5 \%$

Jóvenes (de 18 a 29 años) $\quad 75 \quad 18 \%$

Adultos (de 30 a 64 años) $\quad 5 \quad 46,3 \%$

Adultos mayores (mas de 65 años) $0 \quad 10,2 \%$

Criterio de impacto: El impacto social disminuye a medida que el perfil de usuario posee mayor edad. En otro caso, el agregado de impacto aumenta.

[184]

$\mathrm{F}=$ Fecundidad

Encuesta: socio-demográfica (ESD).

Pregunta: ¿Tiene hijos?

Respuesta posible Impacto $\%$ de la muestra

$0 / 1 / 2 \quad 0 / 10 / 20 \quad 10 \% \quad$ (Estimado

para dos o menos)

3

30

$80 \% \quad$ (Estimado,

media 2,9)

4 hasta $10 \quad 40$ a $100 \quad 10 \% \quad$ (Estimado

para cuatro o mas)

Criterio de impacto: El impacto social aumenta a medida que el perfil de usuario tiene mayor cantidad de hijos [184].

$\mathrm{GD}=$ Grado de dependencias.

Encuesta: socio-demográfica (ESD).

Pregunta: ¿Consume sustancias que podrían afectar a la salud?

Respuesta posible Impacto \% de la muestra

Nunca $\quad 0 \quad 5,2 \%$ (Estimado)

Alguna vez $\quad 30 \quad 7,8 \%$ (Estimado)

Frecuentemente $\quad 60 \quad 46,4 \%$ (Estimado)

Siempre $\quad 100 \quad 40,6 \%$ (Estimado)

Criterio de impacto: El impacto social aumenta a medida que el perfil de usuario consume frecuentemente, o siempre, sustancias que podrían afectar a su salud. [191]

$\mathrm{N}=$ Nacionalidad.

Encuesta: socio-demográfica (ESD).

Pregunta: ¿Cuál es su nacionalidad?

$\begin{array}{lll}\text { Respuesta posible } & \text { Impacto } & \% \text { de la muestra } \\ \text { Argentina } & 0 & 10,53 \% \\ \text { Boliviana } & 0 & 0,71 \% \\ \text { Chilena } & 0 & 11,65 \% \\ \text { Colombiana } & 0 & 6,94 \% \\ \text { Mexicana } & 0 & 10,62 \% \\ \text { Paraguaya } & 0 & 0,96 \% \\ \text { Peruana } & 0 & 3,49 \% \\ \text { Uruguaya } & 0 & 13,47 \% \\ \text { Venezolana } & 0 & 0,87 \% \\ \text { Otra } & 0 & 40,76 \%\end{array}$

Criterio de impacto: No aporta al impacto social auspiciando la igualdad ante nacionalidad. [192]

$\mathrm{NF}=$ Composición del núcleo familiar.

Encuesta: socio-demográfica (ESD).

Pregunta: ¿Cuál es la composición del núcleo familiar? 
Respuesta posible Impacto

Unipersonal: Hogar unipersonal

$$
20 \quad 17,7 \%
$$

No conyugal: Hogar constituido por: sólo parientes no nucleares; sólo no parientes; o la combinación de ambos. 40 $0,9 \%$

Hogar conyugal de familia completa nuclear: jefe/a del hogar y cónyuge, con presencia, o no, de hijos.

$$
60 \quad 62,0 \%
$$

Hogar conyugal de familia completa extensa: jefe/a del hogar y cónyuge, con presencia, o no, de hijos y otros parientes. 100

$18,1 \%$

Hogar conyugal de familia monoparental nuclear: jefe/a del hogar con presencia de hijos

$$
60 \quad 1,3 \%
$$

Hogar conyugal de familia monoparental extensa: jefe/a del hogar con presencia de hijos y otros parientes.

$$
80 \quad 1,3 \%
$$

Hogar conyugal de familia compuesta: constituida por una familia nuclear o extensa, más otros no parientes del jefe $\begin{array}{lll}\text { del hogar. } & 100 & 1,3 \% \\ \text { Otra formación. } & 0 & 0 \%\end{array}$

Criterio de impacto: El impacto social aumenta a medida que aumenta la complejidad relacional entre personas del mismo núcleo familiar.

[184]

$\mathrm{SE}=$ Situación educativa.

Encuesta: socio-demográfica (ESD).

Pregunta: ¿Qué nivel educativo cursa o curso?

$\begin{array}{lll}\text { Respuesta posible } & \text { Impacto } & \text { \%de la muestra } \\ \text { Inicial (jardín) } & 100 & 12,8 \% \\ \text { Primario } & 80 & 37,2 \% \\ \text { EGB } & 60 & 8,1 \% \\ \text { Secundario } & 40 & 20,6 \% \\ \text { Polimodal } & 40 & 6,5 \% \\ \text { Superior no universitario } 20 & 4,3 \% \\ \text { Universitario } & 20 & 10,0 \% \\ \text { Pos-Universitario } & 20 & 0,5 \% \\ \text { Ninguno } & 100 & 0 \%\end{array}$

Criterio de impacto: El impacto social aumenta a medida que el perfil de usuario posee bajos niveles educativos alcanzados.

[177; 180; 184]

Sexo $=$ Sexo del usuario.

Encuesta: socio-demográfica (ESD).

Pregunta: Indique su sexo.

$\begin{array}{lll}\text { Respuesta posible } & \text { Impacto } & \% \text { de la muestra } \\ \text { Femenino } & 0 & 51,33 \% \\ \text { Masculino } & 0 & 48,67 \%\end{array}$

Criterio de impacto: No aporta al impacto social auspiciando la igualdad ante género.

[180; 184]

Se consideran las siguientes variables dependientes para el eje ambiental:

ARA = Afectación a la relaciones afectiva.

Encuesta: adicción a redes sociales (BFAS) [173], cuestionario de múltiples respuestas DSM-IV-MR-J para el juego patológico (DSM) [172] y adicción a Internet (IAT) [93; 82].

Formulación: ARA $=$ BFAS $(14)+$ BFAS $(15)+$ BFAS (16) + DSM (9) + DSM (10) + IAT (4) + IAT (5)
Concepto: Suma de impacto individual de las respuestas para las preguntas 14, 15 y 16 de la escala de adicción a redes sociales (BFAS) [173], 9 y 10 de criterios de múltiples respuestas DSM-IV-MR-J para el juego patológico (DSM) y 4 y 5 de adicción a Internet (IAT) [93; 82].

AS = Aspectos de salubridad.

Encuesta: socio-demográfica (ESD).

Formulación: $\mathrm{AS}=\mathrm{CS}+\mathrm{AFi}+\mathrm{AE}+\mathrm{F}+\mathrm{GD}$

Concepto: Suma de impactos individuales por cobertura de salud (CS), actividad física (AFi), actividad de esparcimiento emocional (AE), fecundidad (F) y grado de dependencias (GD) del perfil de usuario de Internet.

$\mathrm{CPA}=$ Cantidad de accesos al simulador.

Encuesta: Sin encuesta.

Formulación: $\mathrm{CPA}=\Sigma$ Ingresos del perfil de usuario al sistema software simulador

Concepto: Indica la cantidad total de ingresos del perfil de usuario al sistema software simulador durante la simulación.

$\mathrm{EV}=$ Escape de la vida..

Encuesta: escala de medida de la compra compulsiva (CBMS) [174], adicción a redes sociales (BFAS) [173], cuestionario de múltiples respuestas DSM-IV-MR-J para el juego patológico (DSM) [172] y adicción a Internet (IAT) [93; 82].

Formulación: $\mathrm{EV}=\mathrm{CBMS}(3)+\operatorname{BFAS}(7)+\operatorname{BFAS}(8)+$ BFAS (9) + DSM (5) + IAT (2) + IAT (3) + IAT (10) + IAT (12) + IAT (19)

Concepto: Suma de impacto individual de las respuestas para la pregunta 3 de la escala de medida de la compra compulsiva (CBMS) [174], 7, 8 y 9 de la escala de adicción a redes sociales (BFAS) [173], 5 de criterios de múltiples respuestas DSM-IV-MR-J para el juego patológico (DSM) y 3, 10, 12 y 19 de adicción a Internet (IAT) [93; 82].

$\mathrm{H}=$ Hogar y Educación.

Encuesta: socio-demográfica (ESD).

Formulación: $\mathrm{H}=\mathrm{NF}+\mathrm{CH}+\mathrm{SE}$

Concepto: Suma de impactos individuales por el núcleo familiar (NF), la cantidad de habitantes del hogar $(\mathrm{CH})$ y la situación educativa (SE) del perfil de usuario de Internet.

IS = Impacto social.

Encuesta: socio-demográfica (ESD), escala de medida de la compra compulsiva (CBMS) [174], adicción a redes sociales (BFAS) [173], cuestionario de múltiples respuestas DSM-IV-MR-J para el juego patológico (DSM) [172] y adicción a Internet (IAT) [93; 82].

Formulación: $\mathrm{IS}=\mathrm{SP}+\mathrm{AS}+\mathrm{H}+\mathrm{CPA}+\mathrm{PC}+\mathrm{EV}+\mathrm{TO}+$ ARA

Concepto: Sumatoria de todos los impactos individuales de todas las variables dependientes del eje ambiental.

$\mathrm{PC}=$ Pérdida de control.

Encuesta: escala de medida de la compra compulsiva (CBMS) [174], adicción a redes sociales (BFAS) [173], cuestionario de múltiples respuestas DSM-IV-MR-J para el juego patológico (DSM) [172] y adicción a Internet (IAT) $[93 ; 82]$.

Formulación: PC $=$ CBMS (8) + CBMS (9) + BFAS (10)

+BFAS (11) + DSM (4) + IAT (6) + IAT (8) + IAT (13)

Concepto: Suma de impacto individual de las respuestas para la pregunta 8 y 9 de la escala de medida de la compra 
compulsiva (CBMS) [174], 10 y 11 de la escala de adicción a redes sociales (BFAS) [173], 4 de criterios de múltiples respuestas DSM-IV-MR-J para el juego patológico (DSM) y 6, 8 y 13 de adicción a Internet (IAT) $[93 ; 82]$.

$\mathrm{SP}=$ Situación poblacional

Encuesta: socio-demográfica (ESD).

Formulación: $\mathrm{SP}=\mathrm{Edad}+\mathrm{Sexo}+\mathrm{EC}+\mathrm{N}$.

Concepto: Suma de impactos individuales por la edad (Edad), el sexo (Sexo), el estado civil (EC) y la nacionalidad $(\mathrm{N})$ del perfil de usuario de Internet.

$\mathrm{TO}=$ Tendencia al ocultamiento.

Encuesta: escala de medida de la compra compulsiva (CBMS) [174], cuestionario de múltiples respuestas DSMIV-MR-J para el juego patológico (DSM) [172] y adicción a Internet (IAT) [93; 82].

Formulación: TO $=$ CBMS (7) + DSM (7) + IAT (9) + IAT (18)

Concepto: Suma de impacto individual de las respuestas para la pregunta 7 de la escala de medida de la compra compulsiva (CBMS) [174], 7 de criterios de múltiples respuestas DSM-IV-MR-J para el juego patológico (DSM) y 9 y 18 de adicción a Internet (IAT) [93; 82].

4) Aspecto gráfico del campo vectorial del modelo de impacto de consumo

Se presenta gráficamente al modelo conceptual de impacto de consumo (MIC) en la figura 7.

5) Formulaciones finales sobre el campo vectorial del modelo de impacto de consumo

Por lo expuesto en lo precedente, sobre los ejes económico, ambiental y social accionan una serie de encuestas y criterios como se presenta en la Tabla VIII "Encuestas y criterios del modelo de impacto de consumo". Al descomponer cada encuesta, se materializa la acción de cada variable independiente sobre el eje de sustentabilidad, como se muestra en la Tabla IX "Variables independientes por encuesta del modelo de impacto de consumo". Considerando la descomposición de variables independientes y agregando a otras dependientes, se resume el total de variables que dimensionan el subconjunto del dominio del campo vectorial, por eje de sustentabilidad, en la Tabla $\mathrm{X}$ "Total de variables del dominio del campo vectorial del modelo de impacto de consumo".

Una nueva forma matemática que aumenta la Ecuación 2 "Campo vectorial del modelo conceptual de impacto de consumo", podría presentar el desarrollo completo del campo vectorial, permitiendo conocer la forma estadística como se muestra en Ecuación 3 "Forma estadística del campo vectorial del modelo conceptual de impacto de consumo".

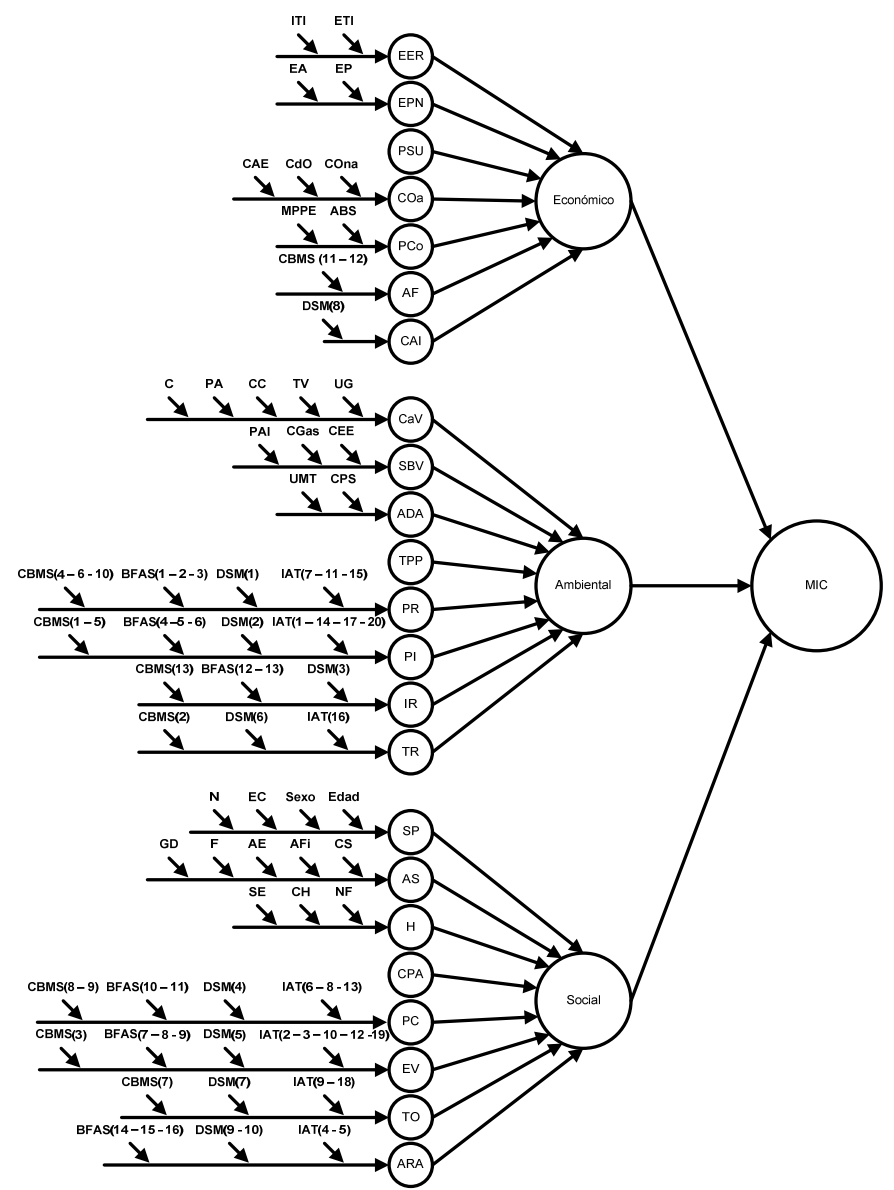

Fig. 7. Aspecto gráfico del campo vectorial del modelo de impacto de consumo

TABLA IX - VARIABLES INDEPENDIENTES POR ENCUESTA DEL MODELO DE IMPACTO DE CONSUMO

\begin{tabular}{|l|l|l|lll|l|l|ll|l|l|l|l|l|lll|l|l|l|}
\hline Encuesta & 1 & 2 & 3 & 4 & 5 & 6 & 7 & 8 & 9 & 10 & 11 & 12 & 13 & 14 & 15 & 16 & 17 & 18 & 19 & 20 \\
\hline IAT & A & S & S & S & S & S & A & S & S & S & A & S & S & A & A & A & A & S & S & A \\
\hline DSM & A & A & A & S & S & A & S & E & S & S & & & & & & & & & & \\
BFAS & A & A & A & A & A & A & S & S & S & S & S & A & A & S & S & S & & & & \\
\hline CBMS & A & A & S & A & A & A & A & S & S & A & E & E & A & & & & & & \\
\hline EOE & E & E & E & E & E & E & E & E & E & & & & & & & & & & \\
EHE & A & A & A & A & A & A & A & A & A & A & & & & & & & & & \\
\hline ESD & S & S & S & S & S & S & S & S & S & S & S & S & & & & & & & \\
\hline
\end{tabular}

TABLA X - TOTAL DE VARIABLES DEL DOMINIO DEL CAMPO VECTORIAL DEL MODELO DE IMPACTO DE CONSUMO

\begin{tabular}{|c|c|c|c}
\hline $\begin{array}{c}\text { Eje de } \\
\text { sustentabilidad }\end{array}$ & $\begin{array}{c}\text { Variables } \\
\text { independientes }\end{array}$ & $\begin{array}{c}\text { Variables } \\
\text { dependientes }\end{array}$ & $\begin{array}{c}\text { Total de variables } \\
\text { del dominio }\end{array}$ \\
\hline Económico & 12 & 1 (PSU) & 13 \\
Ambiental & 37 & $1(\mathrm{TPP})$ & 38 \\
\hline Social & 41 & 1 (CPA) & 42 \\
\hline
\end{tabular}

MIC: |R93 -> |R3 /

MIC (

(ITI, ETI, EA, EP, PSU, CAE, CdO, COna, MPPE, ABS, CBMS(11), CBMS(12), DSM(8)),

(C, PA, CC, TV, UG, PAI, CGas, CEE, UMT, CPS, TPP, CBMS(1), CBMS(2), CBMS(4), CBMS(5), CBMS(6), CBMS(10), CBMS(13), $\operatorname{BFAS}(1), \operatorname{BFAS}(2), \operatorname{BFAS}(3)$, BFAS(4), BFAS(5), BFAS(6), BFAS(12), BFAS(13), DSM(1), 
$\operatorname{DSM}(2), \quad \operatorname{DSM}(3), \quad \operatorname{DSM}(6), \quad \operatorname{IAT}(1), \quad \operatorname{IAT}(7), \quad \operatorname{IAT}(11)$, $\operatorname{IAT}(14), \operatorname{IAT}(15), \operatorname{IAT}(16), \operatorname{IAT}(17), \operatorname{IAT}(20))$,

(N, EC, Sexo, Edad, GD, F, AE, AFi, CS, SE, CH, NF, CPA, CBMS(3), CBMS(7), CBMS(8), CBMS(9), BFAS(7), $\operatorname{BFAS}(8), \operatorname{BFAS}(9), \operatorname{BFAS}(10), \operatorname{BFAS}(11), \operatorname{BFAS}(14)$, BFAS(15), BFAS(16), DSM(4), DSM(5), DSM(7), DSM(9), $\operatorname{DSM}(10), \operatorname{IAT}(2), \operatorname{IAT}(3), \operatorname{IAT}(4), \operatorname{IAT}(5), \operatorname{IAT}(6), \operatorname{IAT}(8)$, $\operatorname{IAT}(9), \operatorname{IAT}(10), \operatorname{IAT}(12), \operatorname{IAT}(13), \operatorname{IAT}(18), \operatorname{IAT}(19)))=$

$\left(\left(\left(\mathrm{k}_{1} * \mathrm{ITI}-\mathrm{k}_{2} * \mathrm{ETI}\right)+\left(\mathrm{k}_{3} * \mathrm{EA}-\mathrm{k}_{4} * \mathrm{EP}\right)+\mathrm{k}_{5} *\right.\right.$ PSU + $\left(\mathrm{k}_{6} * \mathrm{CAE}+\mathrm{k}_{7} * \mathrm{CdO}+\mathrm{k}_{8} * \mathrm{COna}\right)+\left(\mathrm{k}_{9} * \mathrm{MPPE}+\mathrm{k}_{10} * \mathrm{ABS}\right)+$ $\left.\left(\mathrm{k}_{11} * \mathrm{CBMS}(11)+\mathrm{k}_{12} * \operatorname{CBMS}(12)\right)+\mathrm{k}_{13} * \mathrm{DSM}(8)\right)$,

$\left(\left(\mathrm{k}_{14} * \mathrm{C}+\mathrm{k}_{15} * \mathrm{PA}+\mathrm{k}_{16} * \mathrm{CC}+\mathrm{k}_{17} * \mathrm{TV}+\mathrm{k}_{18} * \mathrm{UG}\right)+\right.$ $\left(\mathrm{k}_{19} * \mathrm{PAI}+\mathrm{k}_{20} * \mathrm{CGas}+\mathrm{k}_{21} * \mathrm{CEE}\right)+\left(\mathrm{k}_{22} * \mathrm{UMT}+\mathrm{k}_{23} * \mathrm{CPS}\right)+$ $\mathrm{k}_{24} * \mathrm{TPP},\left(\mathrm{k}_{25} * \mathrm{CBMS}(4)+\mathrm{k}_{26} * \mathrm{CBMS}(6)+\mathrm{k}_{27} * \mathrm{CBMS}(10)+\right.$ $\mathrm{k}_{28} * \operatorname{BFAS}(1)+\mathrm{k}_{29} * \operatorname{BFAS}(2)+\mathrm{k}_{30} * \operatorname{BFAS}(3)+\mathrm{k}_{31} * \mathrm{DSM}(1)+$ $\left.\mathrm{k}_{32} * \operatorname{IAT}(7)+\mathrm{k}_{33} * \operatorname{IAT}(11)+\mathrm{k}_{34} * \operatorname{IAT}(15)\right)+\left(\mathrm{k}_{35} * \operatorname{CBMS}(1)+\right.$ $\mathrm{k}_{36} * \mathrm{CBMS}(5)+\mathrm{k}_{37} * \operatorname{BFAS}(4)+\mathrm{k}_{38} * \operatorname{BFAS}(5)+\mathrm{k}_{39} * \operatorname{BFAS}(6)$ $+\mathrm{k}_{40} * \operatorname{DSM}(2)+\mathrm{k}_{41} * \operatorname{IAT}(1)+\mathrm{k}_{42} * \operatorname{IAT}(14)+\mathrm{k}_{43} * \operatorname{IAT}(17)+$ $\left.\mathrm{k}_{44} * \operatorname{IAT}(20)\right)+\left(\mathrm{k}_{45} * \operatorname{CBMS}(13)+\mathrm{k}_{46} * \operatorname{BFAS}(12)+\right.$ $\left.\mathrm{k}_{47} * \operatorname{BFAS}(13)+\mathrm{k}_{48} * \operatorname{DSM}(3)\right)+\left(\mathrm{k}_{49} * \operatorname{CBMS}(2)+\right.$ $\left.\mathrm{k}_{50} * \operatorname{DSM}(6)+\mathrm{k}_{51} * \operatorname{IAT}(16)\right)$

$\left(\left(\mathrm{k}_{52} * \mathrm{~N}+\mathrm{k}_{53} * \mathrm{EC}+\mathrm{k}_{54} *\right.\right.$ Sexo $\left.+\mathrm{k}_{55} * \mathrm{Edad}\right)+\left(\mathrm{k}_{56} * \mathrm{GD}+\right.$ $\left.\mathrm{k}_{57} * \mathrm{~F}+\mathrm{k}_{58} * \mathrm{AE}+\mathrm{k}_{59} * \mathrm{AFi}+\mathrm{k}_{60} * \mathrm{CS}\right)+\left(\mathrm{k}_{61} * \mathrm{SE}+\mathrm{k}_{62} * \mathrm{CH}+\right.$ $\left.\mathrm{k}_{63} * \mathrm{NF}\right)+\mathrm{k}_{64} * \mathrm{CPA}+\left(\mathrm{k}_{65} * \mathrm{CBMS}(8)+\mathrm{k}_{66} * \mathrm{CBMS}(9)+\right.$ $\mathrm{k}_{67} * \operatorname{BFAS}(10)+\mathrm{k}_{68} * \operatorname{BFAS}(11)+\mathrm{k}_{69} * \operatorname{DSM}(4)+\mathrm{k}_{70} * \operatorname{IAT}(6)+$ $\left.\mathrm{k}_{71} * \operatorname{IAT}(8)+\mathrm{k}_{72} * \operatorname{IAT}(13)\right)+\left(\mathrm{k}_{73} * \operatorname{CBMS}(3)+\mathrm{k}_{74} * \operatorname{BFAS}(7)+\right.$ $\mathrm{k}_{75} * \operatorname{BFAS}(8)+\mathrm{k}_{76} * \operatorname{BFAS}(9)+\mathrm{k}_{77} * \operatorname{DSM}(5)+\mathrm{k}_{78} * \operatorname{IAT}(2)+$ $\left.\mathrm{k}_{79} * \operatorname{IAT}(3)+\mathrm{k}_{80} * \operatorname{IAT}(10)+\mathrm{k}_{81} * \operatorname{IAT}(12)+\mathrm{k}_{82} * \operatorname{IAT}(19)\right)+$ $\left(\mathrm{k}_{83} * \operatorname{CBMS}(7)+\mathrm{k}_{84} * \operatorname{DSM}(7)+\mathrm{k}_{85} * \operatorname{IAT}(9)+\mathrm{k}_{86} * \operatorname{IAT}(18)\right)+$ $\left(\mathrm{k}_{87} * \operatorname{BFAS}(14)+\mathrm{k}_{88} * \operatorname{BFAS}(15)+\mathrm{k}_{89} * \operatorname{BFAS}(16)+\right.$ $\left.\left.\mathrm{k}_{90} * \operatorname{DSM}(9)+\mathrm{k}_{91} * \operatorname{DSM}(10)+\mathrm{k}_{92} * \operatorname{IAT}(4)+\mathrm{k}_{93} * \operatorname{IAT}(5)\right)\right)$

El modelo desarrollado en la presente solución propuesta podría facilitar el desarrollo simultáneo de tres cuestiones:[f] Generar una muestra simulada de perfiles de usuario de Internet a través de la cuantificación de las variables del dominio en los porcentajes de la muestra expuestos para cada una. [g] Analizar el impacto del consumo de bienes y servicios digitalizados por Internet, sobre la muestra simulada de perfiles de usuario. [h] Presentar relaciones entre características comunes de los perfiles de usuario de Internet, tomadas de la cuantificación de las variables del dominio y el impacto en los tres ejes del subconjunto de la imagen.

Para analizar el impacto [g] y desarrollar algún nivel de relacionamiento [h] con las características centrales y orbitales de los perfiles de usuario de Internet, podría considerarse necesario el modo en que se genera la muestra simulada [f].

\section{Cuantificación de la encuesta digital}

Para obtener una muestra representativa de perfiles de usuario de Internet se desarrollo un grupo de tres experimentos evolutivos con un sistema software desarrollado para tal fin.

Se simuló el consumo de bienes y servicios digitalizados por Internet creando un conjunto de datos de perfiles de usuario paralelizando el comportamiento de la sociedad contemporánea de la República Argentina, también apuntalada por actitudes extra-territoriales de usuarios de Internet.

Para cuantificar las variables del modelo conceptual de impacto de consumo se utilizó el método de simulación de Montecarlo [164; 165] de forma que su aleatoriedad se apoye en los porcentajes de la muestra presentados para cada variable de las encuestas, sean centrales u orbitales.
Fueron cuantificadas digitalmente diez mil encuestas de usuario y por cada una se registró una cantidad aleatoria de accesos al sistema, tiempo permanencia y consumo de créditos acorde a cada individuo.

Con los datos experimentales, el modelo conceptual de impacto de consumo presentado en la Figura 7 "Aspecto gráfico del campo vectorial del modelo de impacto de consumo" y expresado matemáticamente en la Ecuación 3 "Forma estadística del campo vectorial del modelo conceptual de impacto de consumo" se expuso a cálculos de regresión lineal múltiple $[167 ; 168 ; 169]$.

Las estadísticas de regresión permitieron inferir la linealidad de las variables respecto al impacto y la posibilidad considerar despreciables a los errores típicos de cada una. En todos los casos se demostró la relación directa y dependiente de correlación entre las variables y el impacto. El coeficiente de correlación múltiple quedó valorizado en " 1 " y el coeficiente de determinación " $\mathrm{R} \wedge 2$ ", se presentó perfecto y sin diferencias entre valores estimados y reales para la totalidad de las observaciones $[167 ; 168 ; 169]$. Los valores de ajustas $\mathrm{k}_{0} \ldots \mathrm{k}_{93}$ se demostraron iguales a "1", reduciendo la formulación del campo a la Ecuación 4 "Forma final del campo vectorial del modelo conceptual de impacto de consumo".

MIC: |R93 -> |R3 /

$\mathrm{MIC} \quad($

(ITI, ETI, EA, EP, PSU, CAE, CdO, COna, MPPE, ABS, CBMS(11), CBMS(12), DSM(8)),

(C, PA, CC, TV, UG, PAI, CGas, CEE, UMT, CPS, TPP, CBMS(1), CBMS(2), CBMS(4), CBMS(5), CBMS(6), CBMS(10), CBMS(13), BFAS(1), BFAS(2), BFAS(3), BFAS(4), BFAS(5), BFAS(6), BFAS(12), BFAS(13), DSM(1), $\operatorname{DSM}(2), \operatorname{DSM}(3), \operatorname{DSM}(6), \quad \operatorname{IAT}(1), \quad \operatorname{IAT}(7), \quad \operatorname{IAT}(11)$, $\operatorname{IAT}(14), \operatorname{IAT}(15), \operatorname{IAT}(16), \operatorname{IAT}(17), \operatorname{IAT}(20))$,

$(\mathrm{N}, \mathrm{EC}, \mathrm{Sexo}$, Edad, GD, F, AE, AFi, CS, SE, CH, NF, CPA, CBMS(3), CBMS(7), CBMS(8), CBMS(9), BFAS(7), $\operatorname{BFAS}(8), \quad \operatorname{BFAS}(9), \operatorname{BFAS}(10), \operatorname{BFAS}(11), \operatorname{BFAS}(14)$, $\operatorname{BFAS}(15), \operatorname{BFAS}(16), \operatorname{DSM}(4), \operatorname{DSM}(5), \operatorname{DSM}(7), \operatorname{DSM}(9)$, $\operatorname{DSM}(10), \operatorname{IAT}(2), \operatorname{IAT}(3), \operatorname{IAT}(4), \operatorname{IAT}(5), \operatorname{IAT}(6), \operatorname{IAT}(8)$, IAT(9), IAT(10), IAT(12), IAT(13), IAT(18), IAT(19))) =

$(((\mathrm{ITI}-\mathrm{ETI})+(\mathrm{EA}-\mathrm{EP})+\mathrm{PSU}+(\mathrm{CAE}+\mathrm{CdO}+\mathrm{COna})+$ $(\mathrm{MPPE}+\mathrm{ABS})+(\mathrm{CBMS}(11)+\mathrm{CBMS}(12))+\mathrm{DSM}(8))$,

$((\mathrm{C}+\mathrm{PA}+\mathrm{CC}+\mathrm{TV}+\mathrm{UG})+(\mathrm{PAI}+\mathrm{CGas}+\mathrm{CEE})+$ $(\mathrm{UMT}+\mathrm{CPS})+\mathrm{TPP},(\mathrm{CBMS}(4)+\mathrm{CBMS}(6)+\mathrm{CBMS}(10)+$ $\operatorname{BFAS}(1)+\operatorname{BFAS}(2)+\operatorname{BFAS}(3)+\operatorname{DSM}(1)+\operatorname{IAT}(7)+$ $\mathrm{IAT}(11)+\operatorname{IAT}(15))+(\mathrm{CBMS}(1)+\mathrm{CBMS}(5)+\mathrm{BFAS}(4)+$ $\operatorname{BFAS}(5)+\operatorname{BFAS}(6)+\operatorname{DSM}(2)+\operatorname{IAT}(1)+\operatorname{IAT}(14)+$ $\mathrm{IAT}(17)+\mathrm{IAT}(20))+(\mathrm{CBMS}(13)+\mathrm{BFAS}(12)+\mathrm{BFAS}(13)+$ $\operatorname{DSM}(3))+(\operatorname{CBMS}(2)+\operatorname{DSM}(6)+\operatorname{IAT}(16))$,

$((\mathrm{N}+\mathrm{EC}+\mathrm{Sexo}+\mathrm{Edad})+(\mathrm{GD}+\mathrm{F}+\mathrm{AE}+\mathrm{AFi}+\mathrm{CS})+$ $(\mathrm{SE}+\mathrm{CH}+\mathrm{NF})+\mathrm{CPA}+(\mathrm{CBMS}(8)+\mathrm{CBMS}(9)+\mathrm{BFAS}(10)$ $+\operatorname{BFAS}(11)+\operatorname{DSM}(4)+\operatorname{IAT}(6)+\operatorname{IAT}(8)+\operatorname{IAT}(13))+$ $(\mathrm{CBMS}(3)+\mathrm{BFAS}(7)+\operatorname{BFAS}(8)+\operatorname{BFAS}(9)+\operatorname{DSM}(5)+$ $\operatorname{IAT}(2)+\operatorname{IAT}(3)+\operatorname{IAT}(10)+\operatorname{IAT}(12)+\operatorname{IAT}(19))+$ $(\operatorname{CBMS}(7)+\operatorname{DSM}(7)+\operatorname{IAT}(9)+\operatorname{IAT}(18))+(\operatorname{BFAS}(14)+$ $\operatorname{BFAS}(15)+\operatorname{BFAS}(16)+\operatorname{DSM}(9)+\operatorname{DSM}(10)+\mathrm{IAT}(4)+$ $\operatorname{IAT}(5))$

\section{EXPERIMENTACIÓN}

En este apartado se presenta una introducción sobre el desarrollo de los experimentos (sección $A$ ), le sigue el diseño de las pruebas (sección $B$ ), para analizar con gráficas e 
interpretaciones los resultados experimentales (sección $C$ ) y obtener posibles conclusiones sobre los mismos (sección $D$ ).

\section{A. Introducción}

El objetivo de la experimentación es obtener resultados de laboratorio a fin de interpretar una posible sensación sobre el consumo masivo de bienes y servicios digitalizados en Internet por usuarios de esa red.

Tomando como base el modelo conceptual de impacto de consumo (presentado en la sección IV de solución propuesta) y utilizando técnicas de simulación apoyadas en herramientas de informática, será factible obtener una muestra significativa de perfiles de usuario de Internet para inferir algunas posibles conclusiones sobre la experimentación con esos datos.

Se ejecutaron las pruebas de los experimentos registrándose incrementos y mejoras en la calidad de la información. El análisis de estadístico validó el avance del conjunto de perfiles de usuario simulados. Este conjunto será objeto de estudio e interpretación a fin de delinear una posible tendencia al momento de consumir bienes y servicios digitalizados por Internet.

Los resultados experimentales no permiten concluir sobre la actividad de los usuarios de Internet, pero podrían aproximan de un modo posible alguna tendencia sobre el consumo masivo de bienes y servicios digitalizados en el ciber-espacio.

\section{B. Diseño experimental}

Se presenta el diseño de los experimentos con la explicación de las variables de estudio (sub-sección 1) y se continúa con el desarrollo y ejecución de los mismos (subsección 2).

\section{1) Variables}

Se explican las variables para el estudio del modelo de impacto masivo del consumo de productos y servicios digitalizados en comercio electrónico escalable. Comenzando con las independientes y dependientes del eje económico (subsección $a$ ), se continúa con las propias del eje ambiental (subsección $b$ ) para finalizar con las del eje social (sub-sección $c$ ).

\section{a) Variables para el estudio del eje económico}

Se consideran las siguientes variables independientes para el eje económico:

ABS: Acceso a bienes y servicio: Es una variable cualitativa e indica el aporte al impacto sobre el eje económico considerando la forma de acceso a la información sobre los productos y servicios que consume el perfil de usuario. Los valores discretos de impacto son:

$\begin{array}{ll}\text { Amigos } & =20 \\ \text { Familiares } & =20 \\ \text { En el trabajo } & =40 \\ \text { Publicidad gráfica } & =60 \\ \text { Publicidad televisiva } & =60 \\ \text { Publicidad en Radio } & =60 \\ \text { Publicidad en Internet } & =80 \\ \text { Otros medios } & =20\end{array}$

CAE: Categoría de actividad económica: Es una variable cualitativa e indica el aporte al impacto sobre el eje económico considerando si el perfil de usuario trabaja percibiendo un pago en dinero o en especie por la tarea que realiza. Los valores discretos de impacto son:

Sólo trabaja

$=100$

Trabaja y estudia

$=100$

Trabaja y percibe jubilación o pensión $\quad=50$
No es mi caso

$=0$

CdO: Categoría de desocupación: Es una variable cualitativa e indica el aporte al impacto sobre el eje económico considerando si el perfil de usuario no tiene ocupación laboral y la busca activamente. Los valores discretos de impacto son:

Sólo busca trabajo $\quad=100$

Busca trabajo y estudia $\quad=100$

Busca trabajo y percibe jubilación o pensión $=50$

No es mi caso $\quad=0$

COna: Condición de ocupación de población económicamente no activa: Es una variable cualitativa e indica el aporte al impacto sobre el eje económico considerando si el perfil de usuario no tiene ocupación laboral y no la busca activamente. Los valores discretos de impacto son:

Estudiante

$=100$

Jubilado o Pensionado

$=50$

No es mi caso

$=0$

EA: Estimación del activo: Es una variable cualitativa e indica el aporte al impacto sobre el eje económico en función del conjunto de bienes y derechos propios, declarado por el perfil de usuario. Los valores discretos de impacto son:

$\begin{array}{ll}\text { Alto } & =0 \\ \text { Medio } & =50 \\ \text { Bajo } & =100\end{array}$

EP: Estimación del pasivo: Es una variable cualitativa e indica el aporte al impacto sobre el eje económico en función de obligaciones y deudas propias, declarado por el perfil de usuario. Los valores discretos de impacto son:

$\begin{array}{ll}\text { Alto } & =0 \\ \text { Medio } & =50 \\ \text { Bajo } & =100\end{array}$

ETI: Egreso total individual: Es una variable cualitativa e indica el aporte al impacto sobre el eje económico en función del egreso, por unidad de tiempo, declarado por el perfil de usuario. Los valores discretos de impacto son:
Hasta U\$S 1000 al mes
$=100$
De U\$S 1001 a U\$S 2000 al mes
$=80$
De U\$S 2001 a U\$S 3000 al mes
$=60$
$=40$
De U\$S 4001 a U\$S 5000 al mes $\quad=20$
Mas de 5000 al mes
$=0$

ITI: Ingreso total individual: Es una variable cualitativa e indica el aporte al impacto sobre el eje económico en función del ingreso, por unidad de tiempo, declarado por el perfil de usuario. Los valores discretos de impacto son:

Hasta U\$S 1000 al mes $\quad=100$

De U\$S 1001 a U\$S 2000 al mes $\quad=80$

De U\$S 2001 a U\$S 3000 al mes $\quad=60$

De U\$S 3001 a U\$S 4000 al mes $\quad=40$

De U\$S 4001 a U\$S 5000 al mes $\quad=20$

Mas de 5000 al mes $\quad=0$

MPPE: Modalidad preferida de pago para el comercio electrónico: Es una variable cualitativa e indica el aporte al impacto sobre el eje económico considerando la modalidad preferida de pago para el comercio electrónico. Los valores discretos de impacto son:

$\begin{array}{ll}\text { Depósito en cuenta } & =100 \\ \text { Trasferencia bancaria } & =80 \\ \text { Tarjeta de crédito o débito } & =60 \\ \text { Portales de pago electrónico } & =40 \\ \text { Cheque o giro postal } & =20\end{array}$


Contra entrega

Otro modo

$=10$

$=10$

Se consideran las siguientes variables dependientes para el eje económico:

AF: Ahogo financiero: Es una variable cuantitativa, perteneciente al intervalo [0,200], que relaciona a dos variables independientes de la escala de medición de compra compulsiva. Explica una posible estimación sobre la inconveniencia financiera que se produce por el exceso de compras determinando imposibilidades de pago y el aporte al impacto sobre el eje económico bajo la formulación: $\mathrm{AF}=\mathrm{CBMS}(11)+\mathrm{CBMS}$ (12).

CAI: Comisión de actos ilegales: Es una variable cuantitativa, perteneciente al intervalo $[0,100]$, que relaciona a una variable independiente de la escala de criterios de múltiples respuestas sobre compulsión en juegos de apuesta. Explica una posible estimación sobre la voluntad de delinquir a fin de obtener dinero para consumir juegos de apuesta y el aporte al impacto sobre el eje económico bajo la formulación: CAI = DSM (8).

COa: Condición de ocupación del individuo: Es una variable cuantitativa, perteneciente al intervalo [0,300], que relaciona a las independientes: Categoría de actividad económica (CAE), Categoría de desocupación (CdO) y Condición de ocupación de población económicamente no activa (COna). Explica la posible situación sobre la condición laboral o no laboral individual y el aporte al impacto sobre el eje económico bajo la formulación: $\mathrm{COa}=$ $\mathrm{CAE}+\mathrm{CdO}+\mathrm{COna}$.

EER: Estimación del estado individual de resultados: Es una variable cuantitativa, perteneciente al intervalo [-100,100], que relaciona a las independientes: Ingreso total individual (ITI) y Egreso total individual (ETI). Explica una posible estimación del estado de resultados individual y el aporte al impacto sobre el eje económico bajo la formulación: EER = ITI - ETI.

EPN: Estimación del estado patrimonial individual: Es una variable cuantitativa, perteneciente al intervalo [-100,100], que relaciona a las independientes: Estimación del activo (EA) y Estimación del pasivo (EP). Explica una posible estimación del estado patrimonial individual y el aporte al impacto sobre el eje económico bajo la formulación: EPN = $\mathrm{EA}-\mathrm{EP}$.

IE: Impacto económico: Es una variable cuantitativa, perteneciente al intervalo $[-170,+\infty]$, que relaciona al conjunto de variables dependientes del eje económico a fin de obtener una posible estimación del impacto económico por el consumo de bienes y servicios digitalizados por Internet del perfil de usuario bajo la formulación: $\mathrm{IE}=\mathrm{EER}$ $+\mathrm{EPN}+\mathrm{PSU}+\mathrm{COa}+\mathrm{PCo}+\mathrm{AF}+\mathrm{CAI}$.

PCo: Preferencia de compras: Es una variable cuantitativa, perteneciente al intervalo [30,180], que relaciona a las independientes: Modalidad preferida de pago para el comercio electrónico (MPPE) y Acceso a bienes y servicios (ABS). Explica una posible estimación sobre la actividad de comercio individual y el aporte al impacto sobre el eje económico bajo la formulación: $\mathrm{PCo}=\mathrm{MPPE}+\mathrm{ABS}$.

PSU: Puntos por consumo de contenidos por usuario en el simulador: Es una variable cuantitativa, perteneciente al intervalo $[0,+\infty]$ e indica la cantidad de puntos que el perfil de usuario utilizó para el consumo de los contenidos digitalizados dentro del sistema software simulador.

\section{b) Variables para el estudio del eje ambiental}

Se consideran las siguientes variables independientes para el eje ambiental:

$\mathrm{C}$ : Existencia de cloacas: Es una variable cualitativa e indica el aporte al impacto sobre el eje ambiental en función de la conexión a la red cloacal de la vivienda que habita el perfil de usuario. Los valores discretos de impacto son:
No
$\mathrm{Si}$
$=100$
$=0$

CC: Características constructivas: Es una variable cualitativa e indica el aporte al impacto sobre el eje ambiental en función de las características constructivas de la vivienda que habita el perfil de usuario. Los valores discretos de impacto son:

$\begin{array}{ll}\text { Cemento } & =0 \\ \text { Ladrillo } & =25 \\ \text { Madera } & =50 \\ \text { Metal } & =75 \\ \text { Otro } & =100\end{array}$

CEE: Consumo de energía eléctrica de red: Es una variable cualitativa e indica el aporte al impacto sobre el eje ambiental en función del consumo de energía eléctrica, estimado por las bocas conectadas, en la vivienda que habita el perfil de usuario. Los valores discretos de impacto son:

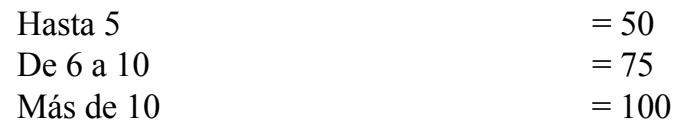

CGas: Consumo de gas de red, envasado o a granel: Es una variable cualitativa e indica el aporte al impacto sobre el eje ambiental en función del consumo de gas, estimado por las bocas conectadas, en la vivienda que habita el perfil de usuario. Los valores discretos de impacto son:
Hasta 5
$=50$
De 6 a 10
$=75$
Más de 10
$=100$

CPS: Consumo de productos y servicios no digitalizados: Es una variable cualitativa e indica el aporte al impacto sobre el eje ambiental en función de la frecuencia con que el perfil de usuario consume bienes y servicios no digitalizados, pero que también se encuentran para el consumo en Internet. Los valores discretos de impacto son: Ninguna

Alguna vez

$$
=0
$$

Varias veces

$=30$

Siempre

$$
=60
$$$$
=100
$$

PA: Procedencia del agua: Es una variable cualitativa e indica el aporte al impacto sobre el eje ambiental en función de la procedencia del agua de la vivienda que habita el perfil de usuario. Los valores discretos de impacto son:

De red pública (agua corriente) $\quad=0$

De perforación con bomba $\quad=20$

De pozo $\quad=40$

De transporte por cisterna $\quad=60$

Agua de lluvia $\quad=80$

Otra $\quad=100$

PAI: Preferencia por el acceso a Internet: Es una variable cualitativa e indica el aporte al impacto sobre el eje ambiental en función de la preferencia del perfil de usuario por el acceso y uso de Internet. Los valores discretos de impacto son: 


$\begin{array}{ll}\text { Acceso (Rapidez) } & =20 \\ \text { Asequibilidad (que se puede usar 7x24) } & =20 \\ \text { Anonimato } & =60 \\ \text { Conveniencia } & =40 \\ \text { Desinhibición } & =80 \\ \text { Escape (inmersión o disociación) } & =100 \\ \text { Interactividad } & =20 \\ \text { Sociabilidad } & =20 \\ \text { Otros motivos } & =0\end{array}$

TV: Tipo de vivienda: Es una variable cualitativa e indica el aporte al impacto sobre el eje ambiental en función del tipo de vivienda que habita el perfil de usuario. Los valores discretos de impacto son:

$\begin{array}{ll}\text { Casa } & =0 \\ \text { Departamento } & =20 \\ \text { Pieza(s) en inquilinato hotel o pensión } & =40 \\ \text { Rancho } & =60 \\ \text { Local (no construido para habitación) } & =80 \\ \text { Casilla } & =100 \\ \text { Vivienda móvil } & =100 \\ \text { En la calle } & =100\end{array}$

UG: Ubicación geográfica: Es una variable cualitativa e indica el aporte al impacto sobre el eje ambiental en función de la ubicación geográfica donde se encuentra la vivienda que habita el perfil de usuario. Los valores discretos de impacto son:

Urbana de 2000 y más habitantes $\quad=100$

Rural agrupada (menos de 2000 habitantes) $=50$

Rural dispersa

$=0$

UMT: Utilización de medio de trasporte: Es una variable cualitativa e indica el aporte al impacto sobre el eje ambiental en función del medio de transporte más utilizado por el perfil de usuario. Los valores discretos de impacto son:

Sin medio de trasporte $=0$

Trasporte público de tren $\quad=25$

Trasporte público de subte $\quad=25$

Trasporte público de colectivo $\quad=50$

Automóvil particular $\quad=100$

Otro medio de trasporte $\quad=100$

Se consideran las siguientes variables dependientes para el eje ambiental:

ADA: Aporte al desgaste ambiental: Es una variable cuantitativa, perteneciente al intervalo $[0,200]$, que relaciona a las independientes: Consumo de productos y servicios no digitalizados (CPS) y Utilización de medio de trasporte (UMT). Explica una posible estimación, sobre el aporte al desgaste ambiental, debido al acceso físico hasta productos y servicios de carácter tangible y el aporte al impacto sobre el eje ambiental bajo la formulación: $\mathrm{ADA}=$ CPS + UMT.

CaV: Características de la vivienda: Es una variable cuantitativa, perteneciente al intervalo $[0,500]$, que relaciona a las independientes: Ubicación geográfica (UG), Tipo de vivienda (TV), Características constructivas (CC), Procedencia del agua (PA) y Existencia de cloacas (C). Explica una posible estimación sobre el conjunto de características de la vivienda que habita el perfil de usuario y el aporte al impacto sobre el eje ambiental bajo la formulación: $\mathrm{CaV}=\mathrm{UG}+\mathrm{TV}+\mathrm{CC}+\mathrm{PA}+\mathrm{C}$.

IA: Impacto ambiental: Es una variable cuantitativa, perteneciente al intervalo $[0,+\infty]$, que relaciona al conjunto de variables dependientes del eje ambiental a fin de obtener una posible estimación del impacto ambiental por el consumo de bienes y servicios digitalizados por Internet del perfil de usuario bajo la formulación: $\mathrm{IA}=\mathrm{CaV}$ $+\mathrm{SBV}+\mathrm{ADA}+\mathrm{TPP}+\mathrm{PR}+\mathrm{PI}+\mathrm{IR}+\mathrm{TR}$.

IR: Intensión de retiro: Es una variable cuantitativa, perteneciente al intervalo [0,400], que relaciona a una variable independiente de la escala de medición de compra compulsiva, dos variables independientes sobre la escala de adicción a las redes sociales y una variable independiente de la escala de criterios de múltiples respuestas sobre compulsión en juegos de apuesta. Explica una posible estimación sobre las posibilidades del perfil de usuario para acotar las sesiones y terminar el consumo de bienes y servicios digitalizados por Internet y el aporte al impacto sobre el eje ambiental bajo la formulación: IR = CBMS (13) + BFAS (12-13) + DSM (3).

PI: Progresión del incremento: Es una variable cuantitativa, perteneciente al intervalo [0,1000], que relaciona a dos variables independientes de la escala de medición de compra compulsiva, tres variables independientes sobre la escala de adicción a las redes sociales, una variable independiente de la escala de criterios de múltiples respuestas sobre compulsión en juegos de apuesta y cuatro variables independientes sobre la escala de adicción a Internet. Explica una posible estimación sobre el avance del perfil de usuario en las cantidades de consumo de bienes y servicios digitalizados por Internet para alcanzar satisfacción y el aporte al impacto sobre el eje ambiental bajo la formulación: PI = CBMS (1-5) + BFAS (4-5-6) + DSM (2) + IAT (1-14-17-20).

PR: Preocupación recurrente: Es una variable cuantitativa, perteneciente al intervalo [0,1000], que relaciona a tres variables independientes de la escala de medición de compra compulsiva, dos variables independientes sobre la escala de adicción a las redes sociales, una variable independiente de la escala de criterios de múltiples respuestas sobre compulsión en juegos de apuesta y cuatro variables independientes sobre la escala de adicción a Internet. Explica una posible estimación sobre el pensamiento continuo de satisfacción que le produce al perfil de usuario el consumo de bienes y servicios digitalizados por Internet y el aporte al impacto sobre el eje ambiental bajo la formulación: PR = CBMS (4-6-10) + BFAS (1-2-3) + DSM (1) + IAT (7-11-15).

SBV: Servicios básicos de la vivienda: Es una variable cuantitativa, perteneciente al intervalo [100, 300], que relaciona a las independientes: Consumo de energía eléctrica de red (CEE), Consumo de gas natural de red, envasado o a granel (CGas) y Preferencia por el acceso a Internet (PAI). Explica una posible estimación sobre el conjunto de servicios básicos de la vivienda que habita el perfil de usuario y el aporte al impacto sobre el eje ambiental bajo la formulación: $\mathrm{SBV}=\mathrm{CEE}+\mathrm{CGas}+\mathrm{PAI}$.

TPP: Tiempo promedio de permanecía en el simulador: Es una variable cuantitativa, perteneciente al intervalo $[0,+\infty] \mathrm{e}$ indica el tiempo promedio de permanencia en el sistema software simulador que el perfil de usuario utilizó para desarrollar todas las actividades propuestas.

TR: Tendencia a la repetición: Es una variable cuantitativa, perteneciente al intervalo [0,300], que relaciona a una variable independiente de la escala de medición de compra 
compulsiva, una variable independiente de la escala de criterios de múltiples respuestas sobre compulsión en juegos de apuesta y una variable sobre la escala de adicción a Internet. Explica una posible estimación sobre las posibilidades del perfil de usuario para volver a consumir bienes y servicios digitalizados por Internet y el aporte al impacto sobre el eje ambiental bajo la formulación: TR = CBMS (2) + DSM (6) + IAT (16).

\section{c) Variables para el estudio del eje social}

Se consideran las siguientes variables independientes para el eje social:

AE: Actividad de esparcimiento emocional: Es una variable cualitativa e indica el aporte al impacto sobre el eje social considerando la frecuencia con que el perfil de usuario realiza actividad de esparcimiento emocional o artística. Los valores discretos de impacto son:

$\begin{array}{ll}\text { Nunca } & =100 \\ \text { Alguna vez } & =60 \\ \text { Frecuentemente } & =30 \\ \text { Siempre } & =0\end{array}$

AFi: Actividad física: Es una variable cualitativa e indica el aporte al impacto sobre el eje social considerando la frecuencia con que el perfil de usuario realiza actividad física. Los valores discretos de impacto son:
Nunca
$=100$
Alguna vez
$=60$
Frecuentemente
$=30$
Siempre
$=0$

$\mathrm{CH}$ : Cantidad de habitantes del hogar: Es una variable cualitativa e indica el aporte al impacto sobre el eje social en función de la cantidad de habitantes de la de vivienda que habita el perfil de usuario. Los valores discretos de impacto son:

$\begin{array}{ll}\text { Hasta } 4 \text { personas } & =25 \\ \text { De } 5 \text { a } 8 \text { personas } & =50 \\ \text { De } 9 \text { a } 12 \text { personas } & =75 \\ \text { Mas de } 12 \text { personas } & =100\end{array}$

CS: Cobertura de Salud: Es una variable cualitativa e indica el aporte al impacto sobre el eje social considerando la cobertura de salud del perfil de usuario. Los valores discretos de impacto son:

$\begin{array}{ll}\text { Obra social (incluye PAMI) } & =60 \\ \text { Prepaga } & =40 \\ \text { Planes estatales de salud } & =80\end{array}$

No tiene obra socia, prepaga o plan estatal $=100$

EC: Estado civil: Es una variable cualitativa e indica el aporte al impacto sobre el eje social considerando el estado civil del perfil de usuario. Los valores discretos de impacto son:
Soltero/a
$=20$
Casado/a
$=100$
Divorciado/a
$=40$
Separado/a legal
$=40$
Viudo/a
$=20$
Desconocido
$=0$

Edad: Es una variable cualitativa e indica el aporte al impacto sobre el eje social considerando la edad el perfil de usuario. Los valores discretos de impacto son:

Niños, niñas y adolescentes (de 0 a 17 años de edad)

$\begin{array}{ll}\text { Jóvenes (de } 18 \text { a } 29 \text { años) } & =100 \\ \text { Adultos (de 30 a } 64 \text { años) } & =75 \\ & =50\end{array}$

Adultos mayores (más de 65 años) $\quad=0$

F: Fecundidad: Es una variable cualitativa e indica el aporte al impacto sobre el eje social considerando la cantidad de hijos del perfil de usuario. Los valores discretos de impacto son:

$0 / 1 / 2 / 3 / 4 / 5 / 6 / 7 / 8 / 9 /$ más de $10=$ De 0 a 100 incrementando 10

GD: Grado de dependencias: Es una variable cualitativa e indica el aporte al impacto sobre el eje social considerando el grado de dependencias sobre sustancias que podrían afectar a la salud del perfil de usuario. Los valores discretos de impacto son:

$\begin{array}{ll}\text { Nunca } & =0 \\ \text { Alguna vez } & =30 \\ \text { Frecuentemente } & =60 \\ \text { Siempre } & =100\end{array}$

$\mathrm{N}$ : Nacionalidad: Es una variable cualitativa e indica el aporte al impacto sobre el eje social considerando la nacionalidad del perfil de usuario. Los valores discretos de impacto son:

$\begin{array}{ll}\text { Argentina } & =0 \\ \text { Boliviana } & =0 \\ \text { Chilena } & =0 \\ \text { Colombiana } & =0 \\ \text { Mexicana } & =0 \\ \text { Paraguaya } & =0 \\ \text { Peruana } & =0 \\ \text { Uruguaya } & =0 \\ \text { Venezolana } & =0 \\ \text { Otra } & =0\end{array}$

(Aportan impacto nulo persiguiendo el espíritu de igualdad ante la nacionalidad)

NF: Composición del núcleo familiar: Es una variable cualitativa e indica el aporte al impacto sobre el eje social en función de la estructura familiar del perfil de usuario. Los valores discretos de impacto son:

Unipersonal: Hogar constituido por una sola persona $=20$

No conyugal: Hogar constituido por: solo parientes no nucleares; solo no parientes; o la combinación de ambos $=40$

Hogar conyugal de familia completa nuclear: jefe/a del hogar y cónyuge, con presencia o no de hijos

$$
=60
$$

Hogar conyugal de familia completa extensa: jefe/a del hogar y cónyuge, con presencia o no de hijos y otros parientes $=100$

Hogar conyugal de familia monoparental nuclear: jefe/a del hogar con presencia de hijos $\quad=60$

Hogar conyugal de familia monoparental extensa: jefe/a del hogar con presencia de hijos y otros parientes

$$
=80
$$

Hogar conyugal de familia compuesta: constituida por una familia nuclear o extensa más otros no parientes del jefe del hogar $\quad=100$

Otra formación. $\quad=0$

SE: Situación educativa: Es una variable cualitativa e indica el aporte al impacto sobre el eje social en función de la educación en curso o alcanzada del perfil de usuario. Los valores discretos de impacto son:

$\begin{array}{ll}\text { Inicial (jardín) } & =100 \\ \text { Primario } & =80 \\ \text { EGB } & =60\end{array}$




$\begin{array}{ll}\text { Secundario } & =40 \\ \text { Polimodal } & =40 \\ \text { Superior no universitario } & =20 \\ \text { Universitario } & =20 \\ \text { Pos-Universitario } & =20 \\ \text { Ninguno } & =100\end{array}$

Sexo: Es una variable cualitativa e indica el aporte al impacto sobre el eje social considerando el sexo del perfil de usuario. Los valores discretos de impacto son:

Femenino

$=0$

Masculino

$=0$

(Aportan un impacto nulo persiguiendo el espíritu de igualdad de género)

Se consideran las siguientes variables dependientes para el eje social:

ARA: Afectación a la relaciones afectivas: Es una variable cuantitativa, perteneciente al intervalo [0,700], que relaciona a tres variables independientes sobre la escala de adicción a las redes sociales, dos variables independientes de la escala de criterios de múltiples respuestas sobre compulsión en juegos de apuesta y dos variables independientes sobre la escala de adicción a Internet. Explica una posible estimación sobre el deterioro de las relaciones afectivas del perfil de usuario debido al consumo de bienes y servicios digitalizados por Internet y el aporte al impacto sobre el eje social bajo la formulación: ARA = BFAS (14-15-16) + DSM (9-10) + IAT (4-5).

AS: Aspectos de salubridad: Es una variable cuantitativa, perteneciente al intervalo [40, 500], que relaciona a las independientes: Cobertura de salud (CS), Actividad física (AFi), Actividad de esparcimiento emocional (AE), Fecundidad (F) y Grado de dependencias (GD). Explica una posible estimación sobre el cuidado de la salud del perfil de usuario y el aporte al impacto sobre el eje social bajo la formulación: $\mathrm{AS}=\mathrm{CS}+\mathrm{AFi}+\mathrm{AE}+\mathrm{F}+\mathrm{GD}$.

CPA: Cantidad de accesos al simulador: Es una variable cuantitativa, perteneciente al intervalo $[0,+\infty]$ e indica la cantidad de veces que el perfil de usuario accedió al sistema software simulador para desarrollar todas las actividades propuestas.

EV: Escape de la vida: Es una variable cuantitativa, perteneciente al intervalo [0,1000], que relaciona a una variable independiente de la escala de medición de compra compulsiva, tres variables independientes sobre la escala de adicción a las redes sociales, una variable independiente de la escala de criterios de múltiples respuestas sobre compulsión en juegos de apuesta y cinco variables independientes sobre la escala de adicción a Internet. Explica una posible estimación sobre la necesidad de consumir bienes y servicios digitalizados por Internet para olvidad las situaciones reales de la vida del perfil de usuario y el aporte al impacto sobre el eje social bajo la formulación: $\mathrm{EV}=\mathrm{CBMS}(3)+\mathrm{BFAS}(7-8-9)+\mathrm{DSM}$ (5) + IAT (2-3-10-12-19).

$\mathrm{H}$ : Hogar y Educación: Es una variable cuantitativa, perteneciente al intervalo [45, 300], que relaciona a las independientes: Núcleo familiar (NF), Cantidad de habitantes del hogar $(\mathrm{CH})$ y Situación educativa (SE). Explica una posible estimación sobre aspectos del hogar y la educación en curso o cursada por el perfil de usuario y el aporte al impacto sobre el eje social bajo la formulación: $\mathrm{H}$ $=\mathrm{NF}+\mathrm{CH}+\mathrm{SE}$
IS: Impacto social: Es una variable cuantitativa, perteneciente al intervalo $[0,+\infty]$, que relaciona al conjunto de variables dependientes del eje social a fin de obtener una posible estimación del impacto social por el consumo de bienes y servicios digitalizados por Internet del perfil de usuario bajo la formulación: $\mathrm{IS}=\mathrm{SP}+\mathrm{AS}+\mathrm{H}+\mathrm{CPA}+\mathrm{PC}+\mathrm{EV}$ $+\mathrm{TO}+\mathrm{ARA}$.

PC: Pérdida de control: Es una variable cuantitativa, perteneciente al intervalo $[0,800]$, que relaciona a dos variables independientes de la escala de medición de compra compulsiva, dos variables independientes sobre la escala de adicción a las redes sociales, una variable independiente de la escala de criterios de múltiples respuestas sobre compulsión en juegos de apuesta y tres variables independientes sobre la escala de adicción a Internet. Explica una posible estimación sobre la imposibilidad del perfil de usuario para mantener acotado el consumo de bienes y servicios digitalizados por Internet y el aporte al impacto sobre el eje social bajo la formulación: $\mathrm{PC}=$ CBMS (8-9) + BFAS (10-11) + DSM (4) + IAT (6-8-13)

SP: Situación poblacional: Es una variable cuantitativa, perteneciente al intervalo [0, 200], que relaciona a las independientes: Edad (Edad), Sexo (Sexo), Estado civil (EC) y Nacionalidad (N). Explica las posibles características poblacionales del perfil de usuario y el aporte al impacto sobre el eje social bajo la formulación: $\mathrm{SP}=\mathrm{Edad}+\mathrm{Sexo}+\mathrm{EC}+\mathrm{N}$.

TO: Tendencia al ocultamiento: Es una variable cuantitativa, perteneciente al intervalo [0,400], que relaciona a una variable independiente de la escala de medición de compra compulsiva, una variable independiente de la escala de criterios de múltiples respuestas sobre compulsión en juegos de apuesta y dos variables independientes sobre la escala de adicción a Internet. Explica una posible estimación sobre la actividad en secreto del perfil de usuario para consumir bienes y servicios digitalizados por Internet y el aporte al impacto sobre el eje social bajo la formulación: TO = CBMS (7) + DSM (7) + IAT (9-18).

2) Grupo de experimentos

Se ejecutaron tres pruebas sobre el banco tecnológico desarrollado para tal fin. Con cada una se obtuvo una muestra simulada de diez mil perfiles de usuario de Internet y el consumo de bienes y servicios digitalizados, asegurando el mejoramiento de la calidad de la información con herramientas de análisis estadístico de datos.

Para la primera prueba se aplicó el método de simulación Montecarlo $[164 ; 165]$ a fin de obtener conductas completamente aleatorias sobre perfiles de usuario de Internet. Los datos de comprobación estadísticos argumentaban la necesidad de mejorar la muestra obtenida.

Para aproximarse a la realidad, se complementó la aleatoriedad del método de simulación Montecarlo [164; 165] con información que permitiera delinear la conducta humana y se ejecutó la segunda prueba. Se comprobó entonces una mejora en la estadística de la muestra resultante de perfiles de usuario y afirmó la hipótesis sobre la optimización de la calidad de los resultados con información de mayor fundamento. Para el desarrollo de esta prueba se utilizó la subjetividad del modelador, sesgando los resultados, pero avanzando hacia la mejora de la muestra. 
En la última prueba se tomó como base lo preparado en la simulación por el método de Montecarlo humanizado (del segundo experimento), y se adicionó información obtenida de diferentes fuentes de estudio económico, ambiental y social, acerca de la realidad en una sociedad particular (la República Argentina) más otros comportamientos referidos a los usurarios de Internet (los detalles de la cuantificación de cada variable del modelo conceptual de impacto de consumo se explica en profundidad en la sección 4: Solución propuesta del presente escrito).

Al avanzar en los experimentos y desarrollar la tercera y última prueba para obtener la muestra de perfiles de usuario de Internet con método de Montecarlo sociabilizado, se consiguieron datos aproximados a la conducta de una sociedad sobre el consumo de bienes y servicios digitalizados por la red. Se comprobó con una herramienta de análisis de datos que la regresión lineal múltiple $[167 ; 168 ; 169]$ de las variables cuantificadas del modelo de impacto de consumo se valían de ajuste a la probabilidad normal.

Al obtener cuantificadas cada una de las variables independientes del modelo y por tal las dependientes, se continuó hacia el desarrollo de las diferentes gráficas por variable para su interpretación.

\section{Gráficas e interpretaciones}

Se exponen las gráficas e interpretaciones sobre el conjunto de perfiles de usuario obtenidos con el método de simulación de Montecarlo sociabilizado y se analiza el posible impacto de modo independiente sobre los ejes: económico (sub-sección 1), ambiental (sub-sección 2) y social (sub-sección 3).

\section{1) Análisis sobre el eje económico}

Se presentan gráficas e interpretaciones sobre el conjunto de variables independientes y dependientes seleccionadas para estudiar el eje económico. Se comienza por el impacto sobre el eje y la variable de consumo (sub-sección $a$ ) para continuar con la estimación del estado de resultados (sub-sección $b$ ). Sigue la estimación sobre el estado patrimonial (sub-sección $c$ ), la condición de ocupación (sub-sección $d$ ), la preferencia por las compras (sub-sección e) y los criterios de ahogo financiero y comisión de actos ilegales (sub-sección $f$ ).

a) Impacto sobre el eje económico y la variable de consumo

En esta sub-sección se analizará el impacto económico (IE) y una variable cuantitativa que indica la cantidad acumulada de puntos que el perfil de usuario utilizó para acceder a los bienes y servicios (PSU).

La cuantificación del impacto económico es función de sus variables dependientes de forma que: $\mathrm{IE}=\mathrm{EER}+\mathrm{EPN}+\mathrm{PSU}$ $+\mathrm{COa}+\mathrm{PCo}+\mathrm{AF}+\mathrm{CAI}$. La gráfica de la curva (IE), se presenta en la Figura 8 "Curva de impacto económico y cantidad de consumo".

El aspecto de la curva de impacto económico (IE) se encuentra influenciado por la actividad del perfil dentro del sistema software simulador al momento de consumir bienes y servicios digitalizados. Esto se expresa en puntos por consumo de contenidos (PSU) que afectan al impacto económico más que cualquier otro sumando. La relación entre el impacto económico (IE) y los puntos por consumo de contenidos (PSU) podría sostener la hipótesis que es esta quien aporta mayor influencia que las complementarias a la formulación. El resto de las dependientes que cuantifican al eje económico presentan una escala de impacto relativamente menor que los puntos por consumo de contenidos (PSU), pero podrían explicar alguna tendencia sobre el conjunto de perfiles de usuario.

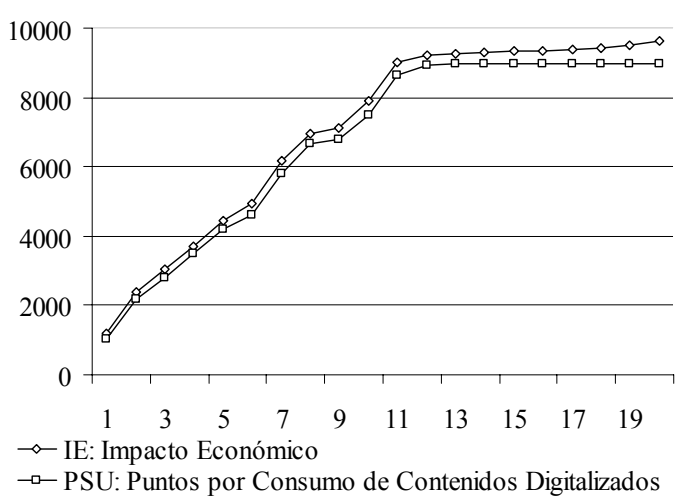

Fig. 8. Curva de valor de impacto económico y valor de impacto por consumo de contenidos digitalizados en el sistema software simulador. (Promedio de a 500 perfiles de usuario, valor de impacto)

\section{b) Estimación del estado de resultados}

En esta sub-sección se analizará la estimación del estado de resultados individual (ERR) de la muestra de perfiles de usuario de Internet. Se consideran las variables de ingreso total individual (ITI) y egreso total individual (ETI) para un mismo período de tiempo. La curva de impacto por ingreso (ITI) crece a medida que el perfil de usuario percibe menos ingresos. Tiende a cero cuando los ingresos individuales son altos. El impacto por egresos (ETI) aumenta cuando los egresos individuales se encuentran en bajada. Decrece cuando los gastos están en alza.

La cuantificación del estado de resultados podría formularse como: EER = ITI - ETI, y la curva resultante del impacto de la estimación del estado de resultados promedio (EER) se presenta en Figura 9 "Curva de impacto por el estado de resultados".

La curva de estimación de estado de resultados (EER) se presenta creciente y podría indicar que la muestra de perfiles percibe ingresos en caída y gasta en aumento.

Se presenta en la Figura 10 "Curva de impacto aportado por ingreso y egreso individual" que el impacto de ingreso medio (ITI) supera al impacto de gasto medio (ETI) y podría sostener la hipótesis que en términos de impacto sobre el eje económico, los egresos tienden a superan a los ingresos. El descalce podría explicarse evaluando el estado de deudas y acreencias.

En esta sub-sección se analizará la estimación del estado patrimonial individual (EPN) de la muestra de perfiles de usuario de Internet. Se consideran las variables de impacto sobre el eje económico por la estimación de activos (EA) e impacto por la estimación de pasivos (EP). Para la estimación de activos (EA) el impacto aumenta a medida que la estimación decrece. Si el conjunto de bienes y derechos propios es alto, el impacto tiende a cero. En la estimación de pasivos (EP) el impacto aumenta a medida que las deudas son bajas. Si el pasivo es alto, el impacto tiende a cero.

La estimación del patrimonio neto individual se formula como: $\mathrm{EPN}=\mathrm{EA}-\mathrm{EP}$. Los términos de estimación de activo individual (EA) y estimación de pasivo individual (EP) podrían dar lugar a la interpretación económica de cada perfil de usuario de la muestra. La curva resultante se presenta en la 
Figura 11 "Curva impacto por la estimación del estado patrimonial".

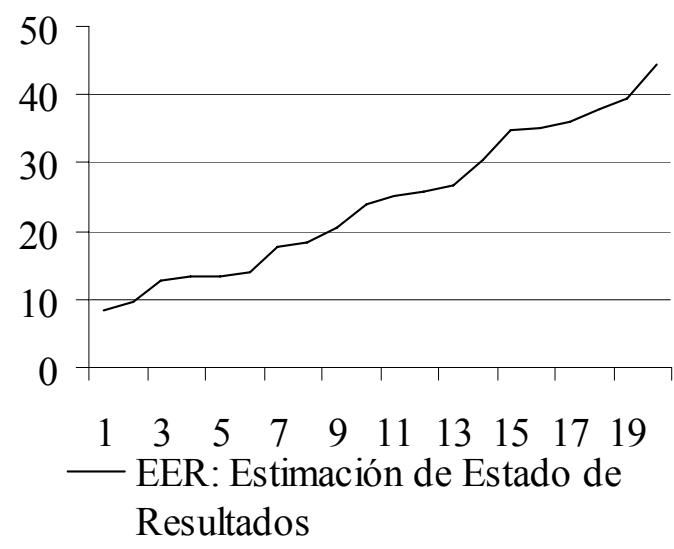

Fig. 9. Curva de valor de impacto aportado por la estimación individual del estado de resultados. (Promedio de a 500 perfiles de usuario, valor de impacto)

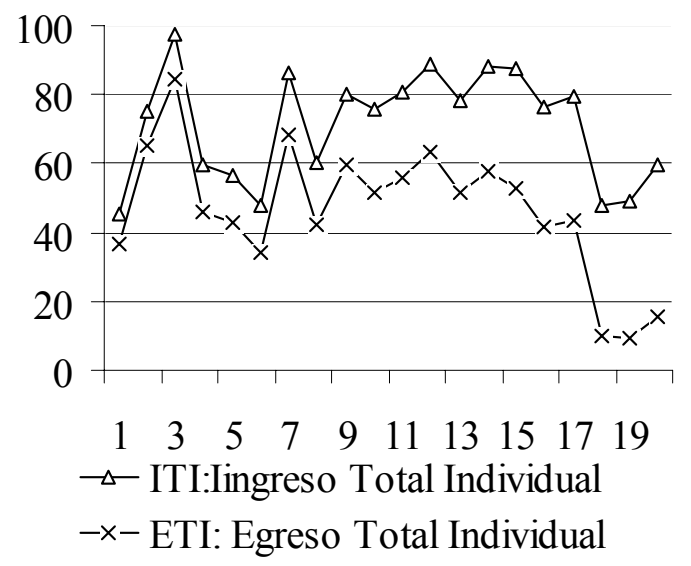

Fig. 10. Curvas de valor de impacto aportado por el ingreso y egreso individual. (Promedio de a 500 perfiles de usuario, valor de impacto)

\section{c) Estimación del estado patrimonial}

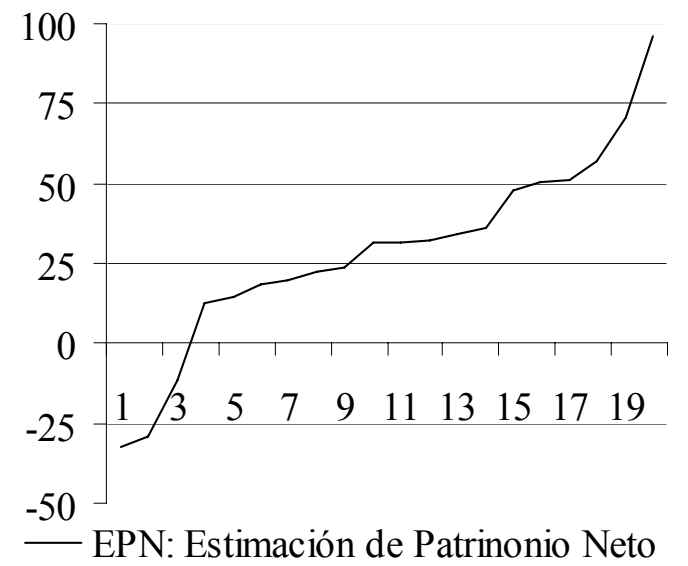

Fig. 11. Curva de valor de impacto aportado por la estimación del estado patrimonial. (Promedio de a 500 perfiles de usuario, valor de impacto)

La curva de estimación del estado patrimonial (EPN) se presenta creciente, desde valores negativos y podría explicar que una cantidad media de perfiles de usuario pasa de disponer algunos bienes y pocas deudas a tomar mayores deudas que conjunto de acreencias.

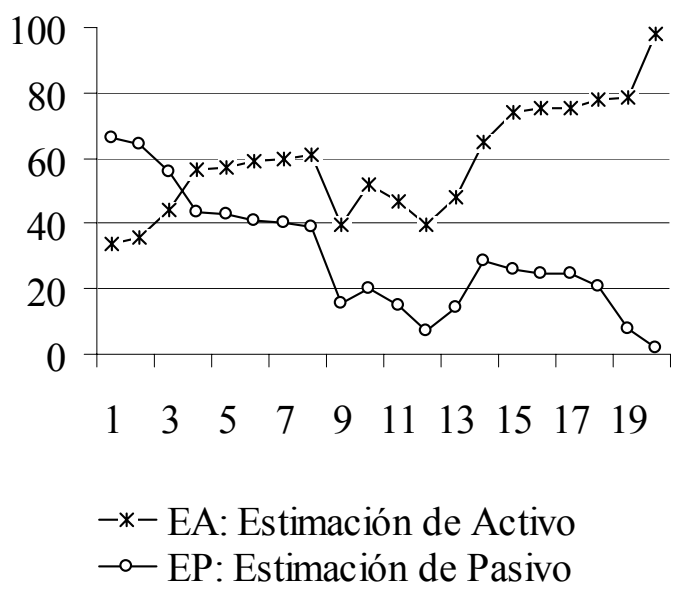

Fig. 12. Curvas de valor de impacto aportado por la estimación de activo y pasivo individual. (Promedio de a 500 perfiles de usuario, valor de impacto)

Al analizar las curvas de las variables independientes se presentan con pendientes inversas según la Figura 12 "Curvas de impacto aportado por la estimación de activo y pasivo individual". Cuando la estimación de pasivo (EP) se encuentra por encima de la estimación de activo (EA) el impacto sobre el eje económico es menor, pudiendo argumentar, en términos de impacto, que un conjunto de perfiles de usuario cuantifica activos mayores que deudas. En el punto donde las curvas se intersectan comienza el cambio de tendencia hacia la inversa. Cuando la estimación de activo (EA) se encuentra por encima de la estimación de pasivo (EP), en términos del impacto, el conjunto de bienes y derechos propios es bajo y el conjunto de deudas es alto.

Las curvas presentadas hasta aquí podrían evidenciar que la muestra de perfiles de usuario presenta patrones alterados sobre el estado de resultados y patrimonial. La evaluación de la actividad que genera su economía podría explicar la situación.

\section{d) Condición de ocupación}

En esta sub-sección se analizará la condición de ocupación (COa) de la muestra de perfiles de usuario de Internet. Se consideran las variables de impacto sobre el eje económico aportado por la condición de actividad económica (CAE), de la población económicamente activa, que aumenta a medida que la actividad laboral decae. Si además de trabajar percibe jubilación o pensión el impacto tiende a cero. La curva de categoría de desocupación $(\mathrm{CdO})$ representa a la población que siendo económicamente activa, se encuentra desocupada. El impacto sobre el eje económico disminuye si el perfil de usuario percibe jubilación o pensión, en otro caso aumenta. La condición de ocupación de la población económicamente no activa (COna) aumenta el impacto cuando el perfil de usuario no realiza actividad y lo disminuye en los casos de recibir jubilación o pensión.

La formulación sobre la condición de ocupación se da por: $\mathrm{COa}=\mathrm{CAE}+\mathrm{COna}+\mathrm{CdO}$ e intenta explicar con sus términos, las diferentes posibilidades en las que se encuentra cada perfil de usuario respecto a la actividad laboral o no laboral. La curva resultante se presenta en la Figura 13“Curva de impacto por la condición de ocupación”. 


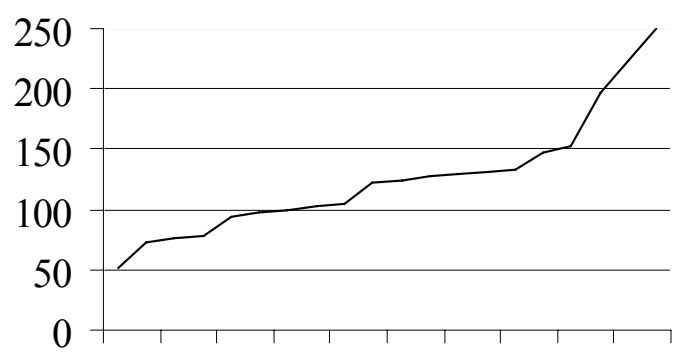

$\begin{array}{llllllllll}1 & 3 & 5 & 7 & 9 & 11 & 13 & 15 & 17 & 19\end{array}$

\section{- COa: Condición de Ocupación de la Población}

Fig. 13. Curva de valor de impacto aportado por la condición de ocupación de la población. (Promedio de a 500 perfiles de usuario, valor de impacto)

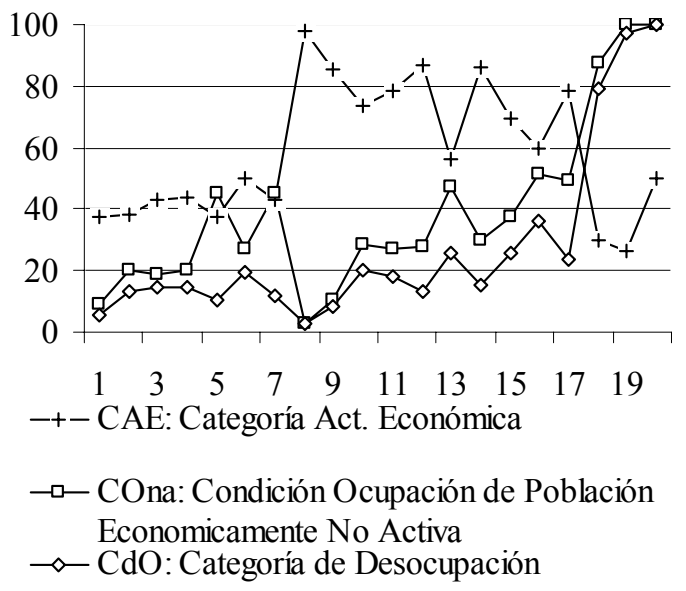

Fig. 14. Curvas de valor de impacto aportado por la estimación de categoría de actividad económica, la condición de ocupación de la población económicamente no activa y la categoría de desocupación. (Promedio de a 500 perfiles de usuario, valor de impacto)

La gráfica de la curva de condición de ocupación (COa) se presenta de tendencia lineal y creciente. La mayor aportación es dada por la categoría de actividad económica media (CAE) indicando, que gran parte de la muestra de perfiles de usuario trabaja y recibe algo a cambio por su labor. En uno de los extremos, la curva pierde la condición de meseta y crece con pendiente pronunciada, lo que podría representar que el impacto sobre el eje económico aumenta cuando los perfiles de usuario formen parte de la población económicamente no activa o se encuentran desocupados.

$\mathrm{Al}$ analizar las curvas de las variables independientes según la Figura 14 "Curvas de impacto aportado por la estimación de categoría de actividad económica, condición de ocupación y categoría de desocupación" se podría considerar que las curvas de condición de ocupación de la población económicamente no activa (COna) y categoría de desocupación $(\mathrm{CdO})$ presentan una figura similar y crecen superando a la categoría de actividad económica (CAE) cuando esta decrece. El punto de intersección podría indicar la cantidad donde la media de perfiles de usuario de la muestra baja la producción de actividad económica y pasa a categorías donde el impacto económico por el consumo de bienes y servicios digitalizados afecta en un grado mayor. Algunos aspectos sobre la comercialización podrían aumentar el entendimiento sobre esta hipótesis.

\section{e) Preferencia por las compras}

En esta sub-sección se analizará la preferencia por las compras (PCo) de la muestra de perfiles de usuario de Internet. Se consideran las variables de impacto sobre el eje referidas al modo de acceso a los bienes y servicios digitalizados (ABS) y la modalidad más utilizada para pago en comercio electrónico (MPPE). El modo de acceso a los bienes y servicios digitalizados (ABS) aumenta el impacto económico cuando se utilizan medios también digitalizados y tienden a cero cuando se trata de otros medios de acceso no relacionados con Internet. La curva referida a la modalidad más utilizada para pago en comercio electrónico (MPPE) produce mayor impacto económico por orden de liquidez. Las modalidades más liquidas afectan más que las menos líquidas.

La preferencia por las compras en comercio electrónico se formula como: $\mathrm{PCo}=\mathrm{MPPE}+\mathrm{ABS}$ y podría introducir aspectos relacionados al acceso a bienes y servicios digitalizados por Internet y la modalidad preferida por la muestra de usuarios para su adquisición. La curva resultante se presenta en la Figura 15 "Curva de impacto por la preferencia de compra".

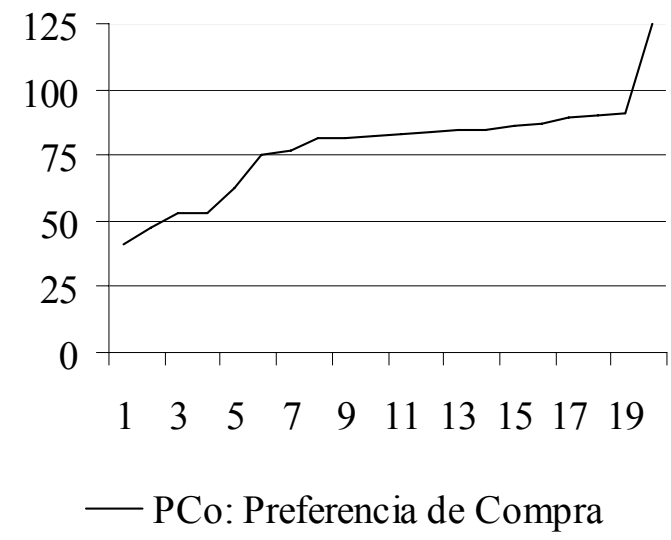

Fig. 15. Curva de valor de impacto aportado por la preferencia de compra. (Promedio de a 500 perfiles de usuario, valor de impacto)

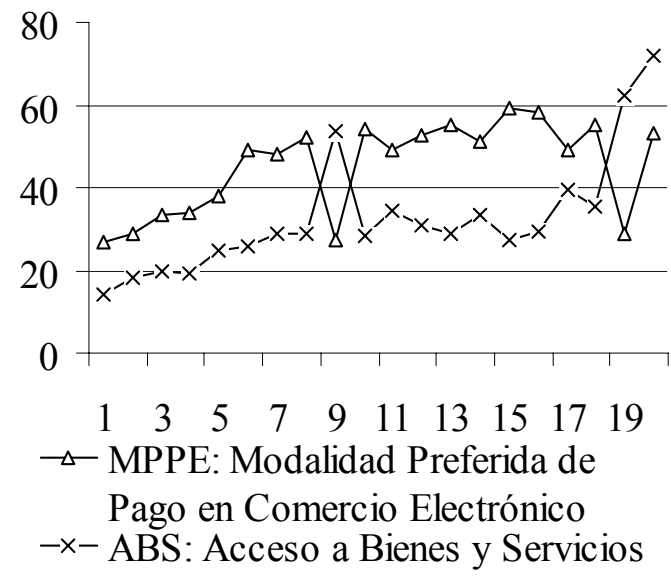

Fig. 16. Curvas de valor de impacto aportado por la modalidad preferida de pago en comercio electrónico y el acceso a bienes y servicios. (Promedio de a 500 perfiles de usuario, valor de impacto)

La curva que representa la preferencia por las compras (PCo) se muestra creciente y con dos saltos relevantes, 
pudiendo sostener la hipótesis que entre los saltos, la media de perfiles de usuario accede y adquiere contenidos digitalizados por Internet por canales y medios de pago similares.

$\mathrm{Al}$ analizar las curvas de las variables independientes según la Figura 16 "Curvas de impacto por la modalidad preferida de pago y acceso a bienes y servicios" se podría considerar que el aspecto de las curvas se presenta similar. Las modalidades preferidas para pagos devenidos del comercio electrónico (MPPE) superan, en términos de impacto, al modo de acceso a los bienes y servicios (ABS). El punto donde se produce el cambio de tendencia podría indicar que el acceso a contenidos adquiridos se realiza por Internet, pero el pago de las operaciones se realiza también en otros medios físicos complementando al dinero electrónico. Las facilidades de acceso y el dinero virtual podrían incrementar las afectaciones económicas y hasta legales por el ejercicio excesivo del comercio electrónico.

\section{f) Ahogo financiero y comisión de actos ilegales}

En esta sub-sección se analizarán los criterios referidos al ahogo financiero (AF) y la comisión de actos ilegales (CAI) sobre de la muestra de perfiles de usuario de Internet.

La variable dependiente que mide el impacto por el ahogo financiero se formula como: $\mathrm{AF}=\mathrm{CBMS}(11-12)$ y refiere a la imposibilidad de afrontar pagos por el exceso en las compras. La comisión de actos ilegales se da por: CAI = DSM (8) y explica la voluntad de delinquir para conseguir dinero y consumir bienes y servicios digitalizados. Las curvas se presentan en la Figura 17 "Curva de impacto por el ahogo financiero y comisión de actos ilegales".

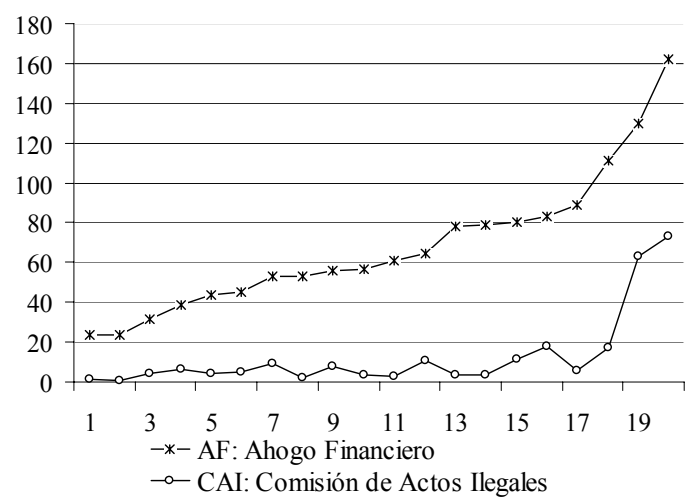

Fig. 17. Curva de valor de impacto por ahogo financiero y valor de impacto por comisión de actos ilegales. (Promedio de a 500 perfiles de usuario, valor de impacto)

En términos de impacto sobre el eje económico, el ahogo financiero (AF) se muestra creciente para la muestra de perfiles de usuario, pudiendo colaborar al efecto los medios de pago y las posibilidades crediticias brindadas por el sistema bancario. Esto podría sostener una hipótesis referida al aumento sobre el consumo, hasta el ahogo, debido a las posibilidades crediticias y el dinero virtual.

La comisión de actos ilegales (CAI) se presenta, para la media de perfiles de usuario, con bajo impacto. Sobre el final, la curva se eleva y podría indicar que los pocos perfiles de usuario que llegan hasta el extremo de cometer actos delictivos, afrontan un fuerte impacto económico por el consumo de bienes y servicios digitalizados por Internet.

\section{2) Análisis sobre el eje ambiental}

Se presentan gráficas e interpretaciones sobre el conjunto de variables independientes y dependientes seleccionadas para estudiar el eje ambiental. Se comienza por el impacto sobre el eje y la variable de permanencia (sub-sección $a$ ) para continuar con las características de la vivienda (sub-sección $b$ ), la estimación sobre los servicios básicos de la misma (subsección $c$ ) y el aporte al desgaste ambiental (sub-sección $d$ ). Le sigue el criterio de preocupación recurrente (sub-sección $e$ ), el de progresión del incremento (sub-sección f), el de intención de retiro (sub-sección $g$ ) y el de tendencia la repetición (subsección $h)$.

a) Impacto sobre el eje ambiental y la variable de permanencia

En esta sub-sección se analizará el impacto ambiental (IA) y una variable cuantitativa que indica la cantidad de tiempo promedio de permanencia del perfil de usuario en el sistema software simulador (TPP), para consumir bienes y servicios digitalizados.

La cuantificación del impacto ambiental es función de sus variables dependientes de forma que: $\mathrm{IA}=\mathrm{CaV}+\mathrm{SBV}+\mathrm{ADA}$ $+\mathrm{TPP}+\mathrm{PR}+\mathrm{PI}+\mathrm{IR}+\mathrm{TR}$. La gráfica de la curva (IA) se presenta en la Figura 18 "Curva de impacto ambiental y tiempo de permanencia".

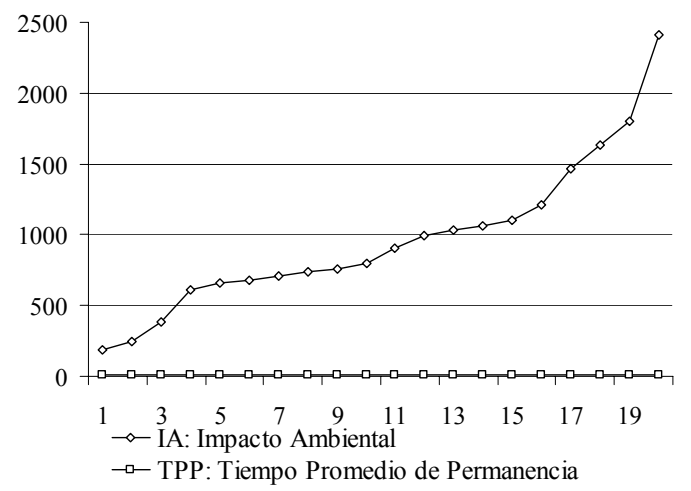

Fig. 18. Curva de valor de impacto ambiental y valor de impacto por tiempo de permanencia en sistema software simulador. (Promedio de a 500 perfiles de usuario, valor de impacto)

Las magnitudes que le dan aspecto a la gráfica del impacto ambiental (IA) podrían argumentar que no se encuentra influenciada por alguna variable dependiente particular, sino por todos los sumandos. No se reconoce una relación con el tiempo promedio de permanencia en sistema (TPP) dado que se presenta despreciable en términos cuantitativos sobre el impacto ambiental.

El análisis del resto de las variables dependientes que cuantifican al eje ambiental podría explicar alguna tendencia sobre el conjunto de la muestra.

\section{b) Características de la vivienda}

En esta sub-sección se analizarán las características de la vivienda $(\mathrm{CaV})$ que habita el perfil de usuario de Internet. Se consideran las variables de conexión a la red cloacal (C), procedencia del agua (PA), características constructivas (CC), tipo de vivienda (TV) y ubicación geográfica (UG) de la vivienda. La curva de conexión a la red cloacal (C) alcanza su máximo impacto si la vivienda no se encuentra conectada a esa red. Tiende a cero cuando se encuentra conectada a la red cloacal. La curva de procedencia del agua (PA) aumenta los valores de impacto si la vivienda no se encuentra conectada a la red de agua potable. Decrece cuando se encuentra conectada a la red de agua potable. El impacto aportado por las características constructivas de la vivienda (dado por la curva: 
CC) aumenta cuando se trata de materiales poco convencionales o precarios y disminuye cuando es cemento y / o ladrillo. El tipo de vivienda (TV) podría explicar la condición habitacional del perfil de usuario. El impacto sobre el eje ambiental aumenta a medida que disminuye el espacio. De modo inverso cuando las condiciones dadas por el tipo de vivienda se optimizan el impacto tiende a cero. La curva de ubicación geográfica (UG) alcanza su máximo impacto si la vivienda se encuentra ubicada en áreas urbanas. Tiende a cero cuando se trata de zonas rurales o dispersas.

Al considerar la característica de la vivienda del perfil de usuario se llega a la ecuación dada por: $\mathrm{CaV}=\mathrm{C}+\mathrm{PA}+\mathrm{CC}+$ $\mathrm{TV}+\mathrm{UG}$. La curva resultante se presenta en la Figura 19 "Curva de impacto por las características de la vivienda".

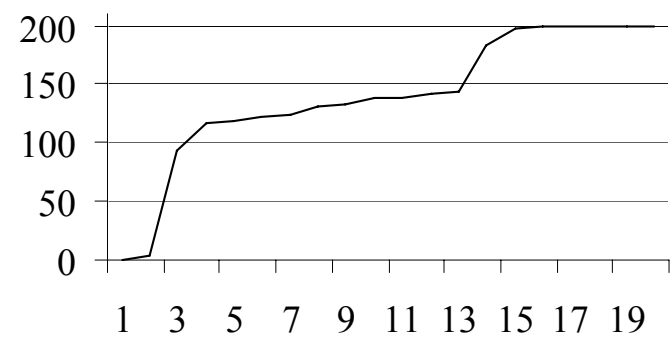

\section{- $\mathrm{CaV}$ : Caracterísiticas de la Vivienda}

Fig. 19. Curva de valor de impacto aportado por las características de la vivienda. (Promedio de a 500 perfiles de usuario, valor de impacto)

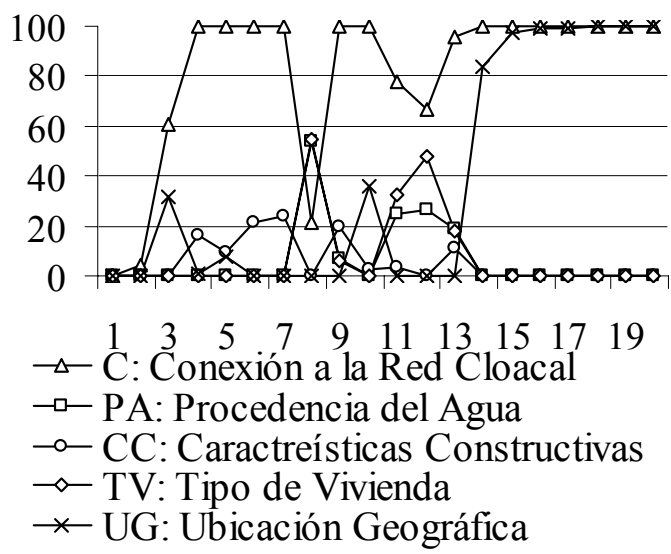

Fig. 20. Curvas de valor de impacto aportado por la conexión a la red cloacal, la procedencia del agua, las características constructivas, el tipo de vivienda y la ubicación geográfica. (Promedio de a 500 perfiles de usuario, valor de impacto)

La gráfica de la curva de características de la vivienda $(\mathrm{CaV})$ se presenta con dos pronunciados saltos y podría sostener la hipótesis de existencia de tres segmentos de perfil de usuario: bajo, medio y alto impacto por las características de la vivienda que habitan.

Al analizar las curvas de las variables independientes según la Figura 20 "Curvas de impacto aportado por la conexión a la red cloacal, la procedencia del agua, características constructivas, tipo de vivienda y la ubicación geográfica" se observa que la conexión a la red cloacal (C) es la variable que presenta mayor aporte a su dependiente e indica que la mayoría de las viviendas de los perfiles de usuario no se encuentran conectadas a la red cloacal. La procedencia del agua (PA) se mantiene cercana al cero para la media de perfiles y muestra dos saltos poco relevantes pudiendo argumentar que la mayoría de las viviendas disponen de agua potable de red.

Las características constructivas (CC) se cuantifica de bajo impacto indicando la posibilidad que la muestra de perfiles de usuario habiten hogares con mayor cantidad de materiales a base de ladrillo y cemento. El tipo de vivienda (TV) se mantiene cercana a cero y podría sostener que la mayoría de la muestra habita casa o departamento. La ubicación geográfica (UG) se mantiene cercana a cero y alcanza picos de impacto medio. Sobre el final crece hasta el valor máximo posible. En este caso se trata de una media de población ciudadana. En los perfiles donde la curva presenta bajo impacto, podría interpretarse que se trata de una población ubicada en centros poco rurales o de baja concentración urbana.

La observación de otras facilidades de la vivienda, que representen impacto sobre el eje ambiental, podría mejorar el conjunto de interpretaciones.

\section{c) Servicios básicos de la vivienda}

En esta sub-sección se analizarán los servicios básicos de la vivienda $(\mathrm{CaV})$ que habita el perfil de usuario de Internet. Se consideran las variables de preferencia de acceso a Internet (PAI), estimación de consumo de gas (CGas) y estimación de consumo de energía eléctrica de red (CEE). La estimación sobre la preferencia de acceso a Internet (PAI) presenta la posibilidad de conocer el motivo por el cual el perfil de usuario utiliza la red. La curva presenta mayor impacto cuando se trata de motivos que afectan a la personalidad de modo que el tiempo de conexión no logra ser del todo controlado por el perfil de usuario. Tiende a cero a medida que los motivos no producen afecciones sino representan a Internet como una herramienta o una posibilidad de acceso a la información. La curva de impacto de la estimación de consumo de gas (CGas) contempla el natural de red, el envasado o a granel. Aumenta a medida que la cantidad de bocas de consumo crece para la vivienda. Disminuye con menor cantidad de aparatos de consumo de gas. La estimación de consumo de energía eléctrica de red (CEE) crece en función de la cantidad de aparatos conectados aumentando el consumo. Tiende a cero cuando la cantidad de aparatos también.

La estimación de los servicios básicos de la vivienda se formula como: $\mathrm{SBV}=\mathrm{PAI}+\mathrm{CGas}+\mathrm{CEE}$. La curva resultante se presenta en la Figura 21 "Curva de impacto por los servicios básicos de la vivienda".

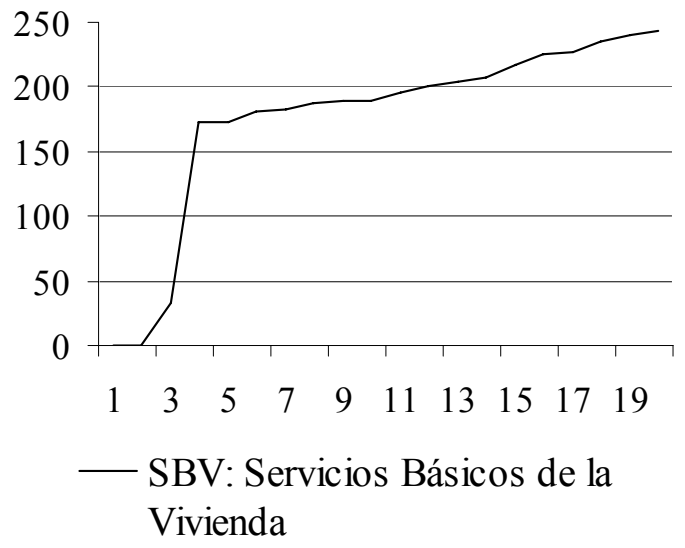

Fig. 21. Curva de valor de impacto aportado por los servicios básicos de la vivienda. (Promedio de a 500 perfiles de usuario, valor de impacto) 


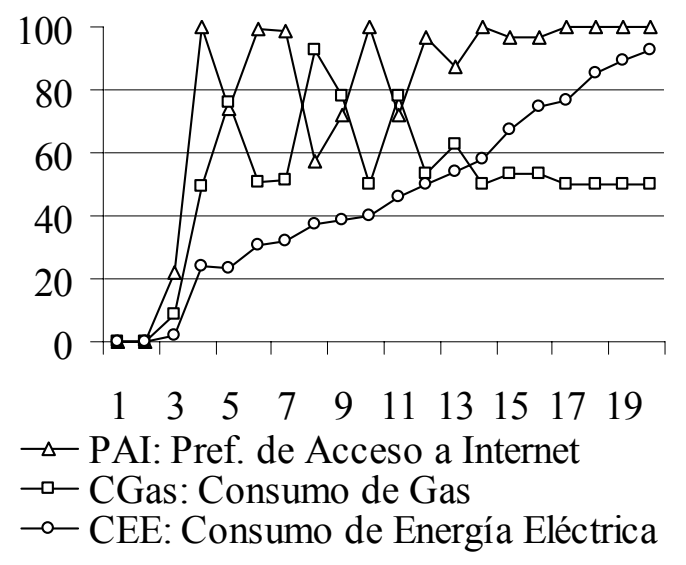

Fig. 22. Curvas de valor de impacto aportado por la preferencia por el acceso a Internet, consumo de gas y consumo de energía eléctrica de la vivienda. (Promedio de a 500 perfiles de usuario, valor de impacto)

La curva resultante de los servicios básicos de la vivienda (SVB) se presenta creciente en términos de impacto, acompañando al crecimiento del consumo de gas y la preferencia por el acceso a Internet. Luego toma forma de meseta y podría explicar que la mayoría de la media de perfiles de usuario dispone de un conjunto de consumos que impactan de modo similar al ambiente. El complemento de los perfiles de usuario no dispone del mismo nivel de servicios básicos.

Al analizar las curvas de las variables independientes según la Figura 22 "Curvas de impacto por la preferencia por acceso a Internet, consumo de gas y consumo de energía eléctrica" se presenta a la curva de consumo de energía eléctrica (CEE) lineal y creciente, superando en términos de impacto al consumo de gas (CGas) pudiendo indicar que desde ese punto de intersección, la cantidad de aparatos conectados a la red de energía eléctrica supera a los conectados al gas para las viviendas. La imagen que presenta la preferencia por el acceso a Internet (PAI) para la media de perfiles de usuarios aporta el mayor impacto a su variable dependiente siendo probable que la muestra se encuentre conectada a Internet durante gran parte de un día por razones relacionadas con el escape, la desinhibición o el anonimato.

Las relaciones presentadas entre variables hasta aquí, intentan perfilar las condiciones habitacionales y serviciales en que los perfiles de usuarios ejercen el consumo de bienes y servicios digitalizados. Podría apoyar a la interpretación la frecuencia de consumo de los bienes de carácter físico y el modo de traslado hacia los mismos.

\section{d) Aporte al desgaste ambiental}

En esta sub-sección se analizarán el aporte al desgaste ambiental (ADA) de la muestra de perfiles de usuario de Internet. Se consideran las variables de preferencia de consumo de productos y servicios no digitalizados (CPS) y la utilización habitual de medios de transporte (UMT). La curva de consumo de productos y servicios no digitalizados (CPS) representa la frecuencia con que la media de perfiles de usuario adquiere productos o servicios no digitalizados pero accesibles por comercio electrónico. El impacto sobre el eje ambiental aumenta a medida que siempre o muchas veces produce este comercio. La curva de impacto disminuye si el perfil de usuario aumenta el consumo de bienes y servicios digitalizados en reemplazo de los físicos. La utilización habitual de medio de transporte (UMT) podría indicar mayor aporte al desgaste ambiental cuando la media de perfiles de usuario utiliza automóviles particulares para el transporte y lo disminuye a medida que viaja por el transporte público o con otros medios no contaminantes.

La formulación del aporte al desgaste ambiental se da por: $\mathrm{ADA}=\mathrm{CPS}+\mathrm{UMT}$. La curva resultante se presenta en la Figura 23 "Curva de impacto por el aporte al desgaste ambiental".

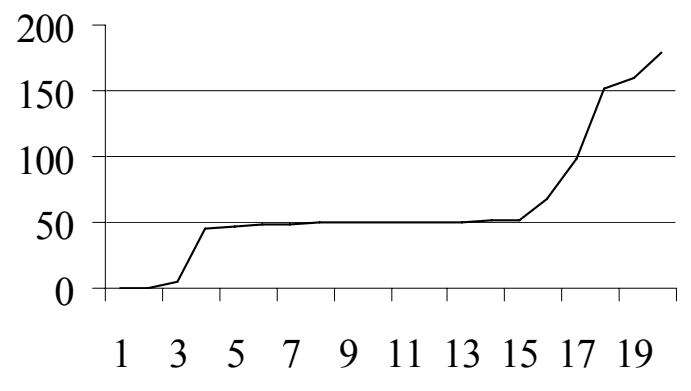

- ADA: Aporte al Desgaste Ambiental

Fig. 23. Curva de valor de impacto por el aporte al desgaste ambiental. (Promedio de a 500 perfiles de usuario, valor de impacto)

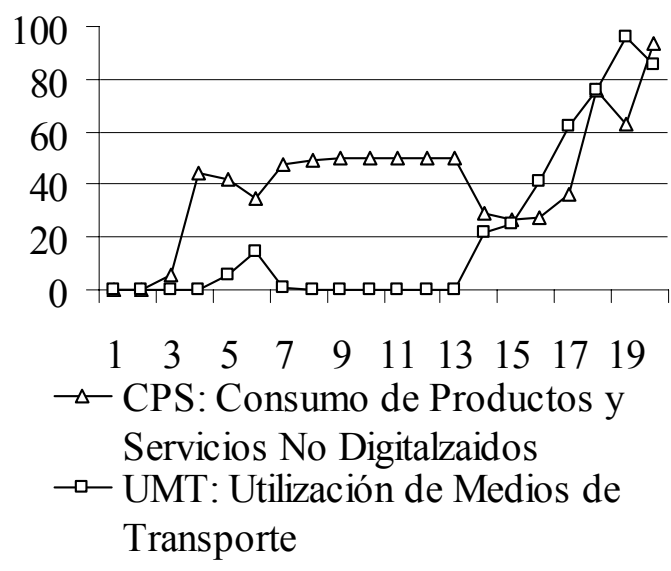

Fig. 24. Curvas de valor de impacto aportado por el consumo de productos y servicios no digitalizados y la utilización de medios de transporte.

(Promedio de a 500 perfiles de usuario, valor de impacto)

La gráfica de aporte al desgaste ambiental (ADA) se presenta de tendencia creciente. La media de perfiles de usuario aporta bajo o medio impacto ambiental, luego crece abruptamente y podría indicar que desde esa cantidad media de perfiles se utilizan medios de transporte más contaminantes para llegar a los bienes y servicios no digitalizados.

Al analizar las curvas de las variables independientes según la Figura 24 "Curvas de impacto por el consumo de productos y servicios no digitalizados y la utilización de medios de transporte" se fundamenta que el consumo de productos y servicios no digitalizados (CPS) presenta mayor impacto ambiental que la utilización de medios de transporte (UMT) para llegar a los mismos. El punto donde se produce el cambio de tendencia podría indicar que el medio de acceso aporta mayor contaminación dado que el consumo de bienes y servicios adquiere un grado de virtualización creciente complementando a los bienes y servicios de carácter físico. Esta facilidad podría producir algún efecto negativo sobre los perfiles de usuario siendo necesario interpretar la posibilidad. 


\section{e) Preocupación recurrente}

En esta sub-sección se analizará el aspecto ambiental devenido del criterio de preocupación recurrente $(\mathrm{PR})$ de la muestra de perfiles de usuario de Internet por el consumo de bienes y servicios digitalizados. Se consideran variables sobre la escala de medida de compra compulsiva CBMS, adicción a redes sociales BFAS, adicción a juegos de apuestas DSM y adicción a Internet IAT.

Una formulación posible para la preocupación recurrente sería: PR = CBMS (4-6-10) + BFAS (1-2-3) + DSM (1) + IAT (7-11-15) e indica que las variables independientes agrupan a los elementos de cada escala concernientes al impacto ambiental. La curva resultante se presenta en la Figura 25 "Curva de impacto por la preocupación recurrente".

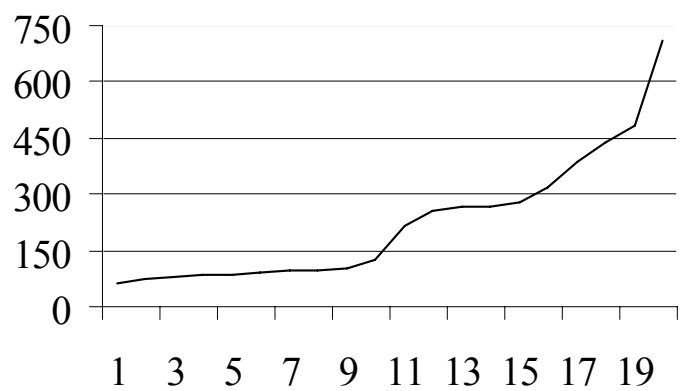

\section{— PR: Preocupación Recurrente}

Fig. 25. Curva de valor de impacto por la preocupación recurrente del perfil de usuario por el consumo de bienes y servicios digitalizados. (Promedio de a 500 perfiles de usuario, valor de impacto)

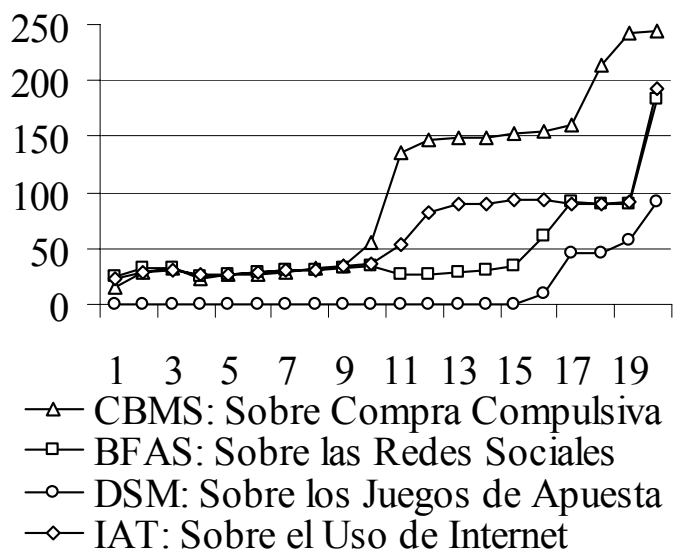

Fig. 26. Curvas de valor de impacto aportado por compras compulsivas, uso de redes sociales, uso de juegos de apuesta y uso de Internet. (Promedio de a 500 perfiles de usuario, valor de impacto)

La curva de preocupación recurrente (PR) presenta un aspecto exponencial y creciente, pudiendo argumentarse de bajo impacto para la mitad de los perfiles de usuario. Para otra cantidad se muestra crecimiento pronunciado. Este efecto podría indicar la situación que los grupos de perfiles de usuario son dos: quienes presentan alto impacto ambiental por la preocupación recurrente por el consumo de bienes y servicios digitalizados por Internet, y los que no.

Al analizar las curvas de las variables independientes según la Figura 26 "Curvas de impacto aportado por compras compulsivas, uso de redes sociales, uso de juegos de apuesta y uso de Internet" se podría argumentar que la curva sobre aspectos ambientales de compras compulsivas (CBMS) supera en términos de impacto a las demás y podría ser el principal aporte a la preocupación recurrente. Siguen las gráficas sobre el uso de Internet (IAT), conexión a las redes sociales (BFAS) y uso de juegos de apuestas (DSM) que podrían generar un pensamiento continuo sobre el tema y alterar algunas esferas del perfil de usuario relacionadas con la ansiedad.

\section{f) Progresión del incremento}

En esta sub-sección se analizará el aspecto ambiental devenido del criterio de progresión del incremento (PI) de la muestra de perfiles de usuario de Internet por el aumento en el consumo de bienes y servicios digitalizados. Se consideran variables sobre la escala de medida de compra compulsiva CBMS, adicción a redes sociales BFAS, adicción a juegos de apuestas DSM y adicción a Internet IAT.

Una formulación posible para la progresión del incremento sería PI = CBMS (1-5) + BFAS (4-5-6) + DSM (2) + IAT (114-17-20) e indica que las variables independientes agrupan a los elementos de cada escala concernientes al impacto ambiental. La curva resultante se presenta en la Figura 27 "Curva de impacto por la progresión del incremento".

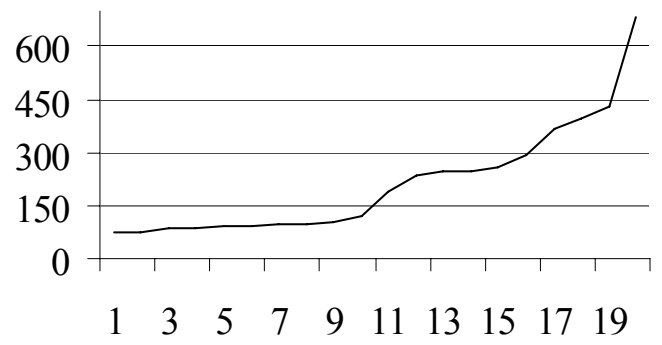

\section{— PI: Progresión del Incremento}

Fig. 27. Curva de valor de impacto por la progresión del incremento del perfil de usuario por el consumo de bienes y servicios digitalizados. (Promedio de a 500 perfiles de usuario, valor de impacto)

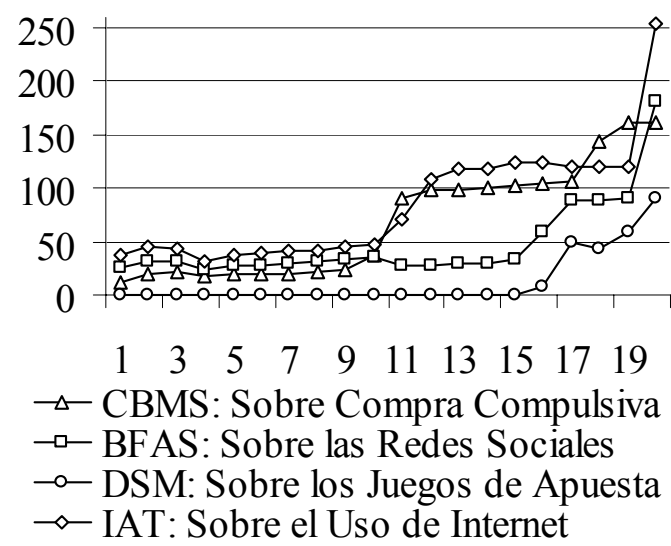

Fig. 28. Curvas de valor de impacto aportado por compras compulsivas, uso de redes sociales, uso de juegos de apuesta y uso de Internet. (Promedio de a 500 perfiles de usuario, valor de impacto)

La curva de progresión del incremento (PI) presenta un aspecto exponencial y creciente, pudiendo sostener la hipótesis de bajo impacto para la mitad de los perfiles de usuario. Para otra cantidad la curva muestra crecimiento pronunciado. Este 
efecto podría indicar la situación que los grupos de perfiles de usuario son dos: quienes presentan alto impacto ambiental por el incremento en el consumo de bienes y servicios digitalizados en Internet y los que no.

$\mathrm{Al}$ analizar las curvas de las variables independientes según la Figura 28 "Curvas de impacto aportado por compras compulsivas, uso de redes sociales, uso de juegos de apuesta y uso de Internet" se podría argumentar que la curva que refiere al uso de Internet (IAT) supera en términos de impacto a las demás y muestra un salto creciente y pronunciado para un grupo de perfiles de usuario lo que podría indicar la necesidad de encontrarse conectado a Internet durante cada vez más tiempo para sentir confort. La progresión del incremento en las operaciones de compra (CBMS) podría indicar que éstas crecen en mayor medida que la participación de redes sociales (BFAS) y el uso de juegos de apuesta (DSM). Estas condiciones podrían relacionarse con la voluntad que presenta cada perfil de usuario para acotar la actividad sobre Internet.

\section{g) Intensión de retiro}

En esta sub-sección se analizará el aspecto ambiental devenido del criterio de intensión de retiro (IR) de la muestra de perfiles de usuario de Internet presentando la voluntad de abandonar el consumo de bienes y servicios digitalizados. Se consideran variables sobre la escala de medida de compra compulsiva CBMS, adicción a redes sociales BFAS y adicción a juegos de apuestas DSM.

Una formulación posible para la intensión de retiro sería: $\mathrm{IR}=$ CBMS (13) + BFAS (12-13) + DSM (3) e indica que las variables independientes agrupan a los elementos de cada escala concernientes al impacto ambiental. La curva resultante se presenta en la Figura 29 "Curva de impacto por la intensión de retiro".

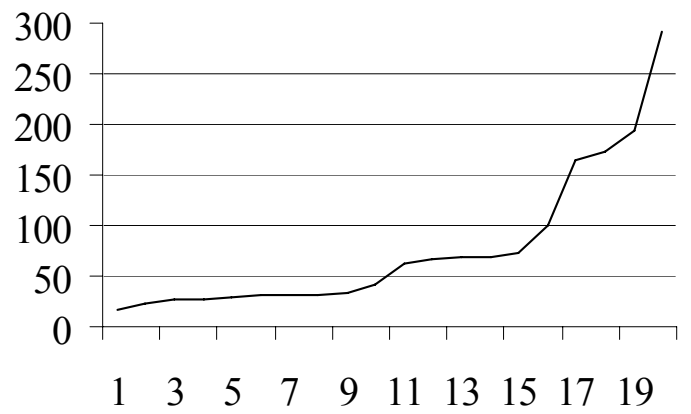

— IR: Intención de Retiro

Fig. 29. Curva de valor de impacto por la intensión de retiro del perfil de usuario durante el consumo de bienes y servicios digitalizados. (Promedio de a 500 perfiles de usuario, valor de impacto)

La curva de intensión de retiro (IR) presenta un aspecto exponencial y creciente pudiendo argumentar que presenta bajo impacto para la mitad de los perfiles de usuario. Para otra cantidad la curva muestra crecimiento pronunciado. Este efecto podría indicar la situación que los grupos de perfiles de usuario son dos: quienes presentan alto impacto ambiental por la intensión de retiro en el consumo de bienes y servicios digitalizados por Internet y los que no.

Al analizar las curvas de las variables independientes según la Figura 30 "Curvas de impacto aportado por compras compulsivas, uso de redes sociales y uso de juegos de apuesta" se podría argumentar que la curva sobre aspectos ambientales en el uso de las redes sociales (BFAS) presenta un pico de impacto por encima de las demás y podría indicar un contenido difícil de abandonar para un algún grupo de perfiles de usuario.

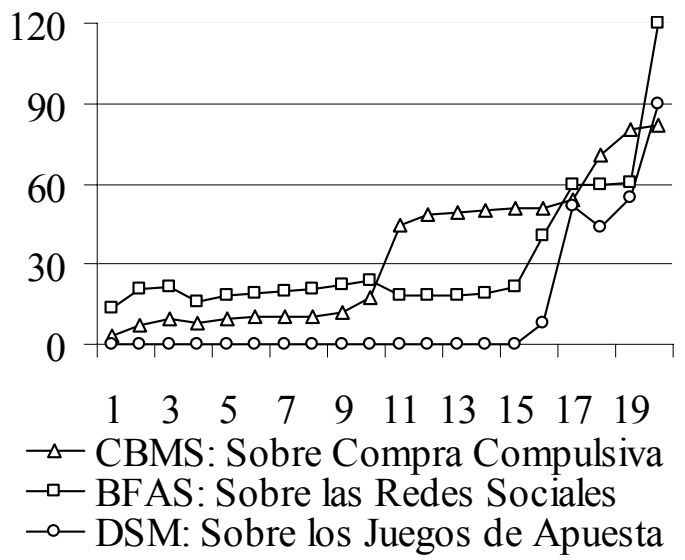

Fig. 30. Curvas de valor de impacto aportado por compras compulsivas, uso de redes sociales y uso de juegos de apuesta. (Promedio de a 500 perfiles de usuario, valor de impacto)

Para la media se presenta de bajo impacto. Al analizar la gráfica de los aportes sobre las operaciones de comercio en los portales de compra (CBMS) podría interpretarse alguna dificultad para retirarse y terminar la sesión, tal vez no tanto como con el uso de las redes sociales (BFAS). La curva sobre el uso de juegos de apuesta (DSM) se presenta de bajo impacto, pero un grupo de perfiles de usuario se muestra con dificultades para retirarse del contenido. Podría ser importante considerar si los excesos de tiempo para consumo de bienes y servicios digitalizados ocurren esporádicamente.

\section{h) Tendencia a la repetición}

En esta sub-sección se analizará el aspecto ambiental devenido del criterio de tendencia a la repetición (TR) de la muestra de perfiles de usuario de Internet en cuanto a la frecuencia por el consumo de bienes y servicios digitalizados. Se consideran variables sobre la escala de medida de compra compulsiva CBMS, adicción a juegos de apuestas DSM y adicción a Internet IAT.

Una formulación posible para la tendencia a la repetición sería TR = CBMS (2) + DSM (6) + IAT (16) e indica que las variables independientes agrupan a los elementos de cada escala concernientes al impacto ambiental. La curva resultante se presenta en la Figura 31 "Curva de impacto por la tendencia a la repetición".

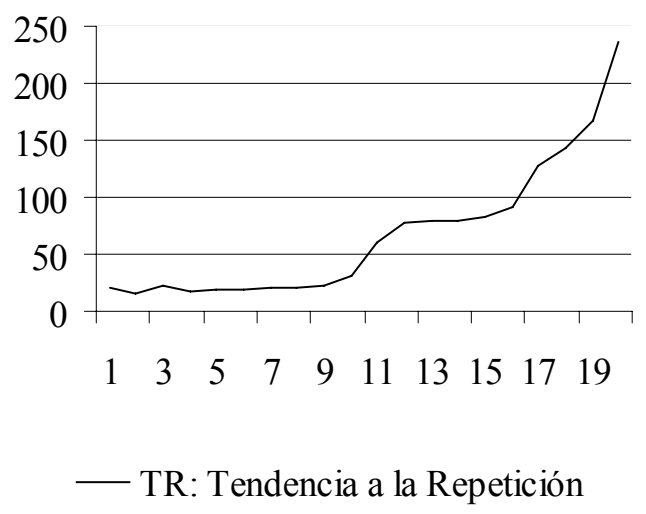

Fig. 31. Curva de valor de impacto por la tendencia a la repetición del perfil de usuario por el consumo de bienes y servicios digitalizados. (Promedio de a 500 perfiles de usuario, valor de impacto) 


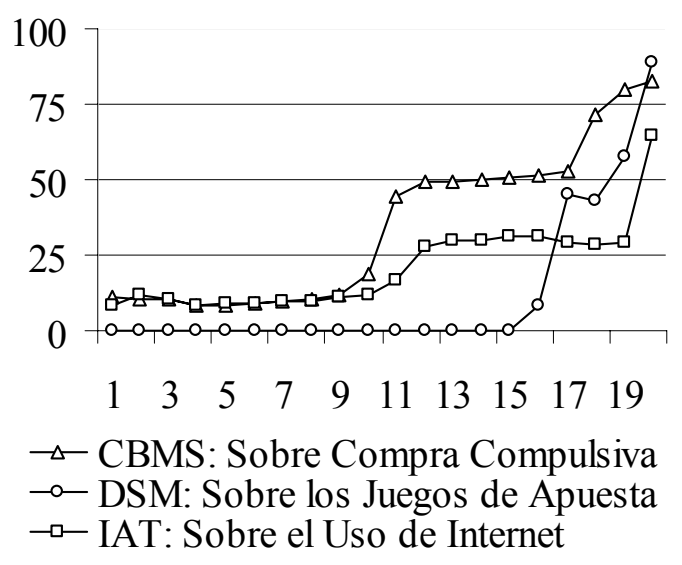

Fig. 32. Curvas de valor de impacto aportado por compras compulsivas, uso de juegos de apuesta y uso de Internet. (Promedio de a 500 perfiles de usuario, valor de impacto)

La curva de tendencia a la repetición (TR) presenta un aspecto exponencial y creciente pudiendo fundamentar que se presenta bajo impacto para la mitad de los perfiles de usuario. Para otra cantidad se muestra crecimiento pronunciado. Este efecto podría indicar la situación que los grupos de perfiles de usuario son dos: quienes presentan alto impacto ambiental por la tendencia a la repetición de uso de los bienes y servicios digitalizados por Internet y los que no.

Al analizar las curvas de las variables independientes según la Figura 32 "Curvas de impacto aportado por compras compulsivas, uso de juegos de apuesta y uso de Internet" se podría argumentar que la curva sobre aspectos ambientales por compras (CBMS) se muestra por encima de las demás y podría indicar que la actividad comercial se repite fuertemente para un grupo de perfiles de usuario. Para la media se presenta de bajo impacto. Al analizar la gráfica de los aportes sobre el uso de Internet (IAT) podría interpretarse alguna dificultad para no reiterar la actividad, tal vez no tanto como con las compras (CBMS). La curva sobre el uso de juegos de apuesta (DSM) se presenta de bajo impacto, pero un grupo de perfiles de usuario se muestra con dificultades para controlar el uso reiterado de los juegos.

3) Análisis sobre el eje social

Se presentan gráficas e interpretaciones sobre el conjunto de variables independientes y dependientes seleccionadas para estudiar el eje social. Se comienza por el impacto sobre el eje y la variable de accesos (sub-sección $a$ ) para continuar con la situación poblacional (sub-sección $b$ ), los aspectos de salubridad (sub-sección $c$ ), hogar y educación (sub-sección $d$ ). El criterio de pérdida de control se presenta (sub-sección $e$ ), sigue el de escape de la vida (sub-sección f), el de tendencia al ocultamiento (sub-sección $g$ ) y el de afectación a las relaciones afectivas (sub-sección $h$ ).

\section{a) Impacto sobre el eje social y la variable de accesos}

En esta sub-sección se analizará el impacto social (IS) y una variable cuantitativa que indica la cantidad de accesos del perfil de usuario en al sistema software simulador (CPA), para consumir bienes y servicios digitalizados.

La cuantificación del impacto social es función de sus variables dependientes de forma que: $\mathrm{IS}=\mathrm{SP}+\mathrm{AS}+\mathrm{H}+\mathrm{CPA}$ $+\mathrm{PC}+\mathrm{EV}+\mathrm{TO}+\mathrm{ARA}$. La gráfica de la curva (IS) se presenta en la Figura 33 "Curva de impacto social y cantidad de accesos al sistema".

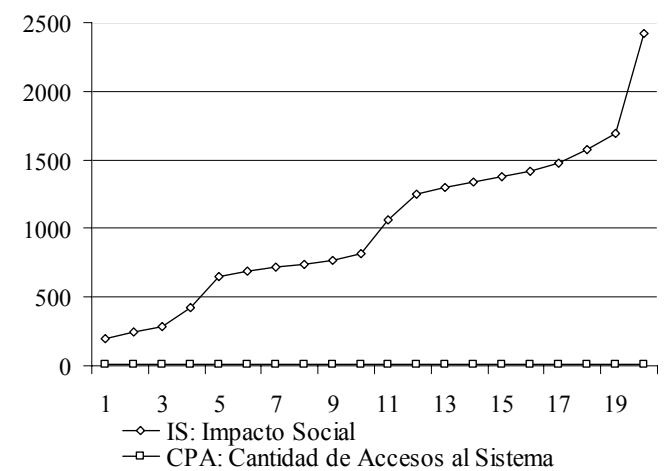

Fig. 33. Curva de valor de impacto social y valor de impacto por cantidad de accesos al sistema software simulador. (Promedio de a 500 perfiles de usuario, valor de impacto)

Las magnitudes que le dan aspecto a la gráfica del impacto social (IS) podrían argumentar que no se encuentran influenciadas por alguna variable dependiente particular, sino por todos los sumandos. No se reconoce una relación con la cantidad de accesos al sistema software simulador de cada perfil (CPA) dado que se presenta despreciable en términos de impacto social.

El análisis del resto de las variables dependientes que cuantifican al eje social podría explicar alguna tendencia sobre el conjunto de la muestra.

\section{b) Situación poblacional}

En esta sub-sección se analizará la situación poblacional (SP) de la muestra de perfiles de usuario de Internet. Se consideran las variables de nacionalidad $(\mathrm{N})$, estado civil (EC), sexo (sexo) y edad (edad) de cada perfil de usuario. Las curvas que indican el sexo (Sexo) y la nacionalidad (N) del perfil de usuario, para el modelo conceptual de impacto de consumo se cuantifican en cero. Esta situación podría ser interpretada como sin impacto para cualquiera de los valores posibles de ambas variables, persiguiendo el espíritu de igualdad ante género y nacionalidad, pudiendo ser considerables en otro tipo de análisis o explotación de de datos. La curva de edad (Edad) aumenta los valores de impacto a medida que el perfil de usuario presenta menor edad. Decrece cuando se trata de adultos. El impacto aportado por el estado civil (EC) aumenta cuando se trata de perfiles de usuario en matrimonio y decae para el soltero.

Al considerar la situación poblacional de la muestra de perfiles de usuario se llega a la ecuación dada por: $\mathrm{SP}=\mathrm{N}+$ $\mathrm{EC}+\mathrm{Sexo}+$ Edad. La curva resultante se presenta en la Figura 34 "Curva de impacto por la situación poblacional".

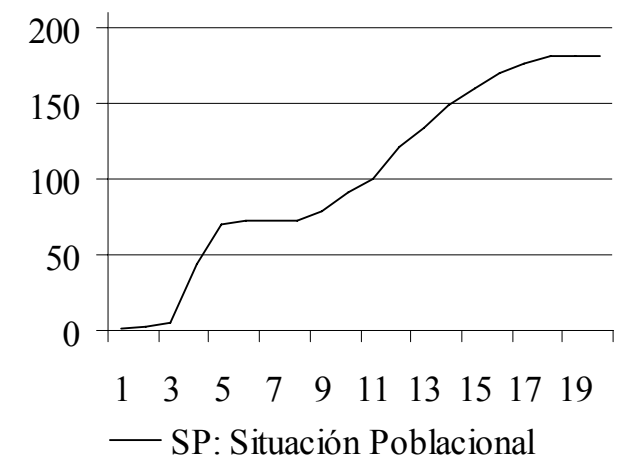

Fig. 34. Curva de valor de impacto por la situación poblacional del perfil de usuario. (Promedio de a 500 perfiles de usuario, valor de impacto) 


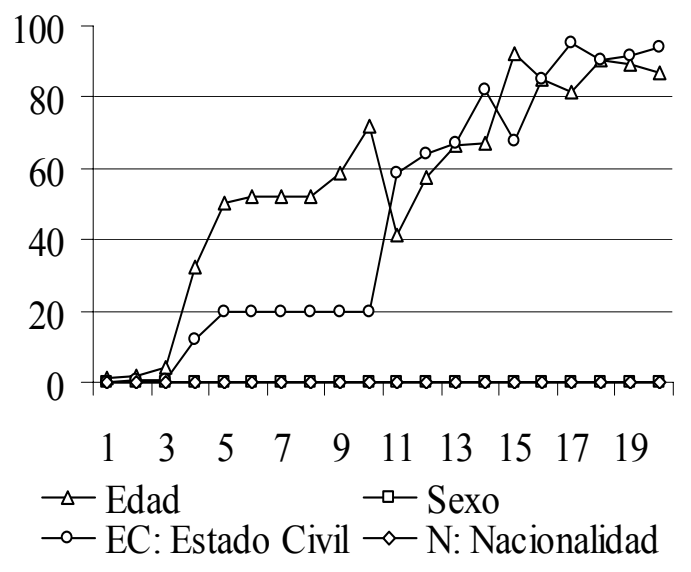

Fig. 35. Curvas de valor de impacto aportado por la edad, el sexo, el estado civil y la nacionalidad. (Promedio de a 500 perfiles de usuario, valor de impacto)

La gráfica de la curva (SP) se presenta creciente, de tendencia lineal para la media de perfiles de usuario y sin alteraciones que pudiesen facilitar alguna interpretación.

$\mathrm{Al}$ analizar las curvas de las variables independientes según la Figura 35 "Curvas de impacto por edad, sexo, estado civil y nacionalidad" se fundamenta que una minoría se corresponde con el grupo de adultos mayores (más de 65 años). La media de la muestra es adulta y donde se presenta mayor impacto se trata de niños o adolescentes. El estado civil (EC) presenta una minoría en soltería y una media divorciada o separada. Acompañando a la curva de edad en el crecimiento, en términos de impacto, podría argumentarse que la media se trata de adultos divorciados o separados. Las curvas de estado civil (EC) y edad (edad) se entrecruzan a medida que crece el impacto para la media de perfiles de usuario, aumentando en similar orden y pudiendo indicar que se presenta mayor impacto en jóvenes (de 18 a 29 años) o adultos (de 30 a 29 años) en matrimonio.

Para ampliar las interpretaciones, sobre el conjunto de perfiles de usuario, podría ser necesario conocer asuntos individuales sobre las actividades y el cuidado de la salud.

\section{c) Aspecto de salubridad}

En esta sub-sección se analizarán algunos aspectos de salubridad (AS) de la muestra de perfiles de usuario de Internet. Se consideran las variables de grado de dependencias (GD), fecundidad (F), actividad de esparcimiento emocional (AE), actividad física (AFi) y cobertura de salud (CS). La estimación del grado de dependencias (GD) indica la frecuencia con que el perfil de usuario consume sustancias que podrían afectar a su salud. El máximo impacto se presenta cuando el consumo es muy frecuente y disminuye en los casos en que no presenta consumo. La curva de impacto por fecundidad (F) indica la cantidad de hijos del perfil de usuario. La cuantificación crece a medida que aumenta la cantidad y tiende a cero cuando no posee hijos. La estimación de la actividad de esparcimiento emocional (AE) presenta la posibilidad de conocer la frecuencia con la que el perfil de usuario realiza actividades de esparcimiento o artísticas. La curva presenta mayor impacto cuando nunca realiza este tipo de actividad y tiende a cero a medida que siempre las realiza. La curva de impacto por actividad física (AFi) contempla la frecuencia con la cual el perfil de usuario realiza este tipo de actividad. Aumenta el impacto si nunca realiza actividad física $\mathrm{y}$ disminuye a medida que aumenta la frecuencia. La estimación que presenta el impacto por el aspecto relacionado con la cobertura de salud (CS) crece cuando el perfil de usuario se encuentra sin plan estatal o cobertura alguna, y decrece, a medida que posee alguna forma de protección, estatal o privada.

La estimación de los aspecto de salubridad de cada individuo se formula como: $\mathrm{AS}=\mathrm{GD}+\mathrm{F}+\mathrm{AE}+\mathrm{AFi}+\mathrm{CS}$. La curva resultante se presenta en la Figura 36 "Curva de impacto por aspectos de salubridad".

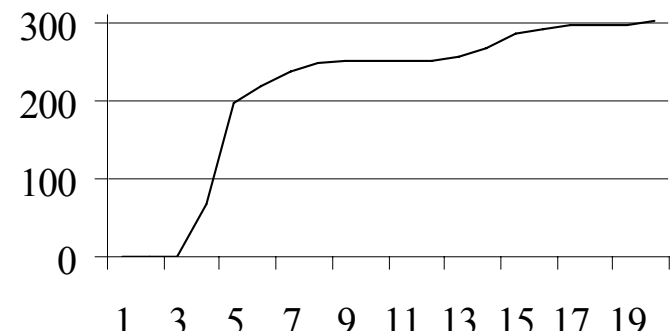

\section{— AS: Aspectos de Salubridad}

Fig. 36. Curva de valor de impacto por aspectos de salubridad del perfil de usuario. (Promedio de a 500 perfiles de usuario, valor de impacto)

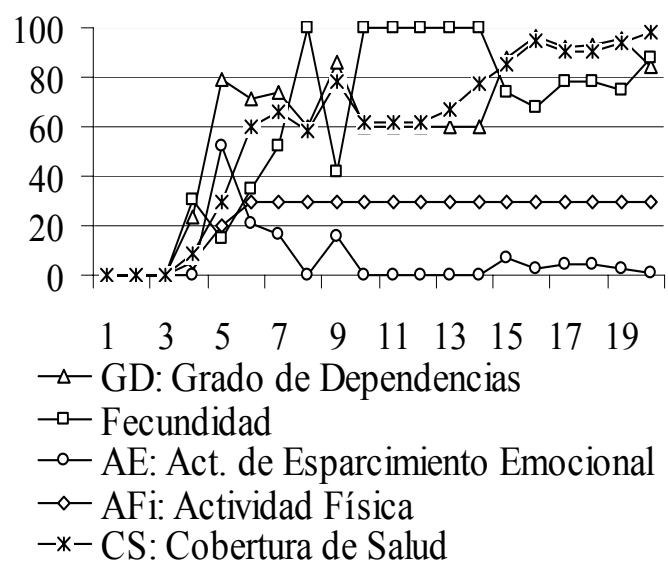

Fig. 37. Curvas de valor de impacto aportado por el grado de dependencias, la fecundidad, la actividad de esparcimiento emocional, la actividad física y la cobertura de salud. (Promedio de a 500 perfiles de usuario, valor de impacto)

La gráfica de la curva sobre aspectos de salubridad (AS) se presenta con un salto pronunciado y podría indicar que los perfiles de usuario se encuentran en dos grupos: los que presentan alto impacto social por descuidos en los aspectos de salubridad y los que no.

Al analizar las curvas de las variables independientes según la Figra 37 "Curvas de impacto por el grado de dependencias, fecundidad, esparcimiento emocional, actividad física $\mathrm{y}$ cobertura de salud" se fundamenta que la curva de impacto por actividades de esparcimiento emocional (AE) se encuentra tendiente a cero y podría presentar que la mayoría de la muestra de perfiles de usuario realiza este tipo de actividad con frecuencia, disminuyendo la posible alienación de la rutina. La imagen que presenta el impacto por la realización actividad física (AFi) para la media de usuario se muestra constante y de bajo valor indicando que la media de perfiles de usuario realiza frecuentemente este tipo de actividad. El mayor impacto es 
presentado en la gráfica de fecundidad $(\mathrm{F})$ y podría indicar que la media de perfiles de usuario tiene hijos y probablemente más de uno o dos. La curva de cobertura de salud (CS) presenta para la media de perfiles de usuario alto impacto indicando que una mayoría de la muestra no tiene planes de cobertura o es de tipo estatal. La gráfica es acompañada por la de grado de dependencias (GD) siendo probable que la muestra de perfiles de usuario siempre consuma sustancias que podrían afectar a la salud.

Las relaciones presentadas entre variables hasta aquí intentan perfilar las condiciones de población y salud para la media de perfiles de usuario que ejercen el consumo de bienes y servicios digitalizados. Podría apoyar a la interpretación alguna observación sobre la célula familiar de la muestra.

\section{d) Hogar y educación}

En esta sub-sección se analizarán la situación educativa y aspectos del hogar $(\mathrm{H})$ de la muestra de perfiles de usuario de Internet. Se consideran las variables de núcleo familiar (NF), cantidad de habitantes del hogar $(\mathrm{CH})$ y situación educativa (SE). La curva que presenta una posible idea sobre la composición del núcleo familiar (NF) aumenta el impacto a la dependiente si se trata de un hogar con estructura social extensa y compuesta. Disminuye a medida que el hogar tiende a ser unipersonal. La curva que representa el impacto social por la cantidad de habitantes del hogar $(\mathrm{CH})$ aumenta con mayor cantidad de habitantes y tiende a cero cuando se trata de uno solo. La situación educativa (SE) podría indicar mayor impacto al eje social cuando el perfil de usuario no presente formación o sea en extremo básica. Decrece cuando el nivel de formación educativa es terciario o superior.

La estimación sobre la situación educativa y aspectos del hogar se formula como: $\mathrm{H}=\mathrm{NF}+\mathrm{CH}+\mathrm{SE}$. La curva resultante se presenta en la Figura 38 "Curva de impacto por hogar y educación".

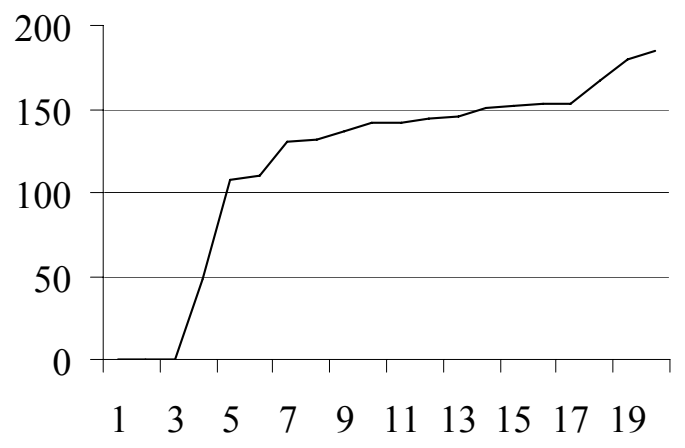

\section{— H: Hogar y Educación}

Fig. 38. Curva de valor de impacto por hogar y educación del perfil de usuario. (Promedio de a 500 perfiles de usuario, valor de impacto)

La gráfica de la curva por aspecto de hogar y educación $(\mathrm{H})$ se presenta con un salto pronunciado y podría indicar que los perfiles de usuario se encuentran en dos grupos: los que presentan alto impacto social por descuidos en aspectos de hogar y educación y los que no.

$\mathrm{Al}$ analizar las curvas de las variables independientes según la Figura 39 "Curvas de situación educativa, cantidad de habitantes del hogar y composición del núcleo familiar" se fundamenta que la gráfica sobre la cantidad de habitantes del hogar $(\mathrm{CH})$ se presenta constante y de bajo impacto para la media de perfiles de usuario. Esto podría significar que una mayoría habita un hogar de familia tipo (cuatro personas). Las curvas sobre la composición del núcleo familiar (NF) y la situación educativa (SE) presentan una tendencia pareja pudiendo indicar que la media se compone de una familia conyugal con presencia de hijos con bajo nivel de educación pudiendo no alcanzar al terciario o superior.

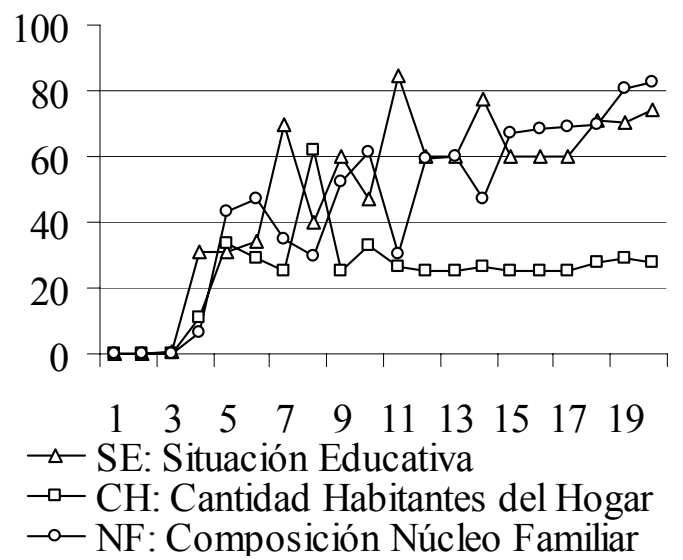

Fig. 39. Curvas de valor de impacto aportado por la situación educativa, la cantidad de habitantes del hogar y la composición del núcleo familiar.

(Promedio de a 500 perfiles de usuario, valor de impacto)

Los aspectos relacionados al individuo en su contexto social podrían delinear las reacciones y el comportamiento hacia el consumo de bienes y servicios digitalizados.

\section{e) Pérdida de control}

En esta sub-sección se analizará el aspecto social devenido del criterio de pérdida de control (PC) de la muestra de perfiles de usuario de Internet, sobre el consumo de bienes y servicios digitalizados. Se consideran variables sobre la escala de medida de compra compulsiva CBMS, adicción a redes sociales BFAS, adicción a juegos de apuestas DSM y adicción a Internet IAT.

Una formulación posible para la pérdida de control sería: $\mathrm{PC}=$ CBMS (8-9) + BFAS (10-11) + DSM (4) + IAT (6-8-13) e indica que las variables independientes agrupan a los elementos de cada escala concernientes al impacto social. La curva resultante se presenta en la Figura 40 "Curva de impacto por pérdida de control".

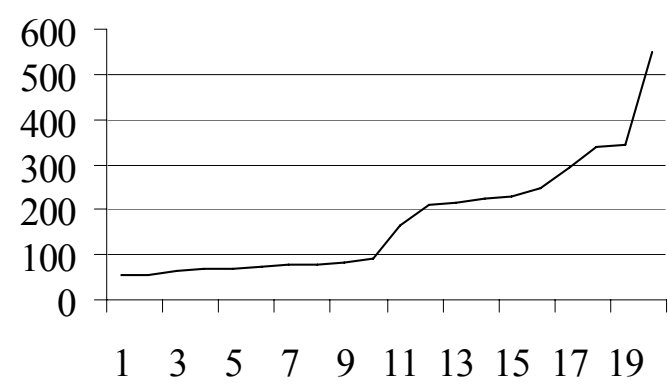

\section{— PC: Pérdida de Control}

Fig. 40. Curva de valor de impacto por pérdida de control por el consumo de bienes y servicios digitalizados. (Promedio de a 500 perfiles de usuario, valor de impacto)

La curva de pérdida de control (PC) presenta un aspecto exponencial y creciente, pudiendo sostener la hipótesis de bajo impacto para la mitad de los perfiles de usuario. Para otra 
cantidad la curva muestra crecimiento pronunciado. Este efecto podría indicar la situación que los grupos de perfiles de usuario son dos: quienes presentan alto impacto social por la pérdida de control por el consumo de los bienes y servicios digitalizados por Internet, y los que no.

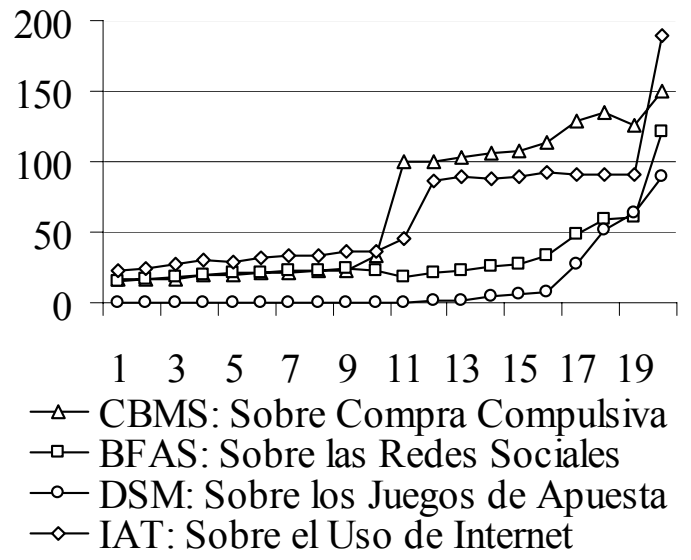

Fig. 41. Curvas de valor de impacto aportado por compras compulsivas, uso de redes sociales, uso de juegos de apuesta y uso de Internet. (Promedio de a 500 perfiles de usuario, valor de impacto)

$\mathrm{Al}$ analizar las curvas de las variables independientes según la Figura 41 "Curvas de impacto aportado por compras compulsivas, uso de redes sociales, uso de juegos de apuesta y uso de Internet" se podría argumentar que la curva sobre aspectos sociales de compras compulsivas (CBMS) supera en términos de impacto a las demás y podría ser el principal aporte a la pérdida de control. Siguen las gráficas sobre el uso de Internet (IAT), conexión a las redes sociales (BFAS) y uso de juegos de apuestas (DSM) que podrían generar un pensamiento continuo sobre el tema para olvidar temporalmente los aspectos de la realidad.

\section{f) Escape de la vida}

En esta sub-sección se analizará el aspecto social devenido del criterio de escape de la vida (EV) de la muestra de perfiles de usuario de Internet anteponiendo el consumo de bienes y servicios digitalizados a otros asuntos de carácter personal. Se consideran variables sobre la escala de medida de compra compulsiva CBMS, adicción a redes sociales BFAS, adicción a juegos de apuestas DSM y adicción a Internet IAT.

Una formulación posible para el escape de la vida sería: EV $=$ CBMS (3) + BFAS (7-8) + DSM (5) + IAT (2-3-10-12-19) e indica que las variables independientes agrupan a los elementos de cada escala concernientes al impacto social. La curva resultante se presenta en la Figura 42 "Curva de impacto por escape de la vida".

La curva que representa al criterio de escape de la vida (EV) presenta un aspecto exponencial y creciente, pudiendo sostener la hipótesis de bajo impacto para la mitad de los perfiles de usuario. Para otra cantidad la curva muestra crecimiento pronunciado. Este efecto podría indicar la existencia de dos grupos de perfiles de usuario: quienes presentan alto impacto por la utilización de bienes y servicios digitalizados por Internet para escapar de las obligaciones y los que no.

Al analizar las curvas de las variables independientes según la Figura 43 "Curvas de impacto aportado por compras compulsivas, uso de redes sociales, uso de juegos de apuesta y uso de Internet" se podría argumentar que la curva sobre aspectos sociales por el uso de Internet (IAT) supera en términos de impacto a las demás y podría ser el principal aporte al escape de la vida. Siguen las gráficas de conexión a las redes sociales (BFAS), compras compulsivas (CBMS) y uso de juegos de apuestas (DSM) que podrían presentar una serie de actividades que permitan al perfil de usuario olvidar sus obligaciones cotidianas y no afrontar los aspectos reales de la vida, pudiendo ser una actividad personal y secreta.

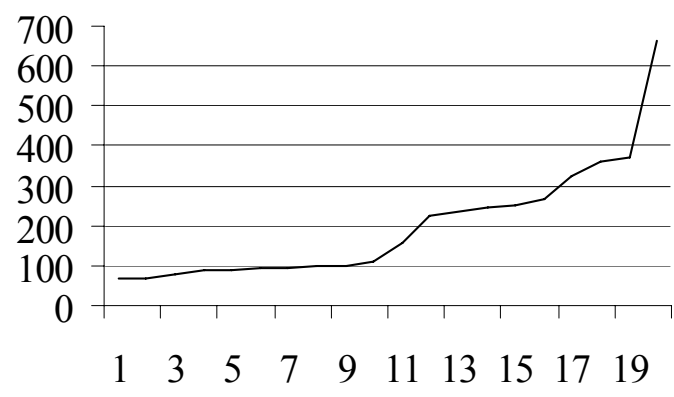

\section{- EV: Escape de la Vida}

Fig. 42. Curva de valor de impacto por el consumo de bienes y servicios digitalizados para escapar de la vida. (Promedio de a 500 perfiles de usuario, valor de impacto)

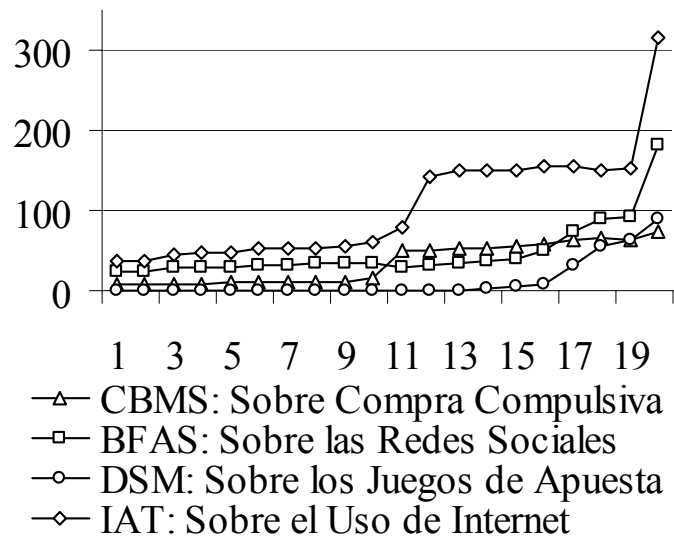

Fig. 43. Curvas de valor de impacto aportado por compras compulsivas, uso de redes sociales, uso de juegos de apuesta y uso de Internet. (Promedio de a 500 perfiles de usuario, valor de impacto)

\section{g) Tendencia al ocultamiento}

En esta sub-sección se analizará el aspecto social devenido de la tendencia al ocultamiento (TO) de la muestra de perfiles de usuario de Internet sobre las actividades privadas de consumo de bienes y servicios digitalizados. Se consideran variables sobre la escala de medida de compra compulsiva CBMS, adicción a juegos de apuestas DSM y adicción a Internet IAT.

Una formulación posible para la tendencia al ocultamiento sería: TO $=$ CBMS (7) + DSM (7) + IAT (9-18) e indica que las variables independientes agrupan a los elementos de cada escala concernientes al impacto social. La curva resultante se presenta en la Figura 44 "Curva de impacto por tendencia al ocultamiento". 


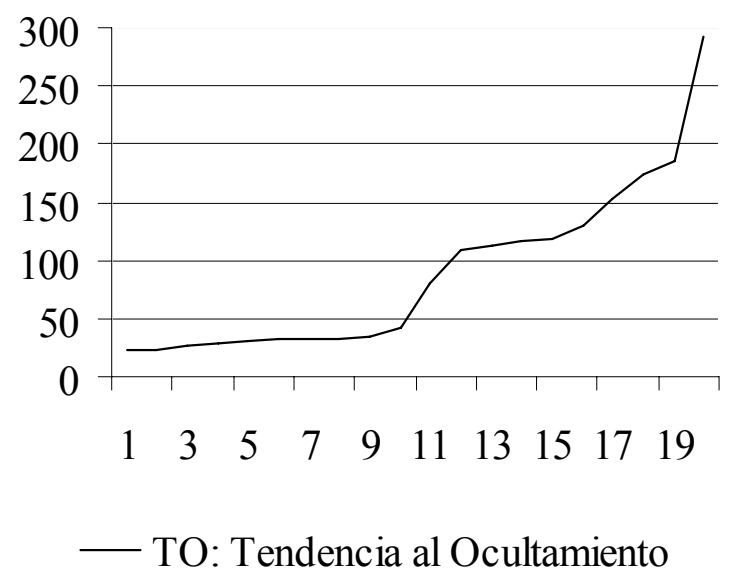

Fig. 44. Curva de valor de impacto por tendencia al ocultamiento por el consumo de los bienes y servicios digitalizados. (Promedio de a 500 perfiles de usuario, valor de impacto)

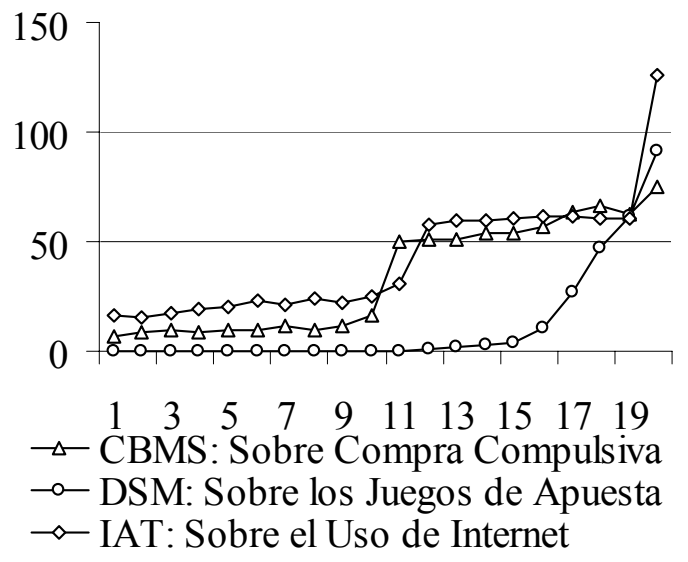

Fig. 45. Curvas de valor de impacto aportado por compras compulsivas, uso de juegos de apuesta y uso de Internet. (Promedio de a 500 perfiles de usuario, valor de impacto)

La curva que representa a la tendencia al ocultamiento (TO) muestra un aspecto exponencial y creciente, pudiendo argumentar que presenta bajo impacto para la mitad de los perfiles de usuario. Para otra cantidad la curva muestra crecimiento pronunciado. Este efecto podría indicar la situación que los grupos de perfiles de usuario son dos: quienes presentan alto impacto social por la tendencia al ocultamiento por el consumo de bienes y servicios digitalizados por Internet y los que no.

Al analizar las curvas de las variables independientes según la Figura 45 "Curvas de impacto aportado por compras compulsivas, uso de juegos de apuesta y uso de Internet" se podría argumentar que la curva sobre aspectos sociales por el uso de Internet (IAT) se muestra por encima de las demás y es acompañada por la curva sobre compras (CBMS) pudiendo indicar que son actividades que tienden a ocultarse. La curva sobre el uso de juegos de apuesta (DSM) se presenta de bajo impacto, pero un grupo de perfiles de usuario se muestra con dificultades para controlar la actividad cayendo en el ocultamiento, incluso ante otros relacionados por sentimientos afectivos.

\section{h) Afectación a las relaciones afectivas}

En esta sub-sección se analizará el aspecto de afectación a las relaciones afectivas (ARA) de la muestra de perfiles de usuario de Internet, que debido al consumo de contenidos digitalizados de esa red, impactan negativamente a los seres afectivamente relacionados. Se consideran variables sobre adicción a las redes sociales BFAS, adicción a juegos de apuestas DSM y adicción a Internet IAT.

Una formulación posible para la afectación a las relaciones afectivas sería: ARA = BFAS (14-15-16) + DSM (9-10) + IAT (4-5) e indica que las variables independientes agrupan a los elementos de cada escala concernientes al impacto social. La curva resultante se presenta en la Figura 46 "Curva de impacto por la afectación de las relaciones afectivas”.

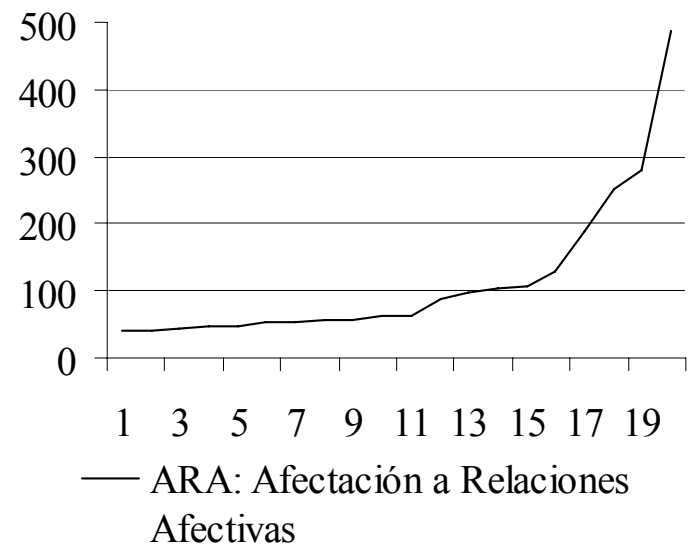

Fig. 46. Curva de valor de impacto por el deterioro de las relaciones afectivas por el consumo de los bienes y servicios digitalizados. (Promedio de a 500 perfiles de usuario, valor de impacto)

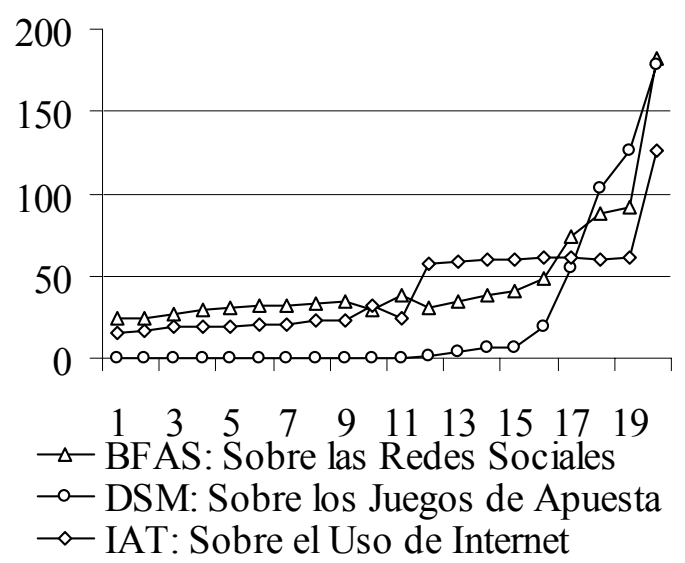

Fig. 47. Curvas de valor de impacto aportado por el uso de redes sociales, uso de juegos de apuesta y uso de Internet. (Promedio de a 500 perfiles de usuario, valor de impacto)

La curva que representa a la afectación de las relaciones afectivas (ARA) muestra un aspecto exponencial y creciente, pudiendo argumentar que presenta bajo impacto para la mitad de los perfiles de usuario. Para otra cantidad la curva muestra crecimiento pronunciado. Este efecto podría indicar la situación que los grupos de perfiles de usuario son dos: quienes presentan alto impacto social afectando a sus relaciones sociales afectivas por el uso de los bienes y servicios digitalizados por Internet y los que no.

Al analizar las curvas de las variables independientes según la Figura 47 "Curvas de impacto aportado uso de redes sociales, uso de juegos de apuesta y uso de Internet" se podría argumentar que la curva sobre aspectos sociales por el uso de Internet (IAT) se muestra por encima de las demás y es 
acompañada por la curva de redes sociales (BFAS) pudiendo indicar que producen el mayor impacto por el detrimento de las relaciones con seres queridos. La curva sobre el uso de juegos de apuesta (DSM) se presenta de bajo impacto, pero un grupo de perfiles de usuario se muestra con dificultades para controlar la actividad cayendo en el deterioro de sus relaciones afectivas.

\section{Resultdos experimentales}

Sobre los ejes económico, ambiental y social, se han presentado varios aspectos y criterios de estudio con dos posibles grupos de impacto: bajo y alto, lo que podría sostener la hipótesis que algunos perfiles de usuario no presentan atracción hacia el consumo masivo de bienes y servicios digitalizados por Internet o mantienen un buen nivel de control de consumo, mientras que otros podrían presentar mayores dificultades.

La información obtenida en los experimentos podría ser procesada con técnicas de explotación de la información a fin de descubrir nuevas reglas e inferencias y complementar las gráficas e interpretaciones sobre las variables del modelo conceptual de impacto de consumo.

\section{CONCLUSIONES}

En este apartado se presentan los aportes de la investigación (sección $A$ ), una síntesis sobre los resultados experimentales (sección $B$ ) y se concluye con las futuras líneas de investigación (sección $C$ ).

\section{A. Aportaciones del trabajo}

En el marco del aporte que realiza el trabajo se alcanzaron resultados que permiten: [a] Presentar una primera versión de modelo conceptual que facilita la comprensión del impacto masivo devenido del consumo de bienes y servicios digitalizados en comercio electrónico escalable. En el centro del modelo conceptual se analizan las características individuales del usuario y orbitalmente se estudia el modo en que desarrolla el consumo de algunos contenidos digitalizados. [b] Poner a disposición una profunda y metodológica investigación documental sobre diferentes entidades de estadística y censo de carácter nacional, regional y otras públicas sobre Internet, que fundamentan el comportamiento de sus usuarios, facilitado la generación de una base de datos informática representativa, que conforma una masa contemporánea de perfiles de consumidores de bienes $\mathrm{y}$ servicios digitalizados de la red. [c] Apoyar los criterios de sustentabilidad a través de la clasificación de las variables de estado, independientes y dependientes del modelo, a fin mantener el equilibrio sobre los ejes: económico, ambiental y social. Este podría ser un modo de analizar la administración de los emprendimientos del futuro cuando rocen con ética controversial. La consideración de las partes involucradas y el mejoramiento conjunto y armonioso de los tres ejes permitirá desarrollar la perpetuidad de esos negocios. [d] Llamar a la concientización de estados modernos, la empresa de órbita privada y principalmente a la masa de usuarios de Internet, acerca de la peligrosidad oculta que conlleva el consumo desmedido de bienes y servicios digitalizados por Internet, como también los beneficios de uso y usufructo equilibrado.

\section{B. Resultados experimentales}

Se toma el sumario de la investigación presentado en el apartado III: Descripción del problema, sección E., para desarrollar una síntesis interpretativa de los resultados experimentales.

[I]¿Podría encontrarse una relación entre el impacto económico de un usuario que ejerce el comercio electrónico de bienes y servicios digitalizados respecto a:

[a] una estimación de su estado de resultados?

Los resultados experimentales indican que la media de perfiles de usuario de Internet que percibe menor resultado (ingreso menos egreso) suele presentar mayor impacto económico por el consumo de bienes y servicios digitalizados.

[b] una estimación de su estado patrimonial?

Los resultados experimentales indican que la media de perfiles de usuario de Internet que dispone de menor patrimonio suele presentar mayor impacto económico por el consumo de bienes y servicios digitalizados.

[c] su condición de ocupación laboral (o no laboral)?

Los resultados experimentales indican que la media de perfiles de usuario de Internet que no dispone de ocupación laboral o es económicamente no activa presenta mayor impacto económico por el consumo de bienes y servicios digitalizados.

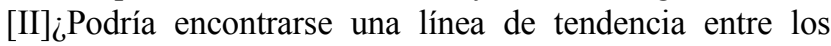
gustos de consumo en comercio electrónico respecto a los bienes tangibles? ¿Se demuestra un cambio hacia la preferencia por las compras de bienes y servicios digitalizados?

Los resultados experimentales no dan base suficiente que permita encontrar una tendencia clara sobre la preferencia. La media de perfiles de usuario de Internet accede y adquiere en in creyendo bienes y servicios digitalizados.

$[\mathrm{III}]_{\text {¿Las }}$ características económicas y financieras del comercio electrónico podrían:

[a] facilitar el aumento del ahogo financiero individual debido a excesos?

Los resultados experimentales indican que la media de perfiles de usuario de Internet aumenta el impacto económico por el ahogo financiero debido al consumo de bienes $y$ servicios digitalizados.

[b] incrementar la comisión de actos ilegales para obtener más recursos y aumentar el nivel de consumo?

Los resultados experimentales indican que la media de perfiles de usuario de Internet no aumenta el impacto económico debido a la comisión de actos ilegales para aumentar el nivel de consumo de bienes y servicios digitalizados. Sólo una pequeña porción manifiesta el problema experimentando alto impacto económico.

[IV] ¿Podría encontrarse alguna relación entre el costo monetario individual en el que se incurre por el consumo de bienes y servicios digitalizados y el posible impacto económico que podría producir?

Los resultados experimentales indican que para la media de perfiles de usuario de Internet existe una relación directa y proporcional entre el costo monetario e impacto económico devenido del consumo de bienes y servicios digitalizados.

[V] ¿Podría encontrarse una relación ambiental entre un usuario que ejerce el comercio electrónico de bienes y servicios digitalizados respecto a:

[a] las características de la vivienda que habita?

Los resultados experimentales indican que se encuentran tres grupos de perfiles de usuario de Internet presentando: bajo, medio y alto impacto ambiental en función de las características de la vivienda que habita.

[b] los servicios básicos de la vivienda que habita? 
Los resultados experimentales indican que la media de perfiles de usuario de Internet que consume bienes y servicios digitalizados presenta alto impacto ambiental derivado del consumo energético de la vivienda que habita.

[c] el aporte al desgaste ambiental por el consumo de bienes y servicios tangibles?

Los resultados experimentales indican que la media de perfiles de usuario de Internet aporta bajo o medio impacto ambiental por el consumo de bienes y servicios digitalizados. Una minoría de perfiles presenta alto impacto ambiental por el consumo de bienes y servicios tangibles sustitutos.

[VI] ¿Se presenta el efecto de preocupación recurrente de un usuario de Internet por el consumo de bienes y servicios digitalizados que esa red brinda? ¿Podría presentarse alguna formulación o tendencia sobre el incremento?

Los resultados experimentales indican que la media de perfiles de usuario de Internet presenta dos grupos: quienes muestran elevada preocupación recurrente por el consumo de bienes y servicios digitalizados y los que no. La tendencia al incremento de consumo acompasa a cada uno de los grupos de forma elevada y despreciable respectivamente.

[VII] ¿Se presentan dificultades al momento de abandonar el consumo de bienes y servicios digitalizados por Internet? ¿Puede controlarse el momento de retiro? ¿Puede comprobarse alguna tendencia sobre la intensión de retiro?

Los resultados experimentales indican que la media de perfiles de usuario de Internet presenta dos grupos: quienes muestran dificultades al momento de abandonar el consumo de bienes y servicios digitalizados y los que no. No existen bases suficientes que permitan explicar el control sobre el momento de retiro o alguna tendencia sobre la intención de retiro.

[VIII] ¿Cómo se presenta la tendencia a la repetición de consumo de bienes y servicios digitalizados? ¿Podría presentar patrones de comportamiento hacia la ciber-adicción?

Los resultados experimentales indican que la media de perfiles de usuario de Internet presenta dos grupos: quienes repiten continuamente el consumo de bienes y servicios digitalizados y los que no. La compra compulsiva por Internet presenta un impacto superior al uso de Internet y a los juegos de apuesta por Internet.

[IX] ¿Podría encontrarse alguna relación entre el tiempo que un usuario utiliza para el consumo de bienes y servicios digitalizados y el posible impacto ambiental que podría producirse?

Los resultados experimentales indican que, para la media de perfiles de usuario de Internet, el impacto ambiental devenido del tiempo de consumo de bienes y servicios digitalizados es mínimo y hasta despreciable.

$[\mathrm{X}]$ ¿Podría encontrarse una relación social entre un usuario que ejerce el comercio electrónico de bienes y servicios digitalizados respecto a:

[a] su situación poblacional?

Los resultados experimentales indican que la media de perfiles de usuario de Internet del grupo niños, niñas o adolescentes registra mayor impacto mayor social por consumo de bienes y servicios digitalizados.

[b] aspectos de salubridad?

Los resultados experimentales indican que se encuentran dos grupos de perfiles de usuario de Internet presentando: bajo y alto impacto social en función de los aspectos de salubridad.

[c] las características del hogar que habita y el ambiente educacional?
Los resultados experimentales indican que se encuentran dos grupos de perfiles de usuario de Internet presentando: bajo y alto impacto social en función de las características del hogar $\mathrm{y}$ ambiente educacional.

[XI] ¿Se presentan dificultades al momento de controlar el consumo de bienes y servicios digitalizados por Internet? ¿Puede un usuario perder el control sobre ese consumo?

Los resultados experimentales indican que la media de perfiles de usuario de Internet presenta dos grupos: quienes se encuentran imposibilitados de para controlar el consumo de bienes y servicios digitalizados y los que no. No existen bases suficientes que permitan explicar el control sobre el consumo de bienes y servicios digitalizados.

[XII] ¿Podría utilizarse al consumo de bienes y servicios digitalizados para lograr evadir los conflictos cotidianos? ¿Sería un mecanismo que permitiera un escape de la vida?

No existen bases suficientes que permitan explicar la evasión de los conflictos cotidianos a través del consumo de bienes y servicios digitalizados. Los resultados experimentales indican que la media de perfiles de usuario de Internet presenta dos grupos: quienes utilizan el consumo de bienes y servicios digitalizados para escapar de los problemas de la vida y los que no.

[XIII] ¿Existe un grado en el cual el consumo de bienes y servicios digitalizados logre afectar a un individuo de modo que oculte profundamente esa actividad? ¿Qué impacto podría producir a un usuario ese ocultamiento?

No existen bases suficientes que permitan identificar el grado de afectación por el ocultamiento en el consumo de bienes y servicios digitalizados. Los resultados experimentales indican que la media de perfiles de usuario de Internet presenta dos grupos: bajo y alto impacto por el ocultamiento del consumo de bienes y servicios digitalizados para escapar de los problemas de la vida.

[XIV] ¿Se presentan dificultades para mantener relaciones sociales afectivas debido al consumo de bienes y servicios digitalizados? ¿Puede un usuario afectar a sus relaciones por el exceso en ese consumo?

No existen bases suficientes que permitan afirmar que el consumo de bienes y servicios digitalizados genere dificultades para mantener relaciones sociales afectivas. Los resultados experimentales indican que la media de perfiles de usuario de Internet presenta dos grupos: quienes registran alto impacto social por el detrimento de las relaciones afectivas por el exceso en el consumo de bienes y servicios digitalizados y los que no.

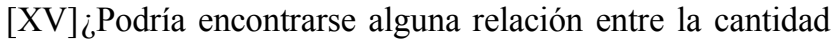
de veces que un usuario utiliza el comercio electrónico para consumir bienes y servicios digitalizados y el posible impacto social que podría producirle?

Los resultados experimentales indican que para la media de perfiles de usuario de Internet el impacto social devenido de la cantidad de veces que consume bienes y servicios digitalizados es mínimo y hasta despreciable.

[XVI] ¿Podría desarrollarse y validarse un modelo conceptual que estime:

[a] el impacto económico por el consumo masivo de bienes y servicios digitalizados?

Los resultados experimentales indican que es posible desarrollar un modelo conceptual que estime el impacto económico generado por del consumo de bienes y servicios digitalizados. 
[b] el impacto ambiental por el consumo masivo de bienes y servicios digitalizados?

Los resultados experimentales indican que es posible desarrollar un modelo conceptual que estime el impacto ambiental aportado por del consumo de bienes y servicios digitalizados.

[c] el impacto social por el consumo masivo de bienes y servicios digitalizados?

Los resultados experimentales indican que es posible desarrollar un modelo conceptual que estime el impacto social causado por del consumo de bienes y servicios digitalizados.

\section{Futuras líneas de investigación}

Durante el desarrollo de la investigación se han detectado las siguientes líneas de trabajo y problemas abiertos:

[a] Desarrollar el modelo conceptual de impacto de consumo a fin de llegar a un estado de maduración que aumente su calidad en pos de la deducción y predicción de resultados. En este sentido podría ser necesario considerar:

[i] Utilizar mayor cantidad de variables independientes y dependientes para optimizar la caracterización de un perfil de usuario de Internet. [ii] Agregar mayor cantidad de encuestas orbitales sobre el uso y abuso en el consumo de bienes y servicios digitalizados.

[b] Desarrollar pruebas de campo no invasivas e inocuas que permitan refinar los perfiles de usuario de Internet con el propósito de mejorar la predictibilidad del comportamiento humano.

[c] Aumentar la muestra de perfiles de usuario generada por la investigación. Con base en esta masa de información utilizar tecnologías de explotación de información para obtener patrones de comportamiento relacionados con adicciones a Internet y a redes sociales, compras y juego compulsivo por Internet.

[d] Explorar resultados individuales, grupales y comparaciones sobre las encuestas orbitales referidas a: adicción a Internet, adicción a redes sociales, compras compulsivas y juego compulsivo por Internet.

\section{REFERENCIAS}

[1] Acta de Libre Comercio y Zona Franca. 1994. Free trade and processing zone act. Por el gobierno de Antigua Barbuda. http://www.antiguagaming.gov.ag/files/Antigua and Barbuda Gaming_Regulations-Final.pdf (Última visita al sitio expuesto: 8 de octubre de 2013).

[2] García, F. y Gertrudix, M. 2011. Naturaleza y características de los servicios y los contenidos digitales abiertos. Cuadernos de Información y Comunicación. Vol. 16: 125-138. ISSN 11357991.

[3] Acta de Prohibición del Juego en Línea. 1997. The Internet gambling prohibition act of 1997. 105th Cong. Hearing on H.R. 4777 Before the H. Comm. on the Judiciary and the Subcomm. on Crime, Terrpros, amd Homeland Security., 109th Cong. (2006) [hereinafter Ohr Statement] (statement of Bruce G. Ohr, Chief of Organized Crime and Racketeering Section, U.S. Dept. of Justice. http://frwebgate.access.gpo.gov/cgiin/getdoc.cgi?dbname $=109$ cong_bills\&docid=f:h4777ih.txt.pd f(Última visita al sitio expuesto: 8 de octubre de 2013).

[4] eCOGRA. 2003. Seguro y reglamento sobre el juego en línea de comercio electrónico (eComerce and online Gambling Regulation and Assurance) http://www.ecogra.org/certificates/certificate.aspx?cid=182\&l= SPA (Última visita al sitio expuesto: 8 de octubre de 2013).
[5] OMC Diferencia DS285. 2007. Medidas que afectan al suministro transfronterizo de servicios de juegos de azar y apuestas. Organización Mundial de Comercio. http://www.wto.org/english/tratop_e/dispu_e/cases_e/ds285_e. htm (Última visita al sitio expuesto 8 de octubre de 2013).

[6] KPMG, 2000. The Economic Value and Public Perceptions of Gambling in the UK. Report for Business in Sport and Leisure. London: KPMG.

[7] People Vs World Interactive Gaming Corp. 1999. State of New York c/ World Interactive Gaming Corp. Estado de New York. 185 Misc. 2d 852, 714 N.Y.S.2d 844 (N.Y. County Sup. Ct. 1999). Estados Unidos de América.

[8] Collins, P. 2003. Gambling and the public interest. Editorial: Praeger Publishers. ISBN: 1-56720-585-2

[9] Krotoski A. 2010. La revolución virtual. Redacción BBC mundo. Reino Unido de Gran Bretaña.

[10] Llinares Pellicer, M. y Lloret Boronat, M. 2008. Ciber adicción: Los riesgos de Internet. Revista de Análisis Transaccional y Psicología Humanista. Nro: 59. Vol: XXVI. Madrid. España. ISSN 0212-9876.

[11] Young, K. 1999b. The Research and Controversy Surrounding Internet Addiction. CyberPsychology and Behavior. Vol.: 2. Nro.:5:381-383.

[12] Araya Dujisin, R. 2005. Internet, política y ciudadanía. Editores Nueva Sociedad. Nro. 195: 56-71. ISSN 0251-3552.

[13] del Río Martinez, J. y González Videgaray, M. 2007. Trabajo prolongado con computadoras: consecuencias sobre la vista y la fatiga. IX Congreso Internacional de Ergonomía. Sociedad de Ergonomistas de México A.C. Distrito Federal. México.

[14] Poletti, O. y Barrios, L. 2007. Sobrepeso, obesidad, hábitos alimentarios, actividad física y uso del tiempo libre en escolares de Corrientes (Argentina). Revista Cubana Pediatría. Vol.: 79. Nro.: 1. Ciudad de la Habana. Cuba. ISSN 1561-3119.

[15] Lamb, C. 2006. Marketing. 8va. Edición. Cengage Learning Editores. ISBN 978-970-68654-7-2.

[16] Comte-Sponville A. 2004. El capitalismo, ¿es moral? Editorial: Ediciones Paidós Ibérica S.A. ISBN 84-493-1605-7.

[17] Del Aguila Obra, A., Padilla Melendez, A., Serarols Tarrés, C., Veciana Verges, J. 2001. La economía digital y su impacto en la empresa: bases teóricas y situación en España. Boletín económico del ICE. Nro: 2705.

[18] Carley, K. 1999. Organizational Change and the Digital Economy: A Computational Organization Science Perspective. Social and Decision Sciences and H.J.Heinz III School of Public Policy and Management. Carnegie Mellon University. Pittsburgh.

[19] Kotler, P. y Keller, K. 2006. Dirección de marketing. Duodécima Edición. Editorial Prentice Hall INC. ISBN 97026-0763-9.

[20] López Sánchez, J. y Sandulli, F. 2002. Evolución de los modelos de negocio en Internet: Situación actual en España de la economía digital. Universidad Complutense de Madrid. España.

[21] CEPAL. 2013. Economía digital para el cambio estructural y la igualdad. Comisión económica para America Latina y el Caribe. Naciones Unidas.

[22] MINCYT. 2009. Libro blanco de la prospectiva TIC: proyecto 2020. Primera Edición. Buenos Aires. Argentina. Ministerio de Ciencia, Tecnología e Innovación Productiva. ISBN 978-987$1632-00-8$

[23] Duarte Cueva, F. 2010. Economía digital sitios web y PYMES del sector artesanía en el Perú. Contabilidad y Negocios. Volumen5.Nro.:9:57-67. 
[24] Glez, F. 2006. La Web 2.0: características, implicancias en el entorno educativo y algunas de sus herramientas. Departamento de Matemática. Universidad de León. España.

[25] Boutilier, R. 2011. La licencia social para operar. Centro para el Desarrollo Comunitario Sustentable. Simon Fraser University. Vancouver. Canadá. SME Manual de Ingeniería Minera. Capítulo17:1779-1796.

[26] Debeljuh, P. 2010. Ética empresarial en el núcleo de la estrategia corporativa. Editorial Cengage Learning, ISBN 978987-1486-13-7.

[27] Zysman, J. y Weber, S. 2000. Governance and Politics of the Internet Economy: Historical Transformation or Ordinary Politics With A New Vocabulary? International Encyclopedia of the Social and Behavioral Sciences. Elsevier Science Limited, Oxford.

[28] Andrade, J. 2000. Formación de precios de los productos de información en redes digitales. Revista Venezolana de Gerencia. Universidad de Zulia. Venezuela. ISSN 1315-9984. http://revistas.luz.edu.ve/index.php/rvg/article/view/7881 (Última visita al sitio expuesto: 8 de octubre de 2013).

[29] van Hooft, F. y Stegwee, R. 2001. E-business strategy: how to benefit from a hype. Logistics Information Management. Vol.: 14. Nro.: 1/2: 44-53. ISSN 0957-6053.

[30] Menascé, D. 2002. TPC-W: A Benchmark for E-Commerce. IEEE Internet Computing. Vol.: 6. Nro.:3: 83-87. ISSN 10897801.

[31] Young, L. y Johnston, R. 2003. The role of the internet in business-to-business network transformations: a novel case and theoretical analysis. Information Systems and E-Business Management. Vol.:1. Nro.: 1: 73-91. ISSN 1617-9846.

[32] Janita Muñoz, M. 2005. Los e-mercados, un nuevo modelo de mercado electrónico B2B. Departamento de economía aplicada y organización de empresas. Universidad de Extremadura. España.

[33] Barua, A., Whinston, A., Konana, P. 2007. Assessing Internet Enabled Business Value: An Exploratory Investigation. Task Report. Center for Research in Electronic Commerce. Department of MSIS. McCombs School of Business. University of Texas at Austin.

[34] Howson, C. 2008. Business Intelligence. Estrategias para una implementación exitosa. Editorial McGraw-Hill Interamericana S.A. de C.V. Edición en Español. ISBN 978-970-10-6759-8.

[35] Nascarella, M. 2009. Modelo de Agregación de Demandas Individuales con Reputación. Tesis de Magister en Ingeniería de Sistemas de Información. Escuela de Posgrado. Facultad Regional Buenos Aires. Universidad Tecnológica Nacional.

[36] Young-Ei, K. y Jung-Wan, L. 2010. Critical factors in promoting customer acceptance of and loyalty to online business management negree programs. African Journal of Business Management Vol.: 5. Nro.:1: 203-211. Academic Journals. ISSN 1993-8233.

[37] Ruíz, M. y Palací, F. 2011. Variables cognitivas y psicología del consumidor. El modelo de la confirmación de expectativas en la actualidad. Boletín de Psicología. Nro.: 103: 61-73. Departamento de Psicología Social y de las Organizaciones. Facultad de Psicología. Universidad Nacional de Educación a Distancia.

[38] Elaluf-Calderwood, S., Sorensen, C., Eaton, B. 2011. Digital Innovation on Mobile Platforms: A Business Model Analysis. London School of Economics and Political Science. London. WC2A 2AE. UK. ACM 1-58113-000-0/00/0010.

[39] Orihuela, J. y Santos, M. 2000. Introducción al diseño digital. Concepción y Desarrollo de Proyectos de Comunicación Interactiva. Editorial Anaya Multimedia. ISBN 9788441509702 .
[40] Islas Carmona, O. 2012. "Primeras estadísticas de Internet en Iberoamérica". Instituto tecnológico y de estudios superiores de Monterrey. Campus Estado de Mexico. Revista Alter, Enfoques Críticos.Año3.Nro.:5:115-125.

[41] IWS. 2013. Internet usages statistics for all the Americas. Usage and population statistics. Internet World Stat.

[42] INDEC. 2013a. Servicio Telefónico Básico y Servicio de Telefonía Celular Móvil. Instituto Nacional de Estadísticas y Censo. Comisión Nacional de Telecomunicaciones.

[43] Pérez Granda, L. 2013. ¿Se constituye el uso del Smartphone en una adicción? Grupo de investigación en estudios clínicos y sociales en psicología. Redes sociales virtuales. Universidad de San Buena Ventura Seccional Medellin.

[44] CACE. 2013. Estudio del comercio electrónico en $\mathrm{La}$ Argentina. Cámara Argentina de Comercio Electrónico. http://www.cace.org.ar/estadisticas/ (Última visita al sitio expuesto: 8 de octubre de 2013).

[45] PMCG. 2013. Listado de proveedores de Internet. Programa de mejora continúa en la gestión. Servicios de Telecomunicaciones de Valor Agregado. Comisión Nacional de Comunicaciones. Secretaría de Comunicaciones del Ministerio de Planificación Federal, Inversión Pública y Servicios.

[46] CESSI. 2013. Reporte semestral del sector de software y servicios informáticos de la Republica Argentina. Observatorio permanente de la industria del software y servicios informáticos de la república. Cámara de empresas de software y servicios informáticos.

[47] Briozzo, A., Baum, G. Bidart, S. 2004. Plan estratégico de SSI 2004-2014: plan de acción 2004-2007 : Libro azul y blanco. Ministerio de Economía y Producción. Secretaría de Industria, Comercio y de la Pequeña y Mediana Empresa.

[48] Barchini, G., Sosa, M., Herrera, S. 2004. La informática como disciplina científica. Ensayo de mapeo disciplinar. Universidad Nacional de Santiago del Estero. Santiago del Estero. Argentina.

[49] Brey, A., Innerarity, D., Mayos, G. 2009. La sociedad de la ignorancia y otros ensayos. Zero Factory S.L. ISBN 978-84613-2970-0.

[50] Raghu, G., Arun, K., Langlois, R. 2003. Managing in the modular age. Architectures, networks and organizations.Blackwell Publishers Ltd. ISBN 0-631-23315-6.

[51] Mahatanankoon, P., Wen, H., Lim, B. 2005. Consumer-based m-commerce: exploring consumer perception of mobile applications. Computer Standards and Interfaces. Vol.: 27. Nro.:4:347-357.

[52] Häkkilä, J. y Isomursu, M. 2005. User experiences on locationaware mobile services. Proceedings of OZCHI2005, ACM. ISBN 1-59593-222-4.

[53] Horst, M., Kuttschreuter, M., Gutteling, J. 2007. Perceived usefulness, personal experiences, risk perception and trust as determinants of adoption of e-government services in The Netherlands. Computers in Human Behaviour. Vol.: 23. Nro.: 4: $1838-1852$.

[54] Fonseca, J. 2003. Conociendo a la generación Y. Ponencia presentada en la 9na Conferencia Anual del College Board. Universidad del Sagrado Corazón. Puerto Rico.

[55] Griffiths, M. 2000. Does Internet and computer "addiction" exist? Some case study evidence. CyberPsychology and Behavior.Vol.:3.Nro.:2:211-218.

http://faculty.mwsu.edu/psychology/dave.carlston/Writing\%20i n\%20Psychology/Internet/4/i12.pdf (Última visita al sitio expuesto: 8 de octubre de 2013).

[56] Phillips, J., Saling, L., Blaszczynski, A. 2006. The Psychology of Mobile Phone Use and Misuse. Nova Science Publishers. ISBN 978-1-60456-436-5. 
[57] Schumpeter, J. 1982. The theory of economic development. Editorial Transaction Publishers. ISBN13 978-0878556984.

[58] Sánchez Vázquez, A. 2005. Ética. Editorial Crítica S.L. ISBN 84-8432-003-0

[59] Infoleg. 2004a. Ley 25856 del honorable congreso de la Nación Argentina. Industria: Protección de Software. Publicada en el Boletín Oficial del 8 de enero de 2004. Número: 30313. Página:3.http://www.infoleg.gob.ar/infolegInternet/verNorma.d o;jsessionid=7A79FF8E5055CAE6C798C727EEF57B42?id=9 1606 (Última visita al sitio expuesto: 8 de octubre de 2013).

[60] Infoleg. 2004b. Ley 25922 del honorable congreso de la Nación Argentina. Ley de promoción de la industria del software. Publicada en el Boletín Oficial del 9 de septiembre de 2004.Nro.:30481:1.http://www.infoleg.gob.ar/infolegInternet/v erNorma.do;jsessionid=E00F9D6E06057E992FFF5A47462637 5E?id=98433 (Última visita al sitio expuesto: 8 de octubre de 2013).

[61] Porter, M. 2001. Strategy and The Internet. Harvard Business Review.https://140.78.51.40/static/0855380/files/strategy\%20a nd\%20the\%20internet.pdf (Última visita al sitio expuesto: 8 de octubre de 2013).

[62] Kenney, M. y Curry, J. 2000. Beyond transaction costs: Ecommerce and the power of internet dataspace. Department of Human and Community Development. University of California.

http://brie.berkeley.edu/econ/publications/wp/internet and geo graphy.pdf (Última visita al sitio expuesto: 8 de octubre de 2013).

[63] Araujo, J. y Calcach, J. 2010. Del E-commerce al E-Businnes. Una base estratégica. Revista de Negocios Dirección Estratégica. Instituto Tecnológico Autónomo de México. D.F. México.http://direccionestrategica.itam.mx/wp-

content/uploads/2010/07/ebusiness.doc (Última visita al sitio expuesto: 8 de octubre de 2013).

[64] Afuah, A. y Tucci, C. 2002. Internet Business Models and Strategies. 2da. Edición. Editorial McGraw-Hill. ISBN 9780072511666

[65] Cavazos Arroyo, J. y Reyes Guerrero, S. 2006. Comercio electrónico: un enfoque de modelos de negocio. Compañía editorial continental. México. ISBN 970-24-1096-7.

[66] Papazoglou, M. y Ribbers, P. 2006. e-Business: Organizational and Technical Foundations. Publisher Wiley. ISBN 9780470843765 .

[67] Levitt, T. 1960. La miopía en el marketing. Universidad de Harvard. Harvard Business Review. Vol.: 38: 24-47. http://piazze.webs.com/La\%20miopia\%20del\%20marketingTheodore\%20Levitt.pdf (Última visita al sitio expuesto: 8 de octubre de 2013)

[68] Jaffe, A. y Trajtember, M. 2002. Patents, Citations, and Innovations: A Window on the Knowledge Economy. The MIT Press. ISBN 0-262-10095-9.

[69] Aspis, A., Pertusi, I., Nieva, H. 2006. Comercio Electrónico: ecommerce. Régimen contractual del comercio electrónico. Aspectos tributarios del comercio electrónico. Nuevas bases para gravar el e-commerce. Editorial Errepar. Bs. As. Argentina. ISBN 978-987-01-0570-1.

[70] Rifkin, J. 2000. La era del acceso. La revolución de la nueva economía. Edición en Español. Editorial Paidos Ibérica. ISBN 978-9501290585

[71] Kraus, G. 2009. Bases para el comercio internacional. 3ra. Edición. Archivos del Sur S.R.L. ISBN 978-987-22723-1-9.

[72] Amit, R. y Zott, C. 2001. Value Creation in E-Business. Strategic Management Journal 22: 493-520. ISSN 1097-0266.

[73] Kenneth, D. 2005. Importancia de una arquitectura de modelo de negocio escalable. Ponencia presentada en Standford Technology Ventures Prrogram. http://academicearth.org/lectures/importance-of-scalablebusiness-model-and-architecture (Última visita al sitio: 10 de marzo de 2012).

[74] Hoque, F. 2000. E-Enterprise, business models, Architecture and componenst. Cambridge University Press. Nueva York. USA. ISBN 978-0521774871.

[75] Ramírez Guerra, C. 2001. Modelo de las configuraciones de Henry Mintzberb. Escuela de gobierno, gestión pública y ciencia política. Instituto de ciencia política. Universidad de Chile.http://www.muece.org.ar/pdf/apuntes/ciclobasico/623/B6 23T02.pdf (Última visita al sitio expuesto: 8 de octubre de 2013).

[76] Diez de Castro, J. y Redondo Lopez, C. 1996. Administración de empresas: libro de actividades, casos, cuestiones y lecturas. Edicion en español. Pirámide Ediciones S.A. ISBN 9788436809237.

[77] Samuelson, P., Nordhaus W., Enrri D. 2003. Economía. Editorial McGraw -Hill, ISBN 978-987-1112-02-9.

[78] Echeburúa, E. 1999. ¿Adicciones Sin Drogas?. Las nuevas adicciones: juego, sexo, comida, compras, trabajo, internet. Editorial: Desclée de Brouwer. Bilbao. España. ISBN 84-3301378-5.

[79] Romero, J. 2009. Uso y abuso de las tecnologías. Manual de ayuda para los padres, educadores y profesionales. Ediciones Sekotia S.L. ISBN: 978-8493505622.

[80] Salanova, M., Llorens, S., Cifre, E. 2008. Tecnoestrés: concepto, medida e intervención psicosocial. Equipo de Investigación WoNT Prevenció Psicosocial. Universitat Jaume I de Castellón. http://www.prlsectoreducativo.es/documentos/documentacion/bibliiografia/nt p_730.pdf (Última visita al sitio expuesto: 8 de octubre de 2013).

[81] Martínez Selva, J. 2011. Tecnoestrés: Ansiedad y adaptación a las nuevas tecnologías en la era digital. Ediciones Paidós. ISBN 978-8449325311.

[82] Young, K. 1999a. Internet Addiction: symptoms, evaluation and tratament. Innovations in clinical practice. Vol.: 17. Professional Resource Exchange Inc. http://www.netaddiction.com/articles/symptoms.pdf (Última visita al sitio expuesto: 8 de octubre de 2013).

[83] Carbonell, X., Fúster, H., Chamarro, A., Oberst, U. 2012. Adicción a Internet y móvil: una revisión de estudios empíricos españoles. Universitat Ramon Llull. Universitat Autónoma de Barcelona. Papeles del Psicólogo. Vol.: 33(2), pp. 82-89. ISSN $0214-7823$.

[84] First, M., Frances, A., Pincus, H. 2004. The essential companion to the diagnostic and statical of mental disorders, fourth edition, text revision. American psiquiatry publications. ISBN 1-58562-068-8.

[85] APA. 2013. Diagnostic and Statistical Manual of Mental Disorders: DSM-5 American Psychiatric Asociations. ISBN 13: 978-0890425558.

[86] Griffiths, M. y Barnes, A. 2005. Internet gambling: An online empirical study among student gamblers. Revista Internacional de Salud Mental y Adicciones. Volume 6. Cuestion:2. ISSN 1557-1882.

[87] Biso-Andrade, A. 2013. Adicción a Internet: Una amenaza emergente contra la salud pública. Revista de la sociedad Peruana de medicina interina. Volumen: 56: 51-52. $\mathrm{http} / / /$ www.sociedadperuanademedicinainterna.org/pdf/01.pdf (Última visita al sitio expuesto: 8 de octubre de 2013).

[88] Greenfield, D. 1999. Psychological Characteristics of Compulsive Internet Use: A Preliminary Analysis. CyberPsychology and Behavior. Vol.: 2. Nro.: 5: 403412.http://online.liebertpub.com/doi/pdf/10.1089/cpb.1999.2.40 3 (Última visita al sitio expuesto: 8 de octubre de 2013). 
[89] Weinstein, A. y Lejoyeux, M. 2010. Internet Addiction or Excessive Internet Use. The American Journal of Drug and Alcohol Abuse. Vol.: 36. Nro.: 5: 277-283. http://informahealthcare.com/doi/abs/10.3109/00952990.2010.4 91880 (Última visita al sitio expuesto: 8 de octubre de 2013).

[90] Abreu, C., Karam, R., Góes, D., Spritzer, D. 2008. Internet and videogame addiction: a review. Revista Brazileira de Psiquiatria. São Paulo. Brazil. Vol.: 2: 156-67. http://www.ncbi.nlm.nih.gov/pubmed/18592108 (Última visita al sitio expuesto: 8 de octubre de 2013).

[91] Yu, L. y Shek, D. 2013. Internet addiction in Hong Kong adolescents: a three-year longitudinal study. Journal of pediatric and adolescent gynecology. http://www.ncbi.nlm.nih.gov/pubmed/23683821 (Última visita al sitio expuesto: 8 de octubre de 2013).

[92] OReilly, M. 1996. Internet addiction: a new disorder enters the medical lexicon. Canadian Medical Association Journal. Vol.: 154. Nro.: 12: 1882-1883. http://www.ncbi.nlm.nih.gov/pmc/articles/PMC1487729/ (Úlitima visita al sitio expuesto: 8 de octubre de 2012).

[93] Young, K. 1996. Internet addiction: The emergence of a new clinical disorder. CyberPsychology and Behavior. Vol.: 1. Nro.: 3: 237-244. http://www.chabad4israel.org/tznius4israel/newdisorder.pdf (Úlitima visita al sitio expuesto: 8 de octubre de 2013).

[94] TELAM. 2013. Advierten que el uso excesivo de las nuevas tecnologías afecta la salud. Agencia de noticias oficial de la República Argentina http://www.telam.com.ar/notas/201309/31857-advierten-queel-uso-excesivo-de-las-nuevas-tecnologias-afecta-la-salud.html (Última visita al sitio expuesto: 8 de octubre de 2013).

[95] Christakis, D. 2010. Internet addiction: a 21st century epidemic? Center for Child Health, Behavior, and Development, Seattle Children's Research Institute. Seattle. Washington. USA. http://www.biomedcentral.com/17417015/8/61 (Última visita al sitio expuesto: 8 de octubre de 2013).

[96] Romano, M., Osborne, L., Truzoli, R., Reed, P. 2013. Differential Psychological Impact of Internet Exposure on Internet Addicts. PLoS ONE Journal information. http://www.plosone.org/article/info\%3Adoi\%2F10.1371\%2Fjo urnal.pone.0055162 (Última visita al sitio expuesto: 8 de octubre de 2013).

[97] Zavala Romero, E. 2011. Incidencia de los sistemas de telefonía móvil en el campo bio-electromagnético humano. Instituto politécnico nacional. México. http://www.repositoriodigital.ipn.mx/handle/123456789/13386 (Úlitima visita al sitio expuesto: 8 de octubre de 2013).

[98] ICNIRP. 2009. Guidelines for limiting exposure to timevarying electric, magnetic, and electromagnetic fields (Up to $300 \mathrm{Hgz}$ ). International commission on non-ionizing radiation protection. Published in Healt Physics.97(3): 257-258. http://www.icnirp.org/documents/StatementEMF.pdf (Última visita al sitio expuesto: 8 de octubre de 2013).

[99] Ji-Geng, Y., Agresti, M., Bruce, T., Hui Yan, Y., Granlund, A., Matloub, H. 2007. Effects of cellular phone emissions on sperm motility in rats. Fertility and Sterility. Vol.: 88. Nro.: 4: 957964.http://www.ncbi.nlm.nih.gov/pubmed/17628553 (Última visita al sitio expuesto: 8 de octubre de 2013).

[100] Martínez, J., Medina, Y. Restrepo, J., Rondón, F., Iglesias Gamarra, A. 2005. No toda erupción cutánea reticulada es livedo reticular. Eritema $\mathrm{Ab}$ igne. Revista colombiana de reumatología. Vol.: 12. Nro.: 2. ISSN 0121-8123.

[101] Cano de Gómez, A. y Lesvia Solís-Rábago, M. 2007. El auxiliar auditivo eléctrico y el teléfono celular. Acta Pediátrica de México. Vol.: 28. Nro.: 2. http://www.medigraphic.com/pdfs/actpedmex/apm- 2007/apm072a.pdf (Última visita al sitio expuesto: 8 de octubre de 2013).

[102] Castells, M. 2000. Internet y la sociedad en red. Conferencia de presentación del programa de doctorado sobre la sociedad de la información y el conocimiento. Universitat Oberta de Catalunya.

https://engage.intel.com/servlet/JiveServlet/downloadBody/261 11-102-1-

31790/INTERNET\%20Y\%20LA\%20SOCIEDAD\%20RED.pd f (Última visita al sitio expuesto: 8 de octubre de 2013).

[103] Froid, S. 1921. Psicología de las masas y análisis del yo. Edición digital de Amazon Digital Services, Inc. ISBN 1479283339.

[104] Kuss, D. y Griffiths, M. 2011. Excessive online social networking: Can adolescents become addicted to Facebook? Education and Healt. Vol.: 29. Nro.: 4: 68-71. http://sheu.org.uk/sites/sheu.org.uk/files/imagepicker/1/eh294m g.pdf(Última visita al sitio expuesto: 8 de octubre de 2013).

[105] Suriá Martínez, R. 2012. Discapacidad y adolescencia, ¿son factores que potencian el riesgo hacia la adicción a las redes sociales online? XII Congreso virtual de psiquiatría. Universidad de Alicante. España. http://www.psiquiatria.com/bibliopsiquis/bitstream/10401/5442 /1/29m1 conf2\%2054580.pdf (Última visita al sitio expuesto: 8 de octubre de 2013).

[106] Winner, L. 1978. Autonomous Technology: Technics-out-ofcontrol as a Theme for Political Thought. MIT Editions. ISBN 978-0262730495.

[107] ALCMEON. 2006. Revista Argentina de Clínica Neuropsiquiátrica. Vol.: 13. Nro.: 2: 74 a 90. ISSN 0327-3954.

[108] Wan, G. y Gut, D. 2011. El caso de los adolescentes chinos y estadounidenses. Objetivos en los procesos formativos. Iberoamerican Communication Review. Nro.: 5: 83-97. ISSN 1889-6251.

[109] Fred, D. 2003. Conceptos de administración estratégica, Novena Edición. Editorial: Prentice Hall. ISBN: 0-13-0497940 .

[110] Sommerville, I. 2005. Ingeniería del software. Séptima Edición. Person Education SA. ISBN 978-84-7829-074-1.

[111] Cabrera, J. 1994. Profesión sistemas - volumen 1. Industrias gráficas Buenos Aires. Tercera edición. ISBN 950-43-5468-8.

[112] Guasch Petit, A. 2002. Modelado y simulación. Aplicación a procesos logísticos de fabricación y servicios. Edicions de la Universitat Politécnica de Catalunya SL. ISBN 84-8301-704-1.

[113] Law, M. 2006. Simulation Modeling and Analysis. McGraw Hill Book Co. ISBN 978-0073294414.

[114] García Dunna, E., García Reyes, H., Cárdenas Barron, L. 2006. Simulación y análisis de sistemas con ProModel. Pearson Education. México. ISBN 970-26-0773-6.

[115] Himmelblau, D. y Kennet, B. 1976. Análisis y simulación de procesos. Editorial Reverté SA. ISBN 84-291-7235-1.

[116] Coss Bu, R. 2003. Simulación. Un enfoque práctico. Editorial Limusa SA. México ISBN 968-18-1506-8.

[117] Greca, I. y Moreira, M. 1998. Modelos mentales, modelos conceptuales y modelización. Caderno catarinense de Ensino de Física. Vol.: 15. Nro.: 2: 107-120. Instituto de Física. UFRGS. $\quad$ Porto Alegre. https://150.162.1.115/index.php/fisica/article/download/6895/1 4041 (Última visita al sitio expuesto: 8 de octubre de 2013).

[118] Barrales, L., Peña, I., Fernández de la Reguera, P. 2004. Validación de modelos: un enfoque aplicado. Nota científica de agricultura técnica. Agricultura Técnica. ISSN 0365-2807.

[119] Tarifa, E. 2001. Teoría de modelos y simulación. Facultad de ingeniería. Universidad Nacional de Jujuy. http://www.econ.unicen.edu.ar/attachments/1051_TecnicasIISi 
mulacion.pdf (Última visita al sitio expuesto: 8 de octubre de 2013).

[120] Gardetti, M. 2003b. Desarrollo sustentable, sustentabilidad y sustentabilidad corporativa. Instituto de estudios para la sustentabilidad corporativa. Buenos Aires. Argentina. Registro de propiedad intelectual Nro.: 274369. Copyright 2003.

[121] Gardetti, M. 2003a. Creando valor sustentable. Instituto de estudios para la sustentabilidad corporativa. Buenos Aires. Argentina. Registro de propiedad intelectual Nro.: 274369. Copyright 2003.

[122] Cassara, A., Layke, C., Ranganathan, J., Tunstall, D., Doering, D., Vanasselt, W. 2002. Tomorrow's markets: Global trends and their implications for business. World Resources Institute, United Nations Environment Programme, World Business Council for Sustainable Development. http://pdf.wri.org/tm_tomorrows_markets.pdf (Última visita al sitio expuesto: 8 de octubre de 2013).

[123] Hart, S. 2005. Capitalism at the Crossroads: The Unlimited Business Opportunities in Solving the World's Most Difficult Problems. Prentice Hall. ISBN 978-0131439870.

[124] Freeman, E. 2010. Strategic Management Paperback: A Stakeholder Approach. Cambridge University Press. ISBN 9780521151740

[125] Gardetti, M. 2004. Sustentabilidad y el valor para los negocios de la relación con los stackholders. Instituto de estudios para la sustentabilidad corporativa. Buenos Aires. Argentina. Registro de propiedad intelectual Nro.: 309441. Copyright 2003.

[126] Gardetti, M. 2009. El gran salto. Dirigiendo la innovación desde la base de la pirámide. Instituto de estudios para la sustentabilidad corporativa. Buenos Aires. Argentina. Registro de propiedad intelectual Nro.: 744850. Copyright 2009.

[127] Angelelli, P. y Glido, N. 2002. Apoyo a la innovación tecnológica en América Central: La experiencia del Fondo para la Modernización Tecnológica y Empresarial de Panamá. División de micro, pequeña y mediana empresa. Banco Interamericano de Desarrollo. Washington DC. http://idbdocs.iadb.org/wsdocs/getdocument.aspx?docnum=370 971 (Última visita al sitio expuesto: 8 de octubre de 2013).

[128] Verena Torres, N., Ramos, D., Lizazo, F., Monteagudo, A. 2008. Modelo estadístico para la medición del impacto de la innovación o transferencia tecnológica en la rama agropecuaria.Revista Cubana de Ciencia Agrícola. Vol.: 42. Nro:2:133-139.

http://www.redalyc.org/articulo.oa?id=193015494003 (Última visita al sitio expuesto: 8 de octubre de 2013).

[129] Dixon, E., Clifton, G., Lighthall, J. Yaghmai, A., Hayes, R..1991. A controlled cortical impact model of traumatic brain injury in the rat. Journal of Neuroscience Methods. Vol.: 39. Nro.:3:253-262.

http://www.sciencedirect.com/science/article/pii/016502709190 1048 (Última visita al sitio expuesto: 8 de octubre de 2013).

[130] Palmer, A., Marion, D., Botscheller, M., Swedlow, P., Styren, S., DeKosky, S. 1993. Traumatic Brain Injury-Induced Excitotoxicity Assessed in a Controlled Cortical Impact Model. Issue Journal of Neurochemistry. Journal of Neurochemistry. Vol.:61.Nro.:6:2015-2024.

http://onlinelibrary.wiley.com/doi/10.1111/j.1471-

4159.1993.tb07437.x/abstract (Última visita al sitio expuesto: 8 de octubre de 2013).

[131] Erbe, C. 2002. Underwater noise of whale-watching boats and potential effects on killer whales (orcinus orca), based on an acoustic impact model. Marine Mammal Science. Vol.: 18. Nro.: $\quad 2$ : 394-418. http://onlinelibrary.wiley.com/doi/10.1111/j.1748-

7692.2002.tb01045.x/abstract (Última visita al sitio expuesto: 8 de octubre de 2013).
[132] Pope, K., Baines, K., Ocampo, A. Ivanov, B. 1994. Impact winter and the Cretaceous/Tertiary extinctions: Results of a Chicxulub asteroid impact model. Earth and Planetary Science Letters. Vol.: 128. Nro.: 3-4: 719725http://www.sciencedirect.com/science/article/pii/0012821X 94901864 (Última visita al sitio expuesto: 8 de octubre de 2013).

[133] Rosegrant, M. 2012. International model for policy analysis of agricultural commodities and trade (IMPACT) model description. International food policy research institute. WashingtonDC.http://www.ifpri.org/sites/default/files/publicati ons/impactwater2012.pdf (Última visita al sitio expuesto: 8 de octubre de 2013).

[134] Chaumun, A. 1999. A change impact model for changeability assessment in object-oriented software systems. Dept. d"Inf. et de Recherche Oper. Montreal Univ. Canada. ISBN 0-76950090-0.

[135] Dalkey, N. 1971. An elementary cross-impact model. Technological forecasting and social change. Vol.: 3: 341-351. http://www.sciencedirect.com/science/article/pii/S0040162571 800227 (Última visita al sitio expuesto: 8 de octubre de 2013).

[136] Herranz Pascual, K y López Barrio, I. 2000. Modelo de impacto del ruido ambiental. Revista de Acústica. Sociedad Española de Acústica. Vol.: 31. ISBN 84-87985-03-3.

[137] Herrero Prieto, L. 2004. Impacto económico de los macrofestivales culturales: reflexiones y resultados. Departamento de economía aplicada. Universidad de Valladolid.

http://www.ccgsm.gov.ar/areas/produccion/industrias/observato rio/documentos/analisis_estudio impacto festivales.pdf (Última visita al sitio expuesto: $\overline{8}$ de octubre de 2013).

[138] Rodríguez Orejuela, A. 2005. Un modelo integral para evaluar el impacto de la transferencia de conocimiento interorganizacional en el desempeño de la firma. Universidad de Murcia. España. Estudios gerenciales. Vol.:21. Nro.: 95. ISSN 0123-5923.

[139] Corral-Verdugo, V. y de Queiroz Pinheiro, J. 2004. Aproximaciones al estudio de la conducta sustentable. Medio ambiente y comportamiento Humano. Editorial Resma. ISSN 1576-6462.

[140] Rosenfeld, E., San Juan, G., Díscoli, C. 2000. Índice de calidad de vida urbana para una gestión territorial sustentable. Instituto de estudios del hábitat. Facultad de arquitectura y urbanismo. Universidad Nacional de La Plata.http://www.asades.org.ar/modulos/averma/trabajos/2000/ 2000-t001-a007.pdf (Última visita al sitio expuesto: 8 de octubre de 2013).

[141] Barton Bray, D., Merino-Pérez, L., Negreros-Castillo, P., Segura-Warnholtz, G., Torres-Rojo, J., Vester, H. 2003. Mexico's Community-Managed Forests as a Global Model for Sustainable Landscapes Conservation Biology. Vol.: 17, Nro.: 3; 672-677. http://onlinelibrary.wiley.com/doi/10.1046/j.15231739.2003.01639.x/full (Última visita al sitio expuesto: $8 \mathrm{de}$ octubre de 2013).

[142] Bonnin, M., Azzaro-Pantel, C., Montastruc, L., Pibouleau, L., Domenech, S. Villeneuve, J. 2013. Development of a Sustainable Copper Scrap Management Model. European symposium on computer aided process engineering. Lappeenranta. Finland. http://oatao.univ-toulouse.fr/8913/ (Última visita al sitio expuesto: 8 de octubre de 2013).

[143] Zehetmeier, S. y Krainer, K. 2013. Researching the Sustainable Impact of Professional Development Programmes on Participating Teachers' Beliefs. Proficiency and beliefs in learning and teaching mathematics. Mathematics teaching and learning.http://link.springer.com/chapter/10.1007/978-94-6209299-0 10 (Última visita al sitio expuesto: 8 de octubre de 2013). 
[144] Lavado, A. 2013. El consumo de youtube en España. Global media juornal México. Vol.: 7. Nro.: 14: 76-92. http://www.gmjei.com/index.php/GMJ_EI/article/view/12 (Última visita al sitio expuesto: 8 de octubre de 2013).

[145] Ruano López, S. y Trabadela, J. 2013. La TV a través de internet móvil: personalización y consumo. Congreso internacional de comunicación y sociedad digital. ISBN 8415626-42-8.

[146] López García, G. 2005. El ecosistema digital. Modelos de comunicación, nuevos medios y público en Internet. Servei de Publicacions de la Universitat de València. ISBN 84-370-63027.

[147] Sieber, S. y Cassiman, B. 2001. El impacto de internet sobre la estructura de los mercados. Economía industrial. Nro.: 339: 1324. ISSN 0422-2784.

[148] Rayport, J. y Sviokla, J. 1995. Exploiting the virtual value chain.HarvardBusinessReview.http://hbr.org/1995/11/exploitin g-the-virtual-value-chain/ar/ (Última visita al sitio expuesto: 8 de octubre de 2013).

[149] González, L. 2010. La protección internacional de la propiedad intelectual (derechos de autor y conexos) en el contexto digital: Quo Vadis. Universidad de Alicante. España. http://www.uaipit.com/files/congresos/doclydia.pdf (Última visita al sitio expuesto: 8 de octubre de 2013).

[150] Vercelli, A. 2009. Repensando los bienes intelectuales comunes. Análisis socio-técnico sobre el proceso de coconstrucción entre las regulaciones de derecho de autor y derecho de copia y las tecnologías digitales para su gestión. Tesis de doctorado con mención en ciencias sociales y humanas. Universidad Nacional de Quilmes. http://www.arielvercelli.org/rlbic.pdf (Última visita al sitio expuesto: 8 de octubre de 2013).

[151] Amatto, Y., Caymes Scutari, P., Bianchini, G. 2010. Impacto Negativo de los Sistemas Informáticos. Laboratorio de Investigación en Cómputo Paralelo/Distribuido. UTN. Facultad RegionalMendoza.http://www.frsf.utn.edu.ar/cneisi2010/archiv os/18-Impacto_Negativo_de_los_Sistemas_Informaticos.pdf (Última visita al sitio expuesto: 8 de octubre de 2013).

[152] Benkler, Y. 2006. The wealth of network: how social production transforms markets and freedom, Yale University Press.USA.http://www.benkler.org/Benkler_Wealth_Of_Netwo rks.pdf (Última visita al sitio expuesto: 8 de octubre de 2013).

[153] Herrera, H., Pacheco, M., Palomar Lever, J, Zavala Andrade, D. 2010. La Adicción a facebook relacionada con la baja autoestima, la depresión y la falta de habilidades sociales. Universidad Iberoamericana. Ciudad de México. México. Psicología Iberoamericana ISSN 1405-0943.

[154] Wasserman, A. 2010. Ciclo Conversando con los Líderes de los Negocios por Internet. Ponencia presentada en la conferencia nacional "E-Comerce Day". Buenos Aires. Argentina.http://www.ecommerceday.org.ar/material/Wasserm an.pdf (Última visita al sitio expuesto: 27 de abril de 2011).

[155] Fernández Garrote, L., Llanes Fernández, L., Llanes Llanes, E. 2004. Reflexiones sobre la ética en la investigación clínica y epidemiológica. Instituto Nacional de Oncología y Radiobiología. Ciudad de La Habana. Cuba. Revista Cubana de Salud Pública. ISSN 0864-3466.

[156] Lolas, F. y Quezada, A. 2003. Pautas éticas de investigación en seres humanos. Nuevas perspectivas. Programa Regional de Bioética. Organización Panamericana de la Salud. Organización Mundial de la Salud. http://salud.edomex.gob.mx/html../Medica/INVESTIGACION \%20EN\%20SUJETOS\%20HUMANOS.\%20PAUTAS\%20ETI CAS.PDF(Última visita al sitio expuesto: 8 de octubre de 2013).
[157] Mancini Rueda, R., Acevedo Pérez, I., Larach Walters, V., Morgado Cádiz, C., O'Ryan Gallardo, M., Quinteros Ramírez, M., Sepúlveda Brito, N., Sepúlveda Salinas, J., Sotomayor Saavedra, M. 2001. Regulación de la ejecución de ensayos clínicos que utilizan productos farmacéuticos en seres humanos. Norma técnica Nro: 57. Ministerio de Salud. Gobierno de Chile. http://www.ispch.cl/sites/default/files/Norma\%20Tecnica\%205 7.pdf (Última visita al sitio expuesto: 8 de octubre de 2013).

[158] Real academia española. 2013. Definición de impacto. Versión en Español. http://lema.rae.es/drae/?val=impacto (Última visita al sitio expuesto: 8 de octubre de 2013).

[159] Asur, S. y Huberman, B. 2010. Predicting the future with social media. Social Computing Lab. HP Lab. http://arxiv.org/abs/1003.5699 (Última visita al sitio expuesto: 8 de octubre de 2013).

[160] Glance, N y Huberman, B. 1994. The dynamics of the social dilemmas. Scientific American. Vol.: 270. Nro.: 3: 76-81. http://www.uvm.edu/ pdodds/teaching/courses/2009-08UVM300/docs/others/everything/glance1994a.pdf (Última visita al sitio expuesto: 8 de octubre de 2013).

[161] Leskovec, J., Adamic, L., Huberman, B. 2006. The dynamics of viral marketing. In Proceedings of the 7th ACM Conference on Electronic Commerce. http://arxiv.org/pdf/physics/0509039.pdf (Última visita al sitio expuesto: 8 de octubre de 2013).

[162] Ander-Egg, E. 2003. Métodos y técnicas de investigación: Técnica para recogida de datos e información social I. Grupo Editorial Lumen. ISBN 987-00-0301-X.

[163] Shannon, R. 1988. Simulación de Sistemas. Diseño, desarrollo e implementación. Editorial Trillas. México. ISBN 978-9682426-73-5.

[164] Kalos, M. y Whitlock P. 2008. Monte Carlo Methods. Second, revised and enlargede edition. Wiley-VCH Verlag $\mathrm{GmbH} \&$ Co. KGaA. ISBN 978-3527407606.

[165] Peña Sánchez de Rivera, D. 2001. Deducción de distribuciones: el método de Montecarlo. Fundamentos de Estadística. Madrid: Alianza Editorial. ISBN 84-206-8696-4.

[166] Pita Ruiz, C. 1995. Cálculo vectorial. Primera Edición. Editorial Pretince Hall Hispanoamericana S.A. ISBN 968-880529-7.

[167] Galton, F. 1889. Natural inheritance. Mcmillan and CO. LondonandNewYork.http://www.mugu.com/galton/books/natur al-inheritance/pdf/galton-nat-inh-1 up-clean.pdf (Última visita al sitio expuesto: 8 de octubre de 2013).

[168] Barrio Castro, T., Clar Lopez, M., Suriñalt Caralt, J. 2002. Modelo de Regresión Lineal Múltiple: especificación, estimación y contraste. Editorial: Universitat Oberta de Catalunya. ISBN 8484296768.

[169] Fuentes, A., Rivera, N., Pinos, R., Zurita, G. 2012. Software Estadístico para Regresión. El caso de Regresión Logística y Regresión Poisson. Instituto de Ciencias Matemáticas. Escuela Superior Politécnica del Litoral. Guayaquil-Ecuador. http://www.dspace.espol.edu.ec/handle/123456789/21644 (Última visita al sitio expuesto: 8 de octubre de 2013).

[170] Leithold, L. 1999. El cálculo. Séptima Edición. Editor San Val. ISBN 9780613837637.

[171] García-Martínez, R., Britos, P., Rodríguez, D. 2013. Information Mining Processes Based on Intelligent Systems. Lecture Notes on Artificial Intelligence, 7906: 402-410. ISBN 978-3-642-38576-6.

[172] Fisher, S. 2000. Developing the DSM IV Criteria to Identify Adolescent Problem Gambling in Non-Clinical Populations. Journal of gambling Studies. Vol 16. Nros 2 y 3: 253-273.

[173] Andreassen, C., Torsheim, T., Brunborg, G., Pallesen, S. 2012. Development of a Facebook addiction scale. Department of 
Psychosocial Science. University of Bergen. The Bergen Clinics Foundation. Norway. ISSN 0033-2941.

[174] Valence, G., d'Astous, A., Fortier, L. 1988. Compulsive buying: Concept and measurement. Journal of Consumer Policy.

Vol.:11.Nro.:4:419-433 http://connection.ebscohost.com/c/articles/6038317/compulsive -buying-concept-measurement (Última visita al sitio expuesto: 8 de octubre de 2013).

[175] Muñoz-Ramos Mas, M. 2012. Implicaciones socioeconómicas de las redes sociales en el mundo global. Tesina para Licenciatura en Publicidad y Relaciones Públicas. Facultad de Ciencias Sociales. Universitat Abat Oliba CEU. http://www.recercat.net/bitstream/handle/2072/182655/TFC-

MU\%C3\%91OZ-2012.pdf?sequence=1 (Última visita al sitio expuesto: 8 de octubre de 2013).

[176] INDEC. 2001a. Población de 14 años y más por condición de actividad económica según sexo. Total del país. Censo Nacional de. Población, Hogares y Viviendas. http://www.indec.gov.ar/nuevaweb/cuadros/4/cuadro9 1.xls (Última visita al sitio expuesto: 8 de octubre de 2013).

[177] INDEC. 2001b. Censo Nacional de Población, hogares y viviendas. Definiciones de la base de datos. Instituto Nacional de Estadística $\quad$ y http://www.indec.gov.ar/redatam/CPV2001ARG/docs/Definici ones\%20CD\%20Base\%20CNPHV2001_d.pdf (Última visita al sitio expuesto: 8 de octubre 2013).

[178] INDEC. 2013b. Glosario. Instituto Nacional de Estadística yCenso.http://www.indec.mecon.ar/glosario/textos glosario.as $\mathrm{p}$ ? id=40 (Última visita al sitio expuesto: 8 de octubre de 2013).

[179] Piñeiro Michel, G. 2012. Pirámide social: revelan qué es ser hoy un "clase media" y cuánto se debe ganar para formar parte. Redacción de i-profesional.com http://www.iprofesional.com/notas/128955-Pirmide-socialrevelan-qu-es-ser-hoy-un-clase-media-y-cunto-se-debe-ganarpara-formar-parte (Última visita al sitio expuesto: 8 de octubre de 2013).

[180] INDEC. 2009. Encuesta permanente de hogares. Diseño de registro y estructura para las bases de micro datos. Individual y Hogar. Instituto Nacional de Estadística y Censo. http://www.santafe.gov.ar/index.php/web/content/download/80 497/388465/file/EPH_disenoreg_09.pdf (Última visita al sitio expuesto: 8 de octubre de 2013).

[181] INDEC. 2011. Indec Informa. Instituto Nacional de Estadística y Censo. Año: 16. Nro.: 7. ISSN 0328-5804.

[182] Adigital. 2012. Libro blanco de comercio electrónico. Guía práctica de comercio electrónico para PYMES. Asociación Española de la Economía Digital y Ministerio de Industria, Energía y Turismo de España. http://libroblanco.adigital.org//descarga.html (Última visita al sitio expuesto: 8 de octubre de 2013).

[183] Zain, A. 2012. Estado del eCommerce en Latinoamerica 2012. Ponencia presentada en el evento de comScore webinar. $\mathrm{http} / /$ www.comscore.com/lat/Insights/Presentations_and_Whit epapers/2012/State_of_eCommere_in_Latin_America_2012 (Última visita al sitio expuesto: 8 de octubre de 2013).

[184] INDEC. 2012. Censo nacional de población, hogares y viviendas 2010: censo del Bicentenario. Instituto Nacional de
Estadística y Censo. Resultados definitivos. Serie B. Nro: 2. 1ra. Edición. ISBN 978-950-896-421-2.

[185] INDEC. 2003. Hábitat y vivienda por medio de datos censales. Instituto Nacional de Estadística y Censo. Dirección Nacional de Estadísticas Sociales y de Población. DNESyP/DEP/P5/PIDSerie Hábitat y Vivienda DT Nro.: 13. Instituto Nacional de Estadística y Censo. http://www.scielo.br/scielo.php?script=sci nlinks\&ref $=000133$ \&pid=S0102-3098201200010000300006\&lng=es (Última visita al sitio expuesto: 8 de octubre 2013).

[186] INTI. 2013. Uso eficiente de energía. Uso residencialArtefactos eléctricos. Centro de investigación y desarrollo de energía. INTI Energía. Instituto Nacional de Tecnología Industrial.http://www.inti.gob.ar/energia/index.php?seccion=u Residencial (Última visita al sitio expuesto: 8 de octubre de 2013).

[187] IGN. 2013. Distribución de la población rural y urbana. Instituto Geográfico Nacional de la Republica Argentina. Ministerio de Defensa. Presidencia de la Nación. http://www.ign.gob.ar/NuestrasActividades/Geografia/DatosAr gentina/Poblacion (Última visita al sitio expuesto: 8 de octubre de 2013).

[188] CNRT. 2013. Transporte público: Estadísticas. Comisión Nacional de Regulación del Transporte. Ministerio del Interior y Transporte. Presidencia de la Nación http://www.cnrt.gob.ar/estadisticas.asp (Última visita al sitio expuesto: 8 de octubre de 2013).

[189] Mendez, P. 2003. Las encuestas de uso del tiempo en México. Instituto Nacional de Estadística y Geografía. México. http://www.eclac.cl/deype/mecovi/docs/TALLER6/27.pdf (Última visita al sitio expuesto: 8 de octubre de 2013).

[190] Erdociaín, L., Solís, D, Isa, R. 2005. El sedentarismo. Red Argentina de Actividad Física. http://www.rafargentina.com.ar/articulos/sedentarismo.pdf (Última visita al sitio expuesto: 8 de octubre de 2013).

[191] OMS. 2004. Neurociencia del consumo y dependencia de sustancias psico-activas. Organización mundial de la salud. ISBN 924 359124X.

[192] BM. 2012. Abonados a Internet por banda ancha fija (por cada cien personas). Unión Internacional de Telecomunicaciones. Informe sobre el Desarrollo Mundial/TIC de las Telecomunicaciones y estimaciones del Banco Mundial. Estadísticas del Banco http://datos.bancomundial.org/indicador/IT.NET.BBND.P2 (Última visita al sitio expuesto: 8 de octubre de 2013).

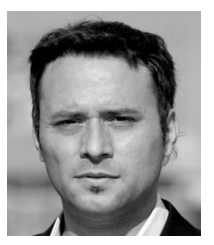

Leonardo Montesano . Es Ingeniero en sistemas de Infromación por la Universidad Tecnológica Nacional. Es Candidato del Programa de Magister en Administracion de Negocios de la Escuela de Postgrado de la Facultad Regional Buenos Aires de la Universidad Tecnológica Nacional. Es Investigador Tesista del Laboratorio de Investigación y Desarrollo en Arquitecturas Complejas del Grupo de Investigación en Sistemas de Información de la Universidad Nacional de Lanús. 